\title{
Alpha and beta glucocorticoid receptor mRNA expression in human bronchial epithelial cells
}

Citation for published version (APA):

Korn, S. H. (1998). Alpha and beta glucocorticoid receptor mRNA expression in human bronchial epithelial cells. [Doctoral Thesis, Maastricht University]. Maastricht University.

https://doi.org/10.26481/dis.19980219sk

Document status and date:

Published: 01/01/1998

DOI:

10.26481/dis.19980219sk

Document Version:

Publisher's PDF, also known as Version of record

\section{Please check the document version of this publication:}

- A submitted manuscript is the version of the article upon submission and before peer-review. There can be important differences between the submitted version and the official published version of record.

People interested in the research are advised to contact the author for the final version of the publication, or visit the DOI to the publisher's website.

- The final author version and the galley proof are versions of the publication after peer review.

- The final published version features the final layout of the paper including the volume, issue and page numbers.

Link to publication

\footnotetext{
General rights rights.

- You may freely distribute the URL identifying the publication in the public portal. please follow below link for the End User Agreement:

www.umlib.nl/taverne-license

Take down policy

If you believe that this document breaches copyright please contact us at:

repository@maastrichtuniversity.nl

providing details and we will investigate your claim.
}

Copyright and moral rights for the publications made accessible in the public portal are retained by the authors and/or other copyright owners and it is a condition of accessing publications that users recognise and abide by the legal requirements associated with these

- Users may download and print one copy of any publication from the public portal for the purpose of private study or research.

- You may not further distribute the material or use it for any profit-making activity or commercial gain

If the publication is distributed under the terms of Article $25 \mathrm{fa}$ of the Dutch Copyright Act, indicated by the "Taverne" license above, 
Alpha and beta glucocorticoid receptor mRNA expression in human bronchial epithelial cells 
Bats

$49+20 \%$

ats

$\mathrm{C}^{2}$ 
The author of this thesis is highly indebted to the following organizations for their financial support:

- Astra Pharmaceuticals, the Netherlands

- De Dr. Ir. J.H.J. van der Laar Stichting

- Nederlands Astma Fonds

- Stichting Klinische Pathologie Zuid-Limburg

The cover is drawn by An Broekhof.

The book is designed and produced by Rocco Mestriner

Alpha and beta glucocorticoid receptor mRNA expression in human bronchial epithelial cells.

${ }^{0}$ Korn, Solange Henriëtte

ISBN nr: 90-9011306-1 
क्ष $\quad \cdots$ 


\title{
Alpha and beta glucocorticoid receptor mRNA expression in human bronchial epithelial cells
}

\author{
Proefschrift
}

ter verkrijging van de graad doctor

aan de Universiteit Maastricht

op gezag van Rector Magnificus, Prof. dr. A.C. Nieuwenhuijzen Kruseman, volgens het besluit van het College van Decanen, in het openbaar te verdedigen op donderdag 19 februari 1998 om 16.00 uur

door

Solange Henriëtte Korn

geboren te Maastricht op 7 maart 1969 


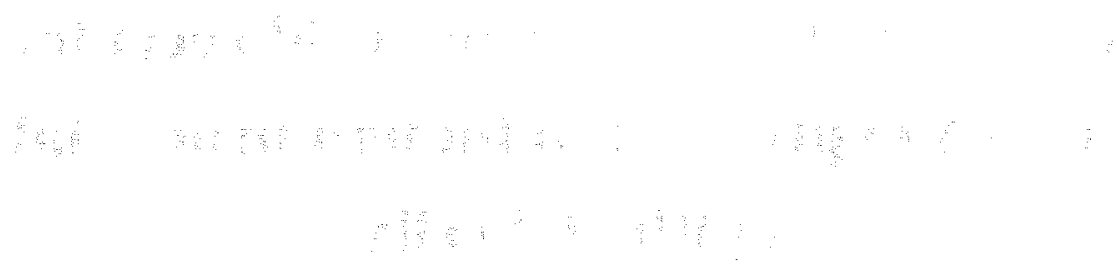

$\because$ 


\section{Promotoren:}

Prof. Dr. E.F.M. Wouters

Prof. Dr. J-W Arends

\section{Co-promotor:}

Dr. F.B.J.M. Thunnissen

\section{Beoordelingscommissie:}

Prof. Dr. P. de Leeuw (voorzitter)

Prof. Dr. G. Joos (Rijksuniversiteit Gent, Belgie)

Prof. Dr. F.C.S. Ramaekers

Prof. Dr. A.J. Struijker Boudier

Prof. Dr. W. Timens (Rijksuniversiteit Groningen) 
Voor mam en pap 

1.1 Steroid treatment in asthma and COPD

1.2 Structure and function of glucocorticoids

1.3 Structure, function and activation of the glucocorticoid receptor

1.4 Anti-inflammatory actions of glucocorticoids

1.5 Purpose of this study

Chapter 2 RNA isolation from human bronchial epithelial cells in vivo
2.1 Introduction
2.2 Materials and methods
2.3 Results
2.4 Discussion

Chapter 3 In vitro and in vivo modulation of $\alpha$ and $\beta$ glucocorticoid receptor mRNA in human bronchial epithelium

Published in: Am. J. Resp. Crit. Care. Med. 1997; 155 (3): 1117-1122
3.1 Introduction
3.2 Materials and methods
3.3 Results
3.4 Discussion

Chapter $4 \alpha$ and $\beta$ Glucocorticoid receptor mRNA expression in rat lung and skeletal muscle after intra-tracheal instillation of budesonide Submitted for publication in modified form
4.1 Introduction
4.2 Materials and methods
4.3 Results
4.4 Discussion 
Chapter 5 Is the $\beta$ glucocorticoid receptor (GR) mRNA level high enough for inhibition of the GR function in COPD? Submitted for publication in combination with chapter 6

5.1 Introduction

5.2 Material and methods

5.3 Results

5.4 Discussion

Chapter 6 Glucocorticoid receptor mRNA levels in bronchial epithelial cells of patients with COPD: Influence of glucocorticoids Submitted for publication in combination with chapter 5

6.1 Introduction

6.2. Materials and methods

6.3 Results

6.4 Discussion

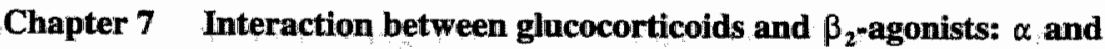
$\beta$ glucocorticoid receptor mRNA expression in human bronchial epithelial cells Submitted for publication

7.1 Introduction

7.2 Materials and methods

7.3 Results

7.4 Discussion

Chapter 8 Concluding remarks

8.1 Introduction

8.2 Technical aspects

8.3 Glucocorticoid receptor mRNA in human bronchial epithelium

8.4 Transcription factor model

8.5 The future 
Summary

Samenvatting

References

Dankwoord

Publications

Curriculum vitae 


\section{ONE}

\section{GENERAL INTRODUCTION}


$\begin{array}{llll}3 & \cdots & \vdots \\ 3 & \vdots\end{array}$

$\therefore \quad \therefore$ 


\section{GENERAL INTRODUCTION}

1.1 Steroid treatment in asthma and COPD

1.2 Structure and function of glucocorticoids

1.3 Structure, function and activation of the glucocorticoid receptor

1.4 Anti-inflammatory actions of glucocorticoids

1.5 Purpose of this study 



\subsection{Steroid treatment in asthma and COPD}

Controlling inflammation is one of the major aims in medicine. Glucocorticoids are known as powerful anti-inflammatory agents and are widely used in the treatment of inflammatory diseases like rheumatic arthritis, inflammatory bowel disease, and psoriasis (1). Since 1950 glucocorticoids are also used in the treatment of various inflammatory lung diseases. Their only limitation are unwanted systemic side effects. Since their introduction more than 40 years ago, research has been concentrated on improvement of the anti-inflammatory action and lowering of the unwanted side effects $(2,3)$. Therefore, a change was made in the application of the glucocorticoids. Whereas at first glucocorticoids were applied systemically (orally or intramuscularly), local distribution at the site of inflammation (inhalation and skin) resulted in the need of lower doses, with subsequent reduced systemic side effects. At present, very potent, topically applied glucocorticoids, with little or no systemic effects, are available for the treatment of inflammatory diseases like asthma.

In chronic inflammatory diseases, cytokines recruit activated inflammatory cells to the site of lesion, thereby amplifying and perpetuating the inflammatory state. Glucocorticoids inhibit several aspects of the inflammatory process by induction of increased or decreased gene transcription in inflammatory cells present at the site of inflammation (4). Many target genes are involved in the action of glucocorticoids. The transcription of most cytokines is imhibited and thereby their effect, amplification of the inflammation by recruitment of inflammatory cells to the site of lesion (5). In bronchial asthma, there is increasing evidence that the airway epithelial cell may in part be responsible for the establishment and/or maintenance of the bronchial inflammation (6-16). This cell type also plays a central role in the anti-inflammatory actions of glucocorticoids, since it is a major target for inhaled glucocorticoids (5).

Glucocorticoids are of indisputable value in some pulmonary diseases, whereas in others their use is still controversial. Both asthma and COPD are characterized by airway inflammation, although the type of inflammation seems to be different (17). In studies with BAL and (induced) sputum a higher number of eosinophils in the airways of asthmatics has been observed, in contrast to a larger number of neutrophils present in the airways of COPD's (18-20). A clear correlation exists between the number of neutrophils 
and the airway obstruction and decline in lung function $(18,21)$. On the contrary, in the bronchial mucosa higher amounts of macrophages and T-lymphocytes have been reported in patients with COPD $(22,23)$. Asthma and COPD are both widespread treated with glucocorticoids, but not equally successful.

In asthma, inhaled glucocorticoids are the most effective and most prescribed therapy currently available (5). Symptoms and airway hyperresponsiveness are reduced, inflammatory responses suppressed, airway functions improved and airway integrity restored (24). Only a small proportion of the patients with asthma does not respond to glucocorticoids. These patients are called steroid resistant. Steroid resistant asthma is defined as a situation in which the patient fails to improve the morning PEF or FEV1 by $>15 \%$, even after administration of an oral dose of 30-40 mg prednisolone for 10-14 weeks (25). Many mechanisms underlying this resístance have been suggested (25-31), but the precise nature remains to be elucidated.

In contrast to patients with asthma, patients with chronic obstructive pulmonary disease (COPD) show little or no benefit on airflow obstruction by glucocorticoids $(32,33)$. Callahan and colleagues demonstrated in only $10 \%$ of the patients a response to oral corticosteroid therapy, measured as a $20 \%$ increase in baseline FEV1 (34). The reason for the limited response to glucocorticoids in patients with COPD is not elucidated yet, but to be able to distinguish between responders and non-responders, long term studies are necessary with well defined patient populations. Several multicenter studies have tested the role of inhaled glucocorticoids on the course of COPD, but today insufficient documentation is available to support the use of glucocorticoids (35). The beneficial effects of glucocorticoids in COPD are at present still under study (36), and the results of this investigation will be gained soon.

\subsection{Structure and function of glucocorticoids}

Glucocorticoid hormones are member of the large steroid hormone family. These hormones all have chemical structures basically similar to cholesterol (figure 1) and are in most instances derived from cholesterol (37). 
Cholesterol

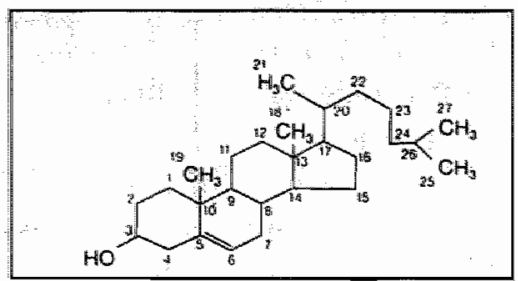

Hydrocortisone 17 a-butyrate

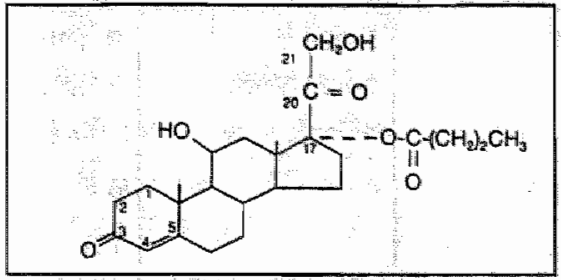

Figure 1: Structure of cholesterol and hydrocortisone.

Glucocorticoid hormones are synthesized in the adrenal cortex and gained their name because of their role in the increase of the blood glucose concentration. Hydrocortisone (cortisol), the principal glucocorticoid in the body, influences the carbohydrate, fat and protein metabolism. During periods of stress, plasma cortisol levels are elevated, protecting the body from tissue damage caused by the body"s defense reactions against stress (37). Cortisone, the natural precursor of cortisol, has been the first glucocorticoid used in the treatment of several diseases.

In 1950 the beneficial effects of glucocorticoids in asthma were described (38). Because of the side effects of cortisone, a search for more ideal anti-inflammatory therapeutics was initiated, more potent than cortisone with less mineralocorticoid side effects. Synthetic glucocorticoid derivatives were developed instead of isolating cortisone from the adrenal glands $(39,40)$. Beclomethasone dipropionate (BDP) was the first synthetic glucocorticoid to be topically inhaled in the lungs (41). In tabell 1 the potency of several glucocorticoids is shown. Inhaled glucocorticoids are highly lipophilic molecules and are thought to enter into the cytoplasm by passive diffusion along the cell membrane $(2,24)$. However, the occurrence of caveolae in this context is not excluded $(42,43)$. In the cytoplasm they bind to an inactive receptor which then becomes activated and is able to exert the ligand induced effect $(44,45)$. Research has unraveled some of the basic mechanisms through which glucocorticoids influence inflammation. However, despite their frequent use, the precise molecular mechanisms involved in the anti-inflammatory actions of glucocorticoids are not yet completely understood. 
Tabel 1: Activity of some glucocorticoids, as modified by Kom $(2,24,40,46)$.

\begin{tabular}{|l|l|l|l|l|}
\hline \hline Generic name & $\begin{array}{l}\text { Relative } \\
\text { mineralcorticoid } \\
\text { effects }\end{array}$ & $\begin{array}{l}\text { Relative anti- } \\
\text { inflammatory } \\
\text { effects }\end{array}$ & $\begin{array}{l}\text { Equivalent dose (mg) } \\
\text { when administered } \\
\text { systemically }\end{array}$ & $\begin{array}{l}\text { GR binding } \\
\text { affinity }\end{array}$ \\
\hline Cortisone & + & 0.8 & 25 & $?$ \\
\hline Hydrocortisone & ++ & 1.0 & 20 & 0.04 \\
\hline Prednisone & + & 4.0 & 5 & 0.03 \\
\hline Triamcinolone & 0 & 5.0 & 4 & 3.6 \\
\hline Dexamethasone & 0 & 30 & 0.75 & 1.0 \\
\hline Budesonide & 0 & $?$ & 2 & 9.4 \\
\hline $\begin{array}{l}\text { Fluticasone } \\
\text { propionate }\end{array}$ & 0 & $?$ & $?$ & 18 \\
\hline
\end{tabular}

$?=$ unknown

\subsection{Structure, function and activation of the glucocorticoid receptor}

A central role in the function of glucocorticoids is played by the glucocorticoid receptor (GR). Direct correlation exists between the concentration of GRs in a cell and the cell's sensitivity to glucocorticoids $(47,48)$. Therefore it is important to understand the factors that regulate GR levels. GR numbers vary between different cell types and in one cell type between different individuals. Location in the cell cycle, aging, state of development, receptor structure and endocrime status also influence receptor levels within a cell at a given time (4). Several biological compounds have been shown to influence the concentration of the GR. The most interesting modulators, however, are the glucocorticoids themselves (49-51).

The GR is situated in the cytoplasm of cells in the absence of steroids (52). After exposure of the cells to glucocorticoids, the receptor becomes activated, translocates from the cytoplasm to the nucleus, and binds as a dimer to the DNA (53). The nuclear localization of the GR reflects a dynamic process, resulting in an equilibrium between receptors situated in the cytoplasm and nucleus. Traffic between nucleus and cytoplasm is 
selective and only possible when the nuclear membrane recognizes certain signals in the protein (54). In the GR two nuclear localization signals are present (figure 2) and believed to be involved in the inward and outward movement to and from the nucleus $(55,56)$.

Due to alternative splicing, two phenotypically distinct isoforms of the GR are found. The first 8 exons (727 amino acids) are identical, but a heterologous carboxyl terminus results in two different receptor forms. The $\alpha$ GR protein is 777 amino acids long with a mRNA length of $7 \mathrm{~kb}$. The $\beta$ GR protein is smaller, about 742 amino acids and has a mRNA length of $5 \mathrm{~kb}$. Recently, a second $\alpha$ form ( $\alpha 2)$ was described with a mRNA size of $5.5 \mathrm{~kb}(57)$. In the same article the $\beta$ GR mRNA was slightly smaller of length ( $4.3 \mathrm{~kb})$. The two $\alpha$ mRNA forms would describe for the same protein (57). Since the $\beta$ GR lacks the ligand binding site, only the $\alpha$ form is able to bind glucocorticoids $(58,59)$. A possible ligand for the $\beta$ form is unknown. For this reason, most of the GR studies performed until now, have investigated the $\alpha$ GR, despite the fact that the $\beta$ GR form has been detected with Northern and Western blotting. Since the probes and antibodies used in these studies are completely or partially directed against the homologous part of the GR, all forms can be detected and separation is based on length. Therefore, with immunostains, no difference can be made between the $\alpha$ and $\beta$ GR. Recently polyclonal antibodies detecting either the $\alpha$ or $\beta$ form have been developed, but so far were not commercially available (4).

The $\alpha 1$ and $\beta$ GR mRNA forms bave been detected in all cell types investigated $(57,60)$. The $\alpha 1$ GR mRNA seems to be more abundantly present in cells than the $\beta$ GR mRNA (57). With transfection studies it has been demonstrated that the $\beta$ GR is able to act as a dominant negative inhibitor of the function of the $\alpha$ form (60). Unclear is whether the $\beta$ GR exerts this effect by occupation of DNA target sequences with non-transactivating $\beta / \beta$ homodimers, or also with $\alpha / \beta$ heterodimers. However, this dominant negative effect only occurs when the $\beta$ GR is present over 5 times more in cells than the $\alpha$ form whereas all cell types express more $\alpha \operatorname{GR}$ mRNA $(60,61)$. The fact that the $\beta$ mRNA form is so widely detected throughout the body, indicates that it may play a role in the cellular response to glucocorticoids. However, the function is largely unknown. On protein level, no reliable studies have been published so far.

The structure of the GR is similar to the structure of other steroid hormone receptors. It can be divided in three domains; a relatively well conserved C-terminal ligand binding domain, a well conserved central DNA binding domain and a variable $\mathrm{N}$-terminal transactivation domain. The various functions of the receptors, ligand binding, dimerization, nuclear translocation, DNA binding, and trans-activation, have been assigned to particular 
amino acid sequences or to more complex regions of the protein. In figure 2 the different domains and their functions are shown $(45,62-64)$.

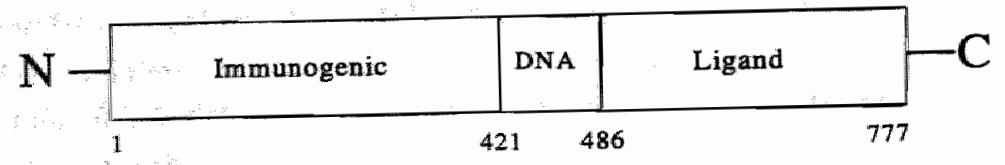

Immunogenic

domain

DNA binding

domain

Ligand binding

domain

Hinge region

Zinc-finger 1

Zinc-finger?

Transactivation

sites

Nuclear Localli-

sation Signals

Dimerization

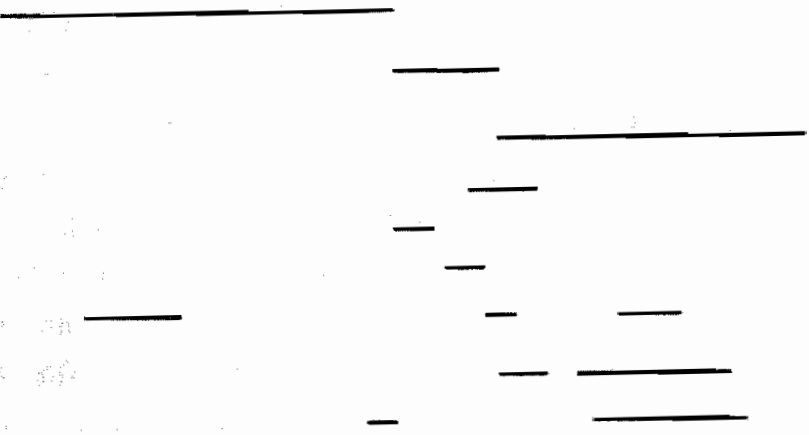

Figure 2: Structural and functional organization of the glucocorticoid receptor.

The non-activated GR exists in the cytoplasm as a heteromeric inactive complex, associated with at least three types of heat shock proteins (HSP). Interaction between the GR and a HSP90 dimer and a HSP70 has been demonstrated (65-67). HSP56 is also part of this complex. It does not interact directly with the receptor, but via the HSP90 dimer $(68,69)$. After binding of the ligand the receptor becomes activated by dissociation of the HSP90 dimer and HSP56 $(70,71)$. HSP70 is thought to dissociate from the GR in the nucleus (67). The HSP90 dimer is important for glucocorticoid binding (72). It is speculated that HSP 90 also functions in the translocation of the GR to the nucleus though interactions with the cytoskeleton (73-75). HSP70 plays a role in the entrance of the GR to the nucleus (54) by unfolding and thereby presenting the nuclear localization signals of the GR to nuclear localization signal binding proteins in the nuclear membrane. HSP56 may play a role in the regulation of the HSP90 function (71). The events that occur to prelude the glucocorticoid effect are schematically drawn in figure $3(63,76,77)$. After 
translocation into the nucleus and dissociation of all HSPs the GR forms a homodimer and binds to glucocorticoid responsive elements in the DNA

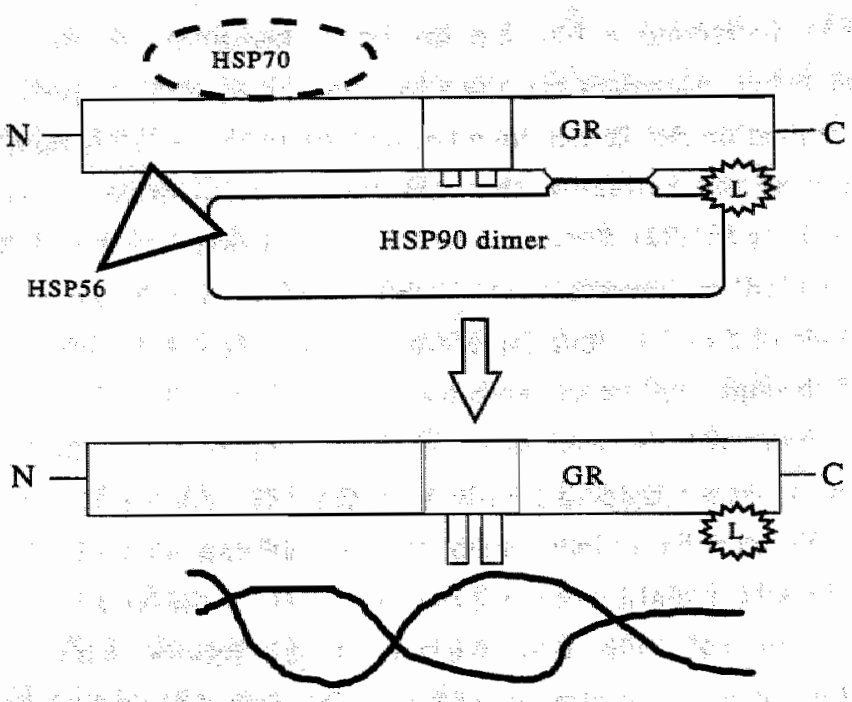

Figure 3: Glucacorticoid recepter activation.

Steroid receptors modulate gene transcription by binding to hormone responsive elements (HRE) on the DNA. Based on the HREs, steroild hormone receptors can be divided into two groups. The first group has a consensus sequence resembling that of the glucocorticoid receptor, the glucocorticoid responsive elements (GRE): GGTACAnnmTGTTCT. The progesterone, androgen, and mimeralocorticoid receptors belong to this group. The second consists of estrogen, thyroid, retinoic acid and vitamin D3 receptors all matching the estrogen response element (ERE): AGGTCAnnnTGACCT (45). However, binding to DNA alone is not sufficient to influence gene transcription (trans-activation). Trans-activation sites, present in all 3 domains of steroid receptors (figure 2), must be activated. So there is a lot of similarity between the different steroid hormones, their receptors and their signal transduction pathways.

Despite these major similarities, every hormone mediates its own response because the requirements for optimal interaction vary for the different hormone receptors $(45,78)$. 
First of all, trans-activation regions within the steroid receptors are specific for every member of the family (64). Especially the trans-activation region in the highly variable $\mathrm{N}$ terminal domain $(\tau 1)$ has a major function in trans-activation activity $(79,80)$. However, activation of the C-terminal trans-activation domain ( $\tau 2)$ depends on binding of a functional ligand (81), indicating a function in signal specificity. Binding of another steroid hormone may result in nuclear translocation, but not in trans-activation. In some studies a third trans-activation site is mentioned to be present in the DNA-binding domain (45). However, there is a basic agreement that this site only contributes to a small part in the trans-activation activity $(81,82)$. Secondly, the highly conserved, central DNA-binding region of the receptor plays an important role in the discrimination between the different ligands. The importance of the DNA-binding region in hormone specificity becomes clear with results obtained through studies using chimeric steroid receptors. By combining the GR DNA binding domain with the estrogene steroid binding region, gene regulation of glucocorticoid responsive genes is facilitated by estradiol (83). Also ERE-mediated gene regulation can be stimulated by retinoic acid, after combining an ERE-DNA binding domain with a retinoic acid ligand binding region (84). The 70 amino acid DNA-binding sequence is cysteine-rich and folds into two zinc finger motifs, with a zinc atom tetrahedrically coordinated to four cysteines $(85,86)$. The first, $\mathrm{N}$-terminal finger which binds to the major groove of the HRE, exhibits two amino acid sequences at the root of the finger, causing distinction between hormone responses of the glucocorticoid receptor group and the estrogen receptor group. Glycine-Serine is the sequence for the glucocorticoid receptor group and Glutamate-Glycine for the estrogen receptor group $(87,88)$. So this first finger is responsible for functional discrimination between a GRE and an ERE $(78,85,86,88)$. The C-terminal finger binds to the sugar-phosphate backbone of the HRE and is possibly involved in receptor dimerization and stabilization, but does not contribute to the specificity of the receptors (85-87). Thirdly, in order to be able to distinguish further between the different steroid hormones, other arnino acids in the first zinc finger are important. Mutation of a single lysine to a glycine keeps the DNA-binding intact but blocks the transcriptional activation (81). Thus, it seems that binding of a receptor to a HRE is only the first (prerequisite) step, but not sufficient for transactivation. Compared to the information that is available about the activation and nuclear influx of the GR, little is known about the events that occur after the GR has bound to DNA and regulated gene transcription. 


\subsection{Anti-inflammatory actions of glucocorticoids}

The precise mechanism of glucocorticoid action remains uncertain, although a lot of progress has been made in the last few years regarding the molecular basis for their antiinflammatory actions. Concerning the control of inflammation, repression of gene transcription is especially of interest. How are glucocorticoids able to modulate genes in a stimulatory (positive) and inhibitory (negative) way? The process is cell dependent, since genes which are upregulated by glucocorticoids in one cell type are downregulated in another cell type. At first it was proposed that two different glucocorticoid responsive elements (GRE) existed. Stimulation of gene transcription was performed through the GRE described above. The number of GREs and their position in the transeribed gene is of importance to the transcriptional response of the gene $(5,77,89)$. Repression of gene transcription, though, was thought to occur through a negative GRE $(25,45)$. However, the presumed 15 base pair constitution of the negative GRE was essentially different from the positive GRE and seemed to be more variable (24). Nevertheless, the ligand-receptor complex should be able to bind to both cis-elements. In more recent studies using the electromobility shift assay, a short $20-30$ base pair stretch of double stranded DNA differing in 2 nucleotides from the original cis-sequence is used as negative control, emphasizing the specificity of the interaction of trans- and cis elements (90). In addition, most genes downregulated by corticosteroids do not have a negative GRE in their promotor region $(25,45,77,91-95)$. Although in recent reviews the theory of negative GRE elements has still been promoted (95), there is relatively little evidence for this negative GRE theory in most genes inhibited by glucocorticoids.

An alternative mechanism proposed to be responsible for gene repression concerns cross-talk between different transcription factors, involving direct protein-protein or protein-DNA interactions $(96,97)$. For the GR direct protein-protein interaction is thusfar described with the key proinflammatory transcription factors activator protein-1 (AP-1) (98-100) and nuclear factor $\mathrm{KB}(\mathrm{NFKB})$ (101-103). Interaction has also been demonstrated with transcription factors CAMP responsive element binding protein (CREB) (104-107) and signal transducers and activators of transcription 5 (Stat5) (108). Recently, the $\beta$ GR has been shown to play a role in this process as a dominant negative inhibitor ${ }_{4}$ able to disturb the $\alpha$ GR function, probably by occupation of the GRE's with transcriptionally 
inactive $\alpha / \beta$ heterodimers and/or $\beta / \beta$ homodimers $(57,60)$. Whether cross-talk takes place in the cytoplasm or in the nucleus, is at present unclear. Initially this was thought to occur within the nucleus. However, recent studies demonstrate that the cytoplasm may be the major site of cross-talk $(109,110)$. In figure 4 a schematic drawing of part of the possible cross-talk between transeription factors is shown.

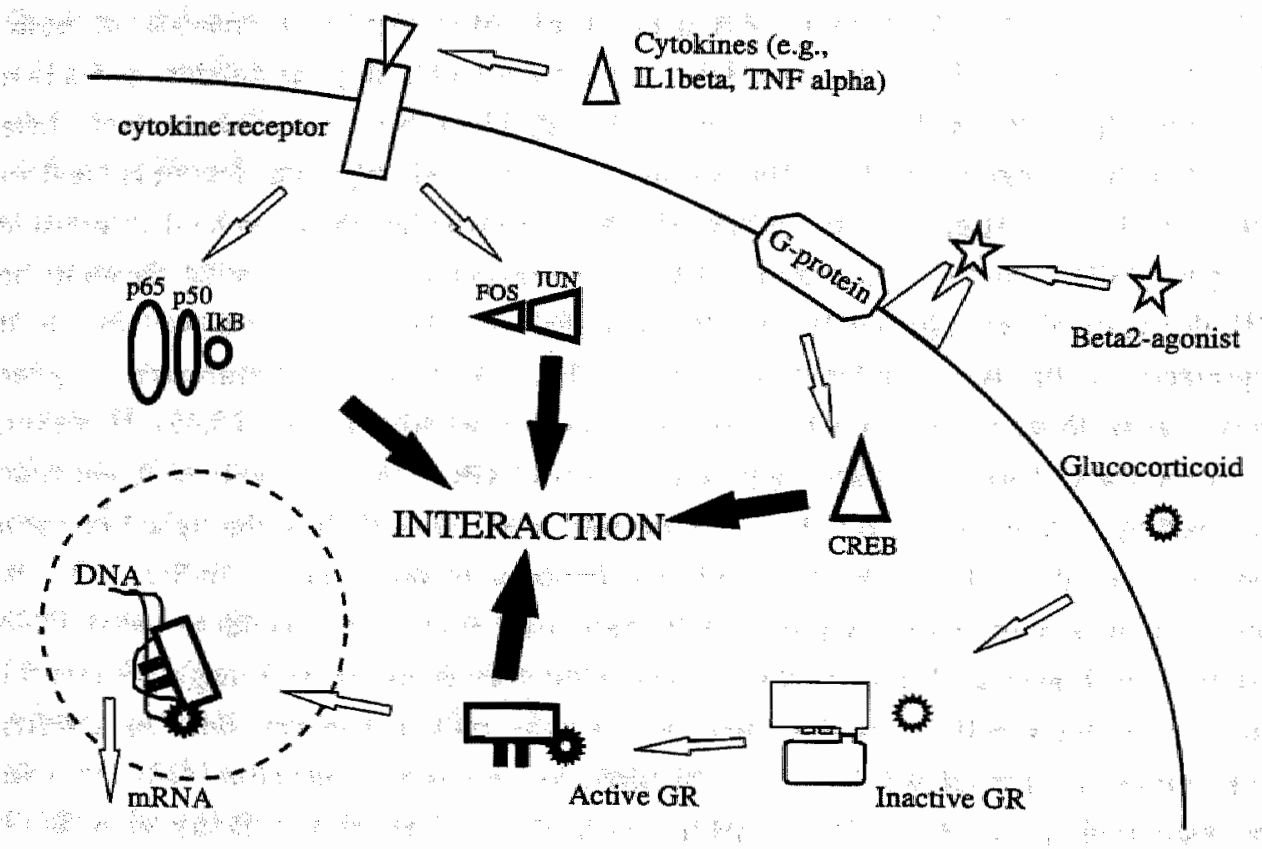

Figure 4: Possible cross-talk between transcription factors modified after Bames (96). $\rightarrow=$ interaction, $\Rightarrow=$ stimulation.

The mechanism of downregulation of GR transcription is not clear. Interaction between transcription factors will probably play a role in this process. The promotor region of the glucocorticoid receptor contains no GREs, but responsive elements for AP-1 $(n=1)$ and CREB $(n=5)$ are demonstrated (91). A mechanism described by Vig and coworkers can be a possible explanation for the GR downregulation (111). AP-1 binds to the GR gene and stimulates transcription. Because of the activation of the GR the c-Jun part of AP-1 binds 
to the transformed GR resulting in a reduced AP-1 binding to DNA and thus an inhibited GR gene transcription and subsequent downregulation of the GR expression. Unclear in this theory is whether AP-1 will dissociate from the DNA after activation of the GR, or whether the influx of AP-1 to the nucleus will stop due to the cross-talk: $A$ similar mechanism ean also apply for CREB, since several CRE sites are present in the GR gene (91,111). The physiologic significance of GR downregulation after glucocorticoid therapy, however, is still not known and needs to be further evaluated.

In chronic inflammatory diseases, such as asthma, several cytokines recruit activated inflammatory cells to the site of the lesion, thereby amplifying and perpetuating the inflammatory state. The anti-inflammatory action of glucocorticoids involves the repression of cytokine secretion by inflammatory cells. The mechanisms behind the modulation of cytokine gene expression can be attained via several pathways (112).

1- The GR binds to a GRE that overlaps or is located close to responsive elements of key proinflammatory transcription factors. These positively regulating transcription factors are therefore unable to bind the DNA and gene transcription is inhibited. This has been described for $\Pi 6(93,113)$.

2- Since most cytokines lack GREs, direct binding between the GR and key proinflammatory transcription factors $\mathrm{AP}-1$ and NFKB is suggested and demonstrated $(98,99,102,103)$. These proinflammatory transcription factors modulate the cytokine gene transcription positively, and by interfering with this pathway the gene regulation is blocked. This is shown for $\Pi 22$ (114), $\Pi L 6$ (113) and $\Pi L 8$ (103).

3- By enhancing the gene expression of IKB, NFkB will become deactivated again and will not stimulated cytokine gene transcription $(92,115)$. This may explain part of the steroid blunting of $\mathbb{L} 1, \mathbb{L} 2, \pi \mathrm{L}, \mathrm{IL} 6, \mathbb{L L} 8$, TNF $\alpha$, IFN $\gamma$ and GM-CSF (115).

4- Post-transcriptionall modulation may also be involved. Half lives of cytokine mRNA can be reduced by glucocorticoids. This has been demonstrated for $1 \mathrm{~L} 1 \beta$ (116) $1 \mathrm{~L} 2$ (117), IL3 (118), IL6, GM-CSF (116), and IFNB (119). The mechanism behind this method is poorly understood, but may involve modulation of stabilizing proteins and/or ribonucleases.

In table 2 a summary is given of the effects of glucocorticoids on the modulation of some genes involved in the inflammatory process $(97,112,120)$. Included are the regulatory elements of these genes and the presence of GREs in the gene (reviewed by Brattsand (112) and Cato (97), modified by Korn). 
Table 2: Modulation by glucocorticoids of genes involved at various levels of inflammation.

\begin{tabular}{|c|c|c|c|c|c|c|c|}
\hline Cytokine & Pffect & $\begin{array}{l}\text { Regulationy } \\
\text { elements }\end{array}$ & GRE & Cytokine, & Effiect & $\begin{array}{l}\text { Regulatory } \\
\text { elentents }\end{array}$ & GRE \\
\hline 1MP & 1 & CREB & & NF $\alpha$ & $y$ & $?$ & 7 \\
\hline IIL 2 & 4 & AP 1 & & Irry & 4 & 12 & \\
\hline $\mathrm{n}$ & 1 & 9 & 9 & Glu csp & 1 & 7 & 7 \\
\hline rit & 4 & ? & 9 & $\mathrm{G} \mathrm{CSP}$ & H1 & $?$ & 12 \\
\hline nt 5 & $\Perp$ & n. & 2 & Missp & 41 & $?$ & 7 \\
\hline 146 & U. & NFKB & $=$ & $\mathrm{TAF} \beta$ & 41 & & \\
\hline 118 & 1) & NFiB & & PDGF & ॥ & $?$ & 7 \\
\hline 110 & 1 & 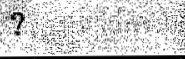 & 9 & CAM-1 & 1 & 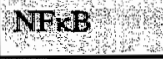 & -2 \\
\hline 1412 & 4 & 7 & 2 & $\mathrm{EI} \times \mathrm{ML}$ & 1 & $N F B^{\prime}$ & \\
\hline
\end{tabular}

$-=$ not present $\|=$ downregulation, $\| \Uparrow=$ down- and upregulation, $?=$ unknown

The inhibitory effects of glucocorticoids on the interleukin-like cytokines (including TNF $\alpha$ and IFN $\gamma$ ) is more homogenous compared to the effects seen in the phase-repair cytokines and growth factors. In summary, glucocorticoids reduce gene expression of the initial and secondary phase cytokimes as well as of the immunomodulatory cytokines. However, the expression of the phase-repair cytokines and growth factors is unaffected or even upregulated by glucocorticoids.

\subsection{Purpose of this study}

When this study was started no information was available about the GR expression in bronchial epithelial cells, despite the fact that this cell type plays a central role in the inflammatory processes involved in asthma and the anti-inflammatory inhalation therapy. Also nothing was known about the $\beta$ GR, except for its existence. Our goal was to study 
both $\alpha$ and $\beta$ GR mRNA forms in bronchial epithelial cells in vitro and in vivo. The following strategy was followed;

First, an existing method to isolate RNA from bronchial epithelial cells obtained through bronchoscopy was modified to increase the amounts of RNA isolated. This is described in chapter 2, the introduction to the experimental work. The modification created the possibility to perform Northern blotting instead of RT-PCR with total RNA obtained from human bronchial epithelial cells in vivo.

Because no information was available about $\alpha$ and $\beta$ GR mRNA levels in bronchial epithelial cells, we were interested in the expression of both GR mRNAs in this cell type. Since the GR is autoregulated by its own ligand and the response of cells to glucocorticoids depends on the GR levels, the response of both GR forms to glucocorticoids was determined. Therefore, in chapter 3, a human bronchial epithelial cell line was exposed to budesonide in a dose and time dependent way. Bronchial epithelial cells of human volunteers were sampled before and after 4 weeks budesonide inhalation and $\alpha$ and $\beta$ GR mRNAs were determined.

To be able to confirm the results obtained in chapter 3 and study the time dependent $\alpha$ and 6 GR mRNA downregulation in vivo, a rat model was developed. To this end rat lungs were sampled 1, 4, and 12 hours after intratracheal instillation of budesonide. As control tissue for the systemic effects a skeletal muscle was investigated. This is described in chapter 4.

Patients with COPD do not respond well to glucocorticoids. Since the response to glucocorticoids is reduced by low levels of GR and/or overexpression of the $\beta$ form, the $\alpha$ and $\beta$ GR mRNA levels and ratios in bronchial epithelial cells of these patients were examined. In chapter 5 the basal $\alpha$ and $\beta$ GR mRNA expression in patients with COPD using no glucocorticoids was compared with an age matched control group.

To test whether the reduced response can be explained by failures in the transcriptional machinery, both $\alpha$ and $\beta$ GR mRNA levels and ratios were checked in patients with COPD after glucocorticoid use. The control group included smoking and non-smoking patients without obstructive disease and glucocorticoids. The results are described in chapter 6.

There is, at present, controversy as to whether regular treatment with $\beta_{2}$-agonists reduces overall asthma control, since despite the use of inhaled $\beta_{2}$-agonists and glucocorticoids, morbidity and mortality of asthma has increased worldwide. An explanation for the detrimental effects of $\beta_{2}$-adrenergic agonists on asthma control might be found in the 
interaction between CREB and GR. In chapter 7 the cross-talk between CREB and GR and the effect of this interaction on gene transcription is studied in vitro in bronchial epithelial cells. In chapter 8 the results of all studies are discussed as well as a possible model for transcription factor interaction. 


\section{TWO}

INTRODUCTION TO THE EXPERIMENTAL WORK 


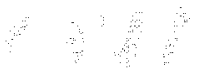


INTRODUCTION TO THE EXPERIMENTAL WORK

2.1 Introduction

2.2 Materials and methods

2.3 Results

2.4 Discussion 



\begin{abstract}
Investigation of the gene expression in human bronchial epithelium with Northern blot analysis is often impeded by difficulties in collecting enough material. For example for the study of the glucocorticoid raceptor gene expression $20 \mu \mathrm{g}$ RNA is necessary. A simple method to isolate up to $90 \mu \mathrm{g}$ RNA out of fresh human bronchial epithelial cells is described. The cells were collected in culture medium during routine bronchoscopy on 29 patients, using 10 brushes from the right middle lobe between the second and fourth order bronchi. By mixing the cell suspension immediately after collecting the cells with an equal volume $8 \mathrm{~mol} / \mathrm{l}$ guanidinium isothiocyanate (GTC), up to 5 times more RNA is obtained than previously feasible. This procedure allows Northern blot analysis of several genes such as the glucocorticoid receptor gene. Therefore, this procedure may facilitate the research on diseases of the human bronchial epithelium such as asthma, smoking related diseases and cystic fibrosis.
\end{abstract}




\subsection{Introduction}

The bronchial epithelium is important in diseases of the lung. It serves as a first barrier for inhaled substances and plays a role in inflammation. The bronchial epithelium produces cytokines, but can also be a target cell for certain cytokines (9). These cytokines may be modulated by steroid treatment. In clinical practice inhalation of steroids is the treatment of choice in several diseases of the lung such as asthma $(5,121-123)$.

Glucocorticosteroids (GCS) penetrate the cell membrane through diffusion forming a hormone-receptor complex with the glucocorticoid receptor $(76,124)$. After translocation of this complex to the nucleus (70), the glucocorticoid receptor (GR) serves as a transcription factor and modulates the gene expression of several genes $(45,63,77)$.

To investigate GR expression in human bronchial epithelial cells with Northern blot analysis, large amounts of RNA are needed. Until now this analysis has not been possible because of the small amounds of RNA obtained from these cells through bronchoscopy. In this study a modification of the protocol by Erzunum et al. (125) is presented, resulting in an increased yield of RNA. We compared both extraction methods and investigated the GR gene expression in human bronchial epithelial cells with Northern blot analysis.

\subsection{Materials and methods}

Bronchial epithelial cells from patients undergoing bronchoscopy were collected using 10 brushes from the right middle lobe between the second and fourth order bronchi. Each brush was firmly shaken in $4 \mathrm{ml}$ DMEM-medium $\left(4^{\circ} \mathrm{C}\right)$ allowing the cells to detach from the brush into the medium. The cell suspension was kept on ice to reduce possible degradation.

Old method: In the initial procedure according to Erzurum et al (125) this suspension was centrifuged $(1500 \mathrm{~g})$ and to the pellet $1 \mathrm{ml}$ PBS was added. From this $1 \mathrm{ml}$ PBSsuspension $25 \mu 1$ was used to make smears for cytology and for other investigations. One of these object slides was airdryed and stained with Giemsa to determine the cellular composition of the brushes. In order to check the amount of blood cells in the sample 200 $\mu \mathrm{l}$ was taken to test the $\mathrm{Hb}$-amount. The remaining suspension was centrifuged again $(1500 \mathrm{~g}$ ) and to the pellet $8 \mathrm{ml} 4 \mathrm{~mol} / \mathrm{GTC}(4 \mathrm{mmol} / \mathrm{l}$ guanidium thiocyanate, $25 \mathrm{mmol} / \mathrm{]}$ 
sodium acetate $\mathrm{pH} 5.2,18 \mathrm{mmol} / \mathrm{N}$-lauroyl-sarcosine) was added and stored at $-70{ }^{\circ} \mathrm{C}$. RNA was isolated using a modification of the cesium chloride $(\mathrm{CsCl})$ gradient method described by Davis et al. (126). In short: The GTC-cell suspension (with the addition of $118 \mathrm{mmol} / \mathrm{h} 2$-mercaptoethanol) was sheared with a $23 \mathrm{G}$ needle $(0.8 \mathrm{~mm})$ and layered upon a $3 \mathrm{ml} \mathrm{CsCl}$ cushion ( $5.7 \mathrm{~mol} / \mathrm{l}$ cesium chloride, $4 \mathrm{mmol} / \mathrm{EDTA} \mathrm{pH} 8.0$ ). The samples were ultracentrifuged at $154,000 \mathrm{~g}$ for 20 hours at $20^{\circ} \mathrm{C}$. RNA was recovered by dissolving the pellet in HES-buffer (10 mmol/ HEPES 7.4, 5 mmol/1 EDTA pH 8.0, 3.5 $\mathrm{mmol} / \mathrm{l}$ sodium dodecyl sulfate) for half an hour, overnight precipitation with 1 volume 2propanol and 0.5 volume $5 \mathrm{~mol} / \mathrm{l}$ ammonium acetate $\mathrm{pH} 5.2$ at $-20{ }^{\circ} \mathrm{C}$ and 30 minutes centrifugation at $16,000 \mathrm{~g}$ at $4{ }^{\circ} \mathrm{C}$. The RNA pellet was dissolved in $10 \mu \mathrm{l}$ distilled water. New method: In an attempt to increase the amount of RNA we adapted the initial procedure. Brushes $(\mathrm{n}=10)$ were collected in $4 \mathrm{ml} \mathrm{DMEM}\left(4^{\circ} \mathrm{C}\right)$. Immediately $3.8 \mathrm{ml}$ cell suspension was added to $4 \mathrm{ml} 8 \mathrm{~mol} / \mathrm{GTC}$. This solution of $8 \mathrm{~mol} / \mathrm{l} \mathrm{GTC}$ was obtained after mixing with a magnetic stirrer at room temperature for a minimum of 3 hours. RNA extraction was performed through $\mathrm{CsCl}$ as described above. Again 200 $\mu \mathrm{l}$ was used for the $\mathrm{Hb}$-test. To obtain better morphology of the cells for cytological investigation an additional brush was taken and the cells of this eleventh brush were immediately smeared on the object glass, without first shaking them into the medium. After airdrying the cells were Giemsa stained.

\section{Study:}

To compare the amount of RNA obtained from the two described procedures we collected cells from 10 brushes sampled in 2 pneumectomy specimens. In these cases the brushes were directly (without a bronchoscope) placed in the bronchus under visual inspection. After division of the cell suspension of each patient in two equal volumes, both procedures were tested. In addition, the yield of total RNA is presented from different patients initially obtained with either the old and later on with the modified RNA extraction procedure.

\section{Northern blot analysis:}

$20 \mu \mathrm{g}$ of RNA was dissolved in sample buffer (1.3xMPS, $2.6 \mathrm{M}$ formaldehyde and 16.3 M formamide) (10xMPS is $200 \mathrm{mM}$ 3-morpholinopropane sulfonic acid, $80 \mathrm{mM}$ sodium acetate and $10 \mathrm{mM}$ EDTA) and fractionated by electrophoresis in an agarose gel (1.2 $\mathrm{mg} / \mathrm{ml}$ agarose in $1 \times$ MPS and $1,11 \%$ formaldehyde with a $1 \times$ MPS running buffer) at 110 
$\mathrm{V}$ and $20^{\circ} \mathrm{C}$ for $2 \mathrm{~h}$. The gel was rinsed 3 times $15 \mathrm{~min}$ in RNase free water, stained with ethidium bromide $(0.5 \mu \mathrm{g} / \mathrm{ml})$, washed in RNase free water 3 times $15 \mathrm{~min}, 20 \mathrm{~min}$ in 0.05 $\mathrm{M} \mathrm{NaOH}$, rinsed shortly in water and finally washed $30 \mathrm{~min}$ in $1 \mathrm{M}$ ammonium acetate. The RNA was transferred onto a Nytran membrane (Schleicher and Schuell) by capillary blotting with $1 \mathrm{M}$ ammonium acetate. After blotting the RNA was fixed to the membrane by UV-crosslinking and $1 \mathrm{hr}$ backing at $80^{\circ} \mathrm{C}$.

\section{Hybridization:}

The GR probe was obtained using a polymerase chain reaction on cDNA of Bet1A cells (127) using the following primers: Sense 5-GATTGGATCCATGGACTCCAAAGAA TCATTAACTCCTGG-3' with a BamH1 site, Anti-sense 5'-GATTGTCTCGAGAGAA AGTTCATCACACAGACTTTGG-3' including a Xhol site. After digestion of the polymerase chain product with BamH1 and Xho1 restriction enzymes the DNA was ligated into Bluescript SK 13+. With sequence analysis it was shown that the insert was simillar to the published sequence (58). Northern blots were hybridized with the GR and GAPDH probes. All probes were labeled with $\left[{ }^{32} \mathrm{P}\right]$-dCTP using the random primed labeling method. Northern blots were hybridized at $65^{\circ} \mathrm{C}$ in $0.5 \mathrm{M} \mathrm{PO}_{4}^{3 *}, 1 \mathrm{mM}$ EDTA, $70 \mathrm{mg} / \mathrm{ml}$ SDS and $5 \mathrm{mg} / \mathrm{ml} \mathrm{BSA}$. All blots were washed at room temperature with $2 \times S S C, 3.5 \mathrm{mM}$ SDS and $0.5 \times S S C, 3.5 \mathrm{mM}$ SDS and at $65^{\circ} \mathrm{C}$ with $0.1 \times S S C, 3.5 \mathrm{mM}$ SDS for 15 min each.

\section{Detection:}

RNA expression of the GR was determined relatively to the control gene GAPDH. The sample signals were analyzed visually as well as semiquantitatively with phosphor imaging system (Molecular Dynamics). The latter was performed by measuring the intensity of the bands relatively to the background signal directly around the bands.

\subsection{Resulits}

The result of the comparison of both RNA extraction methods of bronchial epithelial cells derived from brushes of bronchi in two pneumectomy specimens is shown in figure 1. Note that sharp $18 \mathrm{~S}$ and $28 \mathrm{~S}$ bands are visible in figure 1 . The measured RNA content is shown in table 1 . 


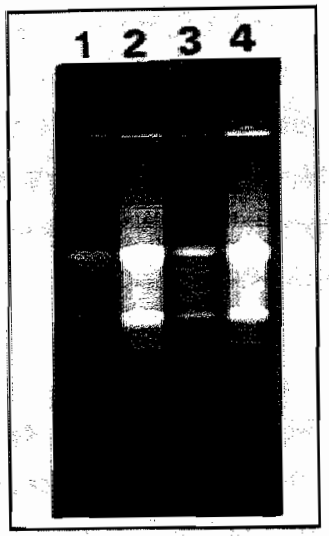

Figure 1: $1 \mu$ l total RNA was loaded onto a $1 \%$ agarose gel and electrophoresis was performed for 30 min at $100 \mathrm{~V}$. Lane 1 and 2 contain RNA from the same patient and lane 3 and 4 from another patient. In lane 1 and 3 RNA is isolated with the old and in lane 2 and 4 with the modified method.

Table 1: Total amount of RNA obtained from the brushes. $2 \mu$ RNA was measured with the OD $260 / 280$ method.

\begin{tabular}{|l|l|l|l|}
\hline $\begin{array}{l}\text { Patient } 1 \\
\text { OLD method }\end{array}$ & $\begin{array}{l}\text { Patient 1 } \\
\text { NEW method }\end{array}$ & $\begin{array}{l}\text { Patient 2 } \\
\text { OLD method }\end{array}$ & $\begin{array}{l}\text { Patient 2 } \\
\text { NEW method }\end{array}$ \\
\hline $17 \mu \mathrm{g}$ RNA & $86 \mu \mathrm{g}$ RNA & $13 \mu \mathrm{g}$ RNA & $70 \mu \mathrm{g}$ RA \\
\hline
\end{tabular}

Before modification of the RNA extraction procedure on bronchial epithelial cells derived during bronchoscopy, the mean recovery of total RNA in 7 patients was $12.2 \mu \mathrm{g}$ for 10 brushes (range 5.5-22.0 $\mu \mathrm{g}$ ). After modification the mean yield of total RNA in 22 patients was $52.6 \mu \mathrm{g}$ (range 26.4-97.5 $\mu \mathrm{g}$ ).

To check the possibility of GR gene expression in the bronchial epithelial cells a Northern blot is hybridized with a GR probe (figure 2). 


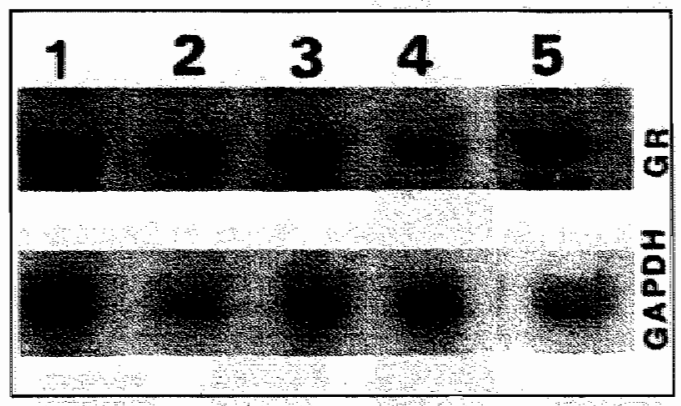

Figure 2: $20 \mu \mathrm{g}$ total RNA was loaded onto a gel and after blotting hybridized with GR probe. The 5 lanes represent RNA from bronchial epithelium from different patients.

The GR mRNA expression is tested in bronchial epithelial cells from 5 patients. In figure 2 a $7 \mathrm{~kb}$ band is seen representing the $\alpha$ GR and a $1.4 \mathrm{~kb}$ band representing the GAPDH control. In figure 3 the GR mRNA expression is measured compared to the GAPDH control. This shows that there is a great variance in GR gene expression between different patients.

With cytological examination more than $50 \%$ of the nuclei of the cells are damaged in the old procedure compared to less than $10 \%$ in the modified method (figure 4 ). The majority of the cells obtained with a brush are epithelial in nature. Occasional inflammatory cells are present as well. 


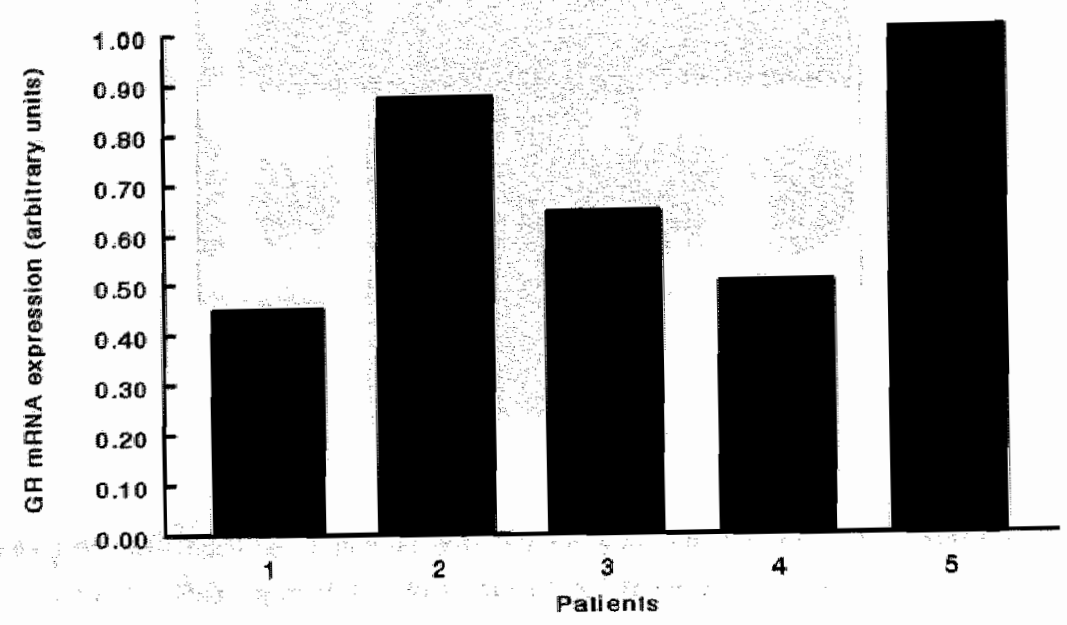

Bronchial epithelitum

Figure 3: Comparison of the GR mRNA expression in bronchial epithelial cells between 5 patients.
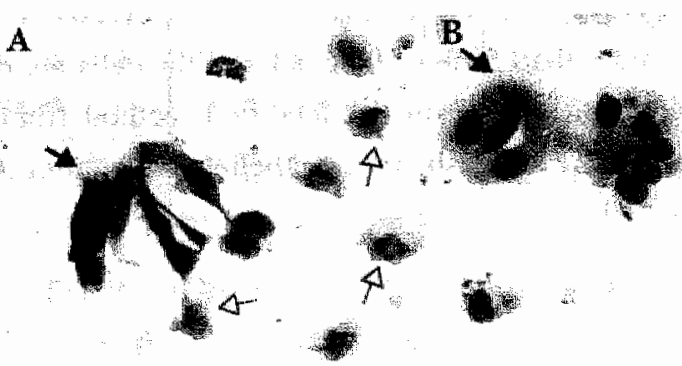

蓶
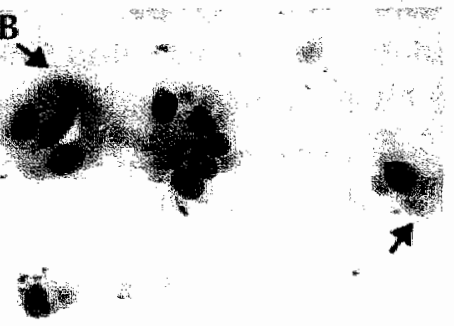

Figure 4: Photographs of Giemsa stained cells with the old (A) and modified (B) procedure (500x). Note that the outline of the nuclei is less sharp and the cytoplasm is disrupted (open arrow) in cells obtained with the old method. In some cells cilia with basal plate are visible (closed arrow). 


\subsection{Discussion}

We have modified a protocol to extract total RNA from human respiratory epithelium in a more efficient and faster manner. The amount of RNA obtained with the modified method was increased by 5 times. This was proven in three ways. Firstly, with RNA obtained from brushes performed in pneumectomy specimens, in which the cell suspensions from two patients were divided in two equal parts and treated in parallel with the old and new procedure. Secondly, the RNA amounts of bronchoscopy material from patients obtained with the old or new method were compared and verified this increased yield of RNA with the new method. Thirdly, Northern blot hybridization of the GR resulted in distinct signals, which previously had not been possible.

The explanation for the increased amount of total RNA obtained with the modified method is twofold. In the new procedure RNA degradation is avoided. By immediately mixing GTC with the cell suspension, the time of uncontrolled RNA degradation is reduced from 40 to less than 5 minutes. A second explanation for the increased yield of total RNA is that in the original procedure only the pellet was used for RNA extraction. If RNA is present in the supernatant either from disrupted cells or possibly from the epithelial lining fluid this will not be collected in the original procedure. This explanation is supported in part by cytological evaluation of the Giemsa stained slides, where in the original procedure less than $50 \%$ intact bronchial epithelial cells were found, suggesting that in the old procedure RNA from the disrupted cells is likely to be lost.

In addition, we observed that the amount of total RNA obtained in brushes from pneumectomic specimens was higher compared to the yield from brushes performed during bronchoscopy. This difference is explained by the accessibility of the bronchi, being easier in pneumectomy specimen, allowing more cells to be sampled.

Because the amount of total RNA sampled from human bronchial epithelial cells with the new method was higher compared to the amounts isolated until now with other RNA isolation techniques, it was important to check the composition of the cellular population. Cytological investigation demonstrated that the cells obtained with the brush were mainly epithelial in nature, indicating that the isolated RNA came from these cells and not from inflammatory cells.

In conclusion, with the modified procedure, more total RNA can be extracted from 
fresh human bronchial epithelial cells, allowing Northern blot analysis of GR gene expression. This modified procedure may facilitate the research on bronchial epithelium related diseases such as asthma and smoking induced diseases as well as the research on gene transfer techniques in e.g. cystic fibrosis. 


\section{THREE}

\section{IN VITRO AND IN VIVO MODULATION OF $\alpha$ AND $\beta$ GLUCOCORTICOID RECEPTOR MRNA IN HUMAN BRONCHIAL EPITHELIUM}

This chapter has been published with permission of the American Journal of Respiratory and Critical Care Medicine. 
$\begin{array}{llll}3 & \therefore\end{array}$ 
IN VITRO AND IN VIVO MODULATION OF $\alpha$ AND $\beta$ GLUCOCORTICOID RECEPTOR MRNA IN HUMAN BRONCHIAL EPITHELIUM
3.1 Introduction
3.2 Materials and methods
3.3 Results
3.4 Discussion 



\section{Abstract}

Despite the central role bronchial epithelial cells play in asthmatic reactions and the widespread use of inhaled corticosteroids in asthma, no information is available on the effect of glucocorticoids on its receptor gene expression in this cell type. In this study the effect of budesonide on $\alpha$ and $\beta$ glucocorticoid receptor (GR) gene expression in human bronchial epithelial cells was investigated in vitro and in vivo. A bronchial epithelial cell line was exposed in vitro to budesonide and a dose- and time dependent synchronous downregulation of $\alpha$ and $\beta$ GR mRNA was observed. 1 hour exposure resulted in a reversible and reduced downregulation compared to continuous exposure. In healthy volunteers $(n=10)$ on average no difference was present in GR mRNA expression before or after 4 weeks of budesonide inhalation in either bronchial epithelial cells or alveolar macrophages. Time between the last inhalation and sampling of cells ranged from 0.5 to 8 hours. However, a significant downregulation of $\propto$ GR mRNA was observed when time passed between last inhalation and sampling of cells was more than 2 hours. Normalization of the downregulation of GR mRNA expression in bronchial epithelial cells is explained by the pharmacokinetics of inhaled budesonide in the human lung. 


\subsection{Introduction}

Despite the central role bronchial epithelial cells play in asthmatic reactions and the widespread use of inhaled corticosteroids in asthma, no information is available on the effect of glucocorticoids on its receptor gene expression in human bronchial epithelial cells. Corticosteroids affect elements of the cellular and humoral immune system, for instance by blocking communication between participating cells of the inflammatory process, thereby reducing airway hyperresponsiveness, suppressing inflammatory responses, improving airway function and restoring airway integrity (24). These actions presumably underlie many of the anti-inflammatory functions of corticosteroids.

The glucocorticoid receptor (GR), which is a well known transcription factor, plays a central role in the function of glucocorticoids (45). Through alternative splicing two glucocorticoid receptor forms, $\alpha$ and $\beta$, can be formed, with a size of 7 and $5 \mathrm{~kb}$, respectively. Only the $\alpha$ GR has ligand binding capacity $(58,59)$, while both forms are found in variable amounts in several cell types (60).

After entering the cell by passive diffusion, glucocorticoids form a complex in the cytoplasm with an inactive cytosolic glucocorticoid receptor (2). In this inactive, ligand binding form, the $\alpha$ GR is anchored to several heat shock proteins which keep the receptor in a non-DNA binding state. Dissociation of these heat shock proteins from the receptor occurs after binding of the ligand; thereby transforming the $\alpha$ GR (44) to enable binding to DNA $(128,129)$. Which genes are modulated not only depends on the presence or absence of glucocorticoid responsive elements in the promotor region of genes, but also on the interaction of activated glucocorticoid receptors with other transcription factors (25). Until now direct protein-protein interaction of the $\alpha$ GR is described with activator protein-1 (AP-1) $(98,99)$, nuclear factor $\mathrm{KB}$ (101) and cAMP-responsive element binding protein $(104,105)$. Although the mechanism of the acquired form of steroid resistance in asthma is not elucidated yet, changes in the levels of the different transcription factors have been put forward as a possible explanation (25).

In vitro, in epithelial cell lines as well as lymphoma and fibroblastic cell lines, treatment of cells with glucocorticoids downregulates the cellular GR in a dose- and time dependent manner. Downregulation of the GR is due to shortening of the half-life time of the protein and reduction of the mRNA transcription rate $(89,111,130)$. This is also demonstrated in vivo in liver tissue from adrenalectomized rats $(50,131)$. Ex vivo studies 
on the GR were performed with human peripheral lung tissue (132) and peripheral blood monocytes (129). To our knowledge, no information is available about the effect of corticosteroids on the GR gene expression in vitro and in vivo in human bronchial epithelial cells.

In most of the GR mRNA studies performed, only the $\alpha$ form is investigated $(111,130,132)$. In a few studies the $\beta$ form was shown to be present in the cells and downregulated by glucocorticoids, but this was only mentioned briefly in general for both receptor forms and not separately diseussed $(50,58,131)$. On protein level no clear separation between the $\alpha$ and $\beta$ form has been made (129). Antibodies recognizing either the $\alpha$ or the $\beta$ receptor form are not available. Recently, Chrousos and coworkers (60) used a transfection model system and described the $\beta$ GR as a dominant negative inhibitor of the $\alpha \mathrm{GR}$, disturbing the gene regulatory function after activation by glucocorticoids. In addition, they demonstrated the presence of the $\alpha$ and $\beta$ GR receptor mRNA in several tissues. Therefore, it has become very interesting to study the $\beta$ GR form and its transcriptional regulation by different modulators and its relation to the $\alpha$ GR form in human bronchial epithelial cells in vitro and in vivo.

To this end, a cell line from human bronchial epithelial cells (Bet1A) was exposed to budesonide in a dose- and time dependent way. A continuous exposure was compared to a 1 hour "hit and run" exposure. The in vivo experiment was performed in 10 volunteers. Bronchial epithelial cells and alveolar macrophages were collected by brushing and BAL through fiberoptic bronchoscopy before and after the 4 weeks inhalation period: Variable time intervals were taken between the last budesonide inhalation and sampling of the cells, ranging from 0.5 to 8 hours.

\subsection{Materials and methods}

\section{In vitro experiments:}

Bet1A, a human bronchial epithelial cell line transformed by the SV40 virus (133), was cultured in LHC-8 medium containing $200 \mathrm{nM}$ hydrocortisone (LHC-8+, Biofluids, Rockville, MD) and an addition of $3.3 \mathrm{mM}$ retinoic acid and $5.46 \mathrm{mM}$ epinephrine (134). During the experiments LHC-8 medinm without hydrocortisone (LHC-8-, Biofluids, Rockville, MD) was used with the two additives. Before addition of the glucocorticoid in the dose- and short term time experiments a 12 hour preincubation was done with LHC-8- 
medium in order to create an upregulation of the glucocorticoid receptor. The experiments were planned with harvesting of the cells at approximately 70-90\% confluency.

Continuous exposure; Budesonide (Astra, Zoetermeer, The Netherlands), dissolved in $100 \%$ alcohol, was added in fresh LHC-8- medium. Incubation was performed for 12 hours using different concentrations budesonide $(0.1 \mathrm{nM}-1000 \mathrm{nM})$. During the short term time experiment incubation times of $0.25,0.5,0.75,1,2,3,6$ and 12 hours with a budesonide concentration of $1 \mu \mathrm{M}$ were used. Control samples consisted of only $100 \%$ alcohol and were taken at every time point collected.

Hit and Run; In order to mimic the in vivo situation, where after inhalation of budesonide a sharp increase and subsequent rapid decline (75\% within one hour) of the corticosteroid in human peripheral lung tissue and animal trachea occurs (2,135-137), a short term exposure to budesonide was performed. In this "hit and run" phenomenon, as described by Brattsand (138), cells are incubated with $1 \mu \mathrm{M}$ budesonide for one hour in fresh LHC-8- medium and subsequently cultured in LHC-8- medium alone for different incubation times $(1,2,3,6,12,24 \mathrm{hrs})$. Incubation of the control samples was performed with equivalent amounts $(8 \mu \mathrm{l})$ of $100 \%$ alcohol at every time point sampled.

\section{In vivo experiments:}

10 healthy, non-smoking volunteers ( 6 males, 4 females, age range $23-43$ yrs) on no inhaled medications were asked to inhale $800 \mu \mathrm{g}$ budesonide twice a day for 4 weeks. One week before the first inhalation and after the 4 weeks inhalation period they underwent bronchoscopy according to the guidelines of the American Thoracic Society (139). Premedication consisted of $0.5 \mathrm{mg}$ atropine given intramuscularly. For local anesthesia lidocaine spray and solution were applied in the pharynx and the trachea. Bronchial epithelial cells and alveolar macrophages were collected via fiberoptic bronchoscopy. Bronchoalveolar lavage was performed 3 times with $50 \mathrm{ml} 0.9 \% \mathrm{NaCl}$. Only the last two fractions were used in this investigation. To collect epithelial cells bronchoscopic brush samples were taken in the right middle lobe from second to fourth order bronchi. 10 Brushes were used for RNA extraction and an additional brush for the preparation of smears. These were Giemsa stained to check the cellular composition. The quantification of cellular differentiation in the brushes was performed as described before $(140,141)$. The second bronchoscopy was done at variable times after the last inhalation which was taken in the morning by all 10 volunteers between 8.30 and $9.15 \mathrm{AM}$. Time between the last inhalation and sampling of cells was recorded and ranged from 0.5 to 8 hours. This 
study was approved by the institutional review board and a written informed consent was obtained from all volunteers.

\section{RNA-isolation:}

RNA was isolated from the cells as described by Davis et all (126), with slight modifications. BetlA cells were harvested by removing the culture medium from the monolayered cells and adding $8 \mathrm{ml} 4 \mathrm{M}$ GTC-solution (4 M guanidinium isothiocyanate, $25 \mathrm{mM}$ sodium acetate, $118 \mathrm{mM}$ 2-mercaptoethanol, $18 \mathrm{mM} \mathrm{N}$-lauroylsarcosine) directlly to the tissue culture plates. The bronchial epithelial cells obtained through bronchoscopy were sampled in $4 \mathrm{ml}$ culture medium (DMEM) to which $4 \mathrm{ml} 8 \mathrm{M} \mathrm{GTC}$ was added. This solution of $8 \mathrm{M}$ GTC was obtained after mixing with a magnetic stirrer at room temperature for a minimum of 3 hours. The alveolar macrophages were first pelleted (15 $\min , 1500 \mathrm{rpm}$ ) and then resolved in $8 \mathrm{ml} 4 \mathrm{M}$ GTC. The GTC-solution was sheared 5 times with a needle $(0.8 \mathrm{~mm}$ diameter) and layered upon a $3 \mathrm{ml} 5.7 \mathrm{M} \mathrm{CsCl}(5.7 \mathrm{M} \mathrm{CsCl}$ and $4 \mathrm{mM}$ EDTA $\mathrm{pH} 8.0$ ) cushion. The samples were separated by ultracentrifugation at $154,000 \mathrm{~g}$ at $20^{\circ} \mathrm{C}$ for $20 \mathrm{~h}$. RNA was recovered by dissolving the pellet in $200 \mu \mathrm{l} \mathrm{HES-}$ solution (10 mM HEPES pH 7.4,5 mM EDTA pH 7.5 and $3.5 \mathrm{mM}$ sodium dodecyl sulfate, (SDS)), overnight precipitation with 2 volumes 2-propanol and 1 volume $5 \mathrm{M}$ ammonium acetate $\mathrm{pH} 5.2 \mathrm{at}-20^{\circ} \mathrm{C}$ and centrifugation at $16,000 \mathrm{~g}$ at $4^{\circ} \mathrm{C}$ for $30 \mathrm{~min}$. The RNA pellet was dissolved in $10 \mu \mathrm{l}$ distilled water. Total RNA concentration and purity were determined by A260/A280 measurements and checked by a 1\% agarose gel.

\section{Northem blot analysis:}

RNA $(20 \mu \mathrm{g})$ was dissolved in sample buffer (1.3xMOPS, 2.6 M formaldehyde and 16.3 M formamide) (10xMOPS: $200 \mathrm{mM}$ 3-morpholinopropane sulfonic acid $80 \mathrm{mM}$ sodium acetate and $10 \mathrm{mM}$ EDTA) and fractionated by electrophoresis in a $1.2 \%$ agarose gel $(1.2 \mathrm{mg} / \mathrm{ml}$ agarose in $1 \times$ MOPS and $1 \mathrm{M}$ formaldehyde with a 1xMOPS running buffer) at $110 \mathrm{~V}$ and room temperature for $2 \mathrm{~h}$. The gel was rinsed 3 times for $15 \mathrm{~min}$ in RNAse free water, colored with ethidium bromide, washed in RNAse free water 3 times

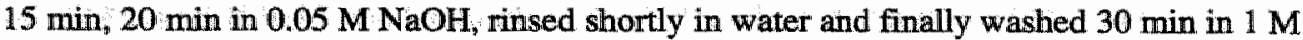
ammonium acetate. The RNA was transferred onto a Nytran membrane (Schleicher and Schuell, Dassel, Germany) by overnight (17 hrs) capillary blotting with $1 \mathrm{M}$ ammonium acetate. After blotting the RNA was fixed to the membrane by UV-crosslinking and $1 \mathrm{hr}$ baking at $80^{\circ} \mathrm{C}$. 


\section{Hybridization:}

Northern blots were hybridized with the $\mathrm{GR}_{\text {; }}$ Glyceraldehyde-3-phosphate dehydrogenase (GAPDH) and metallothionein-2 (MT2) probes in the same order. RNA expression of the MT2 gene is upregulated by corticosteroids $(142,143)$ and therefore, served as an internal control. The GR probe was obtained using a polymerase chain reaction on CDNA of Bet1A cells with primers specific for a BamH1 and Xhol restriction site. After digestion of the polymerase chain product with BamH1 (Boehringer, Mannheim, Germany) and Xho1 (Boehringer, Mannheim, Germany) the DNA was ligated into Bluescript $13+$. The $2.67 \mathrm{~kb}$ probe was sequenced using the sequenase method. Both the $\alpha$ and the $\beta$ form are detected with this probe $(58,59)$. Sequence analysis of the glucocorticoid receptor probe revealed a similar nucleotide composition as known except for aminoacid 235, were the base composition was TTT in stead of TTC, translating to the same amino acid. The MT probe was also obtained through PCR from cDNA of Bet1A cells with primers specific for an EcoR1 and Xhol restriction site and cloned in Bluescript 13+. The GAPDH probe was kindly provided by Dr. R.G. Crystal, NIH. All probes were labeled with $\left[{ }^{32} \mathrm{P}\right]-\mathrm{dCTP}$ (Amersham, Buckinghamshire, England) using the random primed labeling method. Northern blots were hybridized at $65^{\circ} \mathrm{C}$ in $0.5 \mathrm{M}$ phosphate, 1 $\mathrm{mM}$ EDTA, $70 \mathrm{mg} / \mathrm{ml} \mathrm{SDS}$ and $5 \mathrm{mg} / \mathrm{ml} \mathrm{BSA}$. All blots were washed at room temperature with $2 x S S C, 3.5 \mathrm{mM}$ SDS and $0.5 x S S C, 3.5 \mathrm{mM}$ SDS and at $65^{\circ} \mathrm{C}$ with $0.1 \mathrm{xSSC}, 3.5$ $\mathrm{mM}$ SDS for $15 \mathrm{~min}$ each. The sample signals were analyzed visually as well as semiquantitatively with a phosphorimaging system (Molecular Dynamics, Sunnyvale, CA). RNA expressions of the GR and MT2 were compared to the control samples which contain only the diluent and were set to $100 \%$. Ratios between the $\alpha$ and $\beta$ GR mRNA were determined from the values obtained with the phosphorimager.

\section{Statistics:}

For all studies mean \pm standard deviation (SD) was calculated and the Mann-Whitney $U$ test was performed to determine the differences. Differences of $p<0.05$ were considered statistically significant. From the in vivo study one sample of the bronchial epithelial cells could not be evaluated due to crushing of the centrifuge tube during centrifugation. 


\subsection{Results}

In vitro experiments:

Northern blot analysis revealed an expression of the $\alpha$ and $\beta$ GR mRNA in the Bet1A cell line. In general, a strong band at $7 \mathrm{~kb}(\alpha \mathrm{GR}$ mRNA) and a weaker band at $5 \mathrm{~kb}(\beta$ GR mRNA) was obtained (figure 1).

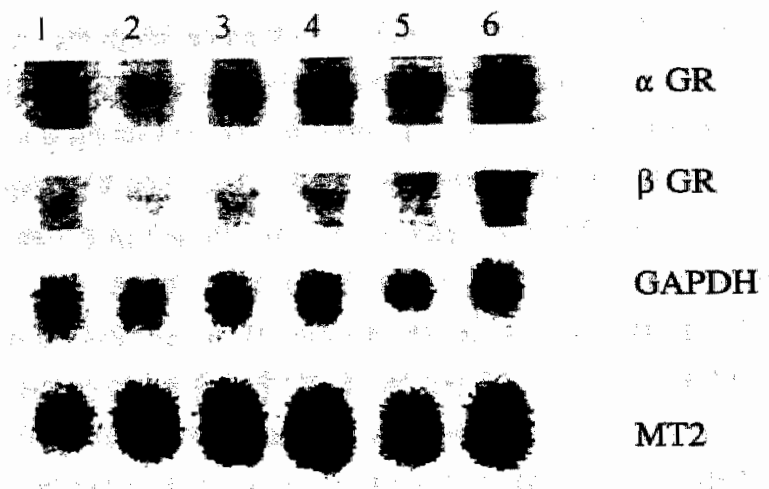

Figure 1: Northem blot presentation of the concentration dependent downregulation of $\alpha$ and $\beta$ GR gene expression by budesonide in Bet1A cells. Bronchial epithelial cells were incubated for 12 hours with different concentrations budesonide (lane $2=1 \mu \mathrm{M}$, lane $3=10^{-1} \mu \mathrm{M}$, lane 4 $=10^{-2} \mu \mathrm{M}$, lane $5=10^{-3} \mu \mathrm{M}$ and lane $6=10^{-4} \mu \mathrm{M}$ ) or $100 \%$ alcohol (lane 1). Northern blots were thybridized with the GR, GAPDH and MT2 probes.

MT2 signals (1.2 kb) showed an upregulated gene expression to maximal $500 \%$ in the in vitro experiments after budesonide incubation.

Ratios between the $\alpha$ and $\beta$ GR mRNA were calculated for each experiment and the overall average value was $2.6 \pm 0.7$. Almost no difference was demonstrated in ratios within 1 experiment, but a slight variation in ratio was observed between the experiments. 


\section{Continuous exposure:}

In the dose-response experiments a concentration range from $10^{-4} \mu \mathrm{M}$ to $1 \mu \mathrm{M}$ was tested (figure 2).

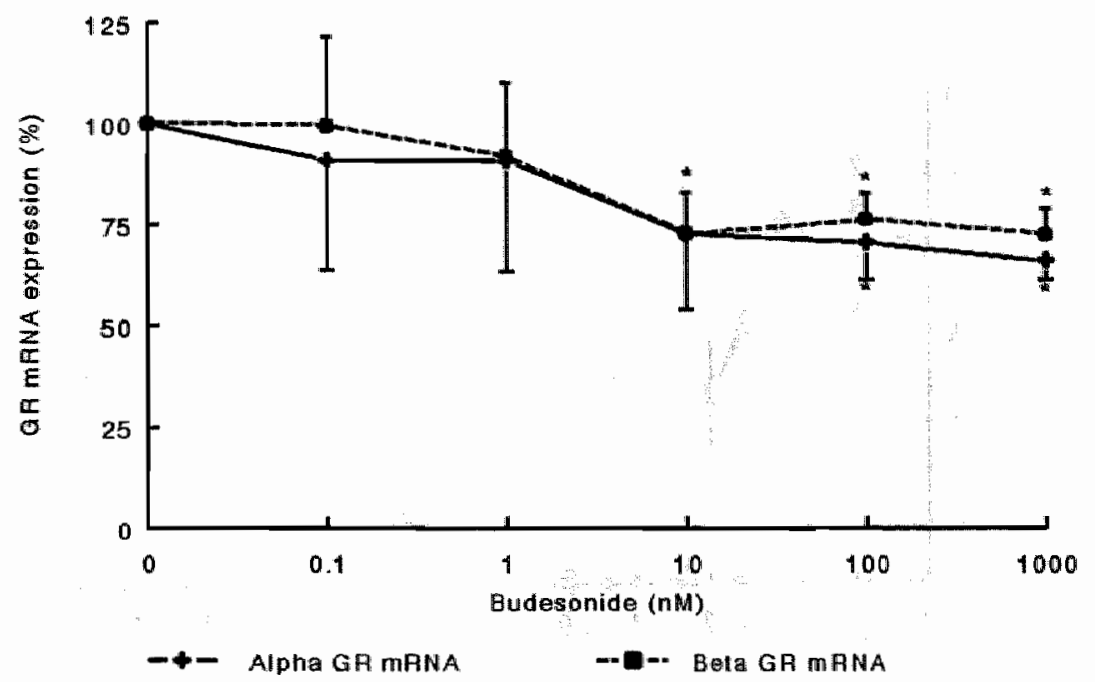

Figure 2: Significant $(*=\mathrm{p}<0.05) \alpha$ and $\beta$ GR mRNA downregulation after incubation of Bet $1 \mathrm{~A}$ cells with different concentrations budesonide for 12 hours is displayed. The control values were set to $100 \%$ and the exposed values were calculated relative to the control values. The data shown represent the mean of four experiments.

Budesonide exposure for 12 hours gave a downregulation of both glucocorticoid receptor mRNA forms in a dose dependent fashion. A maximum significant downregulation of the $\alpha$ and $\beta$ GR mRNA was observed at a concentration of $1 \mu \mathrm{M}$ budesonide, to $66 \%$ and $73 \%$ of the control samples, respectively $(\mathrm{p}<0.05)$.

From the short term time experiment (figure 3 ) it was observed that after addition of 1 $\mu \mathrm{M}$ budesonide a significant downregulation occurred of the $\alpha$ and $\beta$ GR mRNA at three 
hours lasting as long as 12 hours, to $55 \%$ and $60 \%$, respectively $(\mathrm{p}<0.05)$. At two hours a slight (112\%), borderline significant ( $p=0.053$ ) upregulation of the $\alpha$ GR mRNA was seen after addition of the glucocorticoid, whereas at this time point no difference was found for $\beta$ GR mRNA. Within the first hour no change was observed in GR mRNA expression (data not shown).

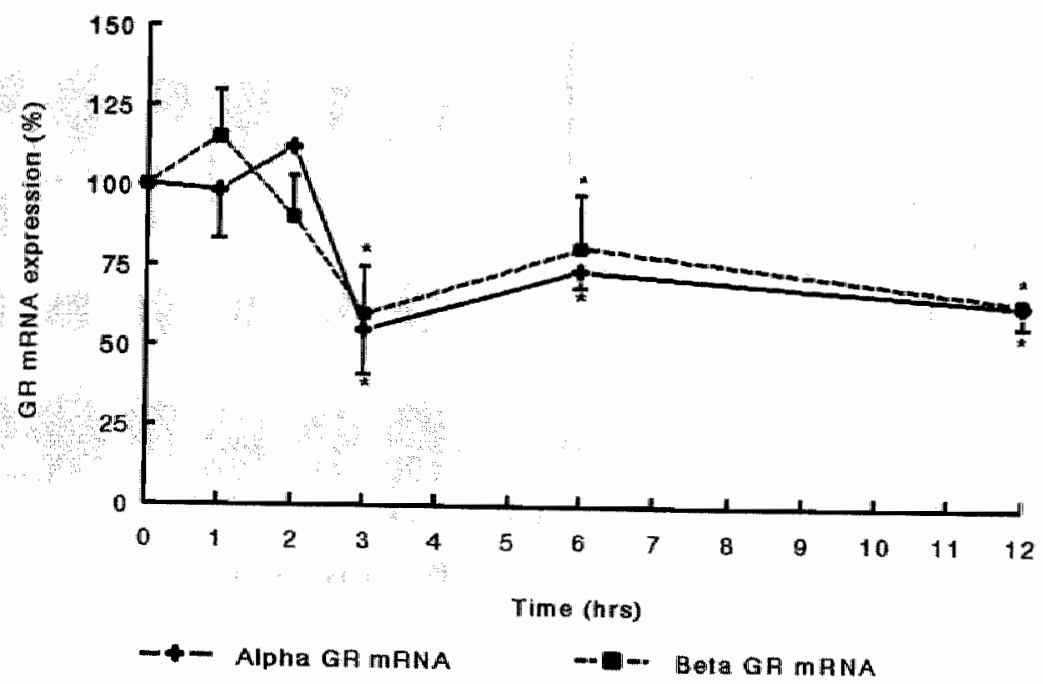

Figure 3: Significant $(*=p<0.05)$ downregulation of the $\alpha$ and $\beta$ GR gene expression by budesonide after different exposure times. Bronchial epithelial cells were continuously exposed to budiesonide for different periods of time. The data shown represent a mean of three experiments.

\section{Hit and run:}

The data of the $\alpha$ and $\beta$ GR mRNA from variable time periods after a 1 hour budesonide exposure are shown in figure 4. A reversible downregulation of the $\alpha$ and $\beta$ GR mRNA was found at 3 and 6 hours compared to continuous exposure. A significant downregulation to $70 \%$ of the $\alpha$ and $87 \%$ of the $\beta$ form was achieved which normalized within 12 hours ( $\mathrm{p}<0.05$ ). 


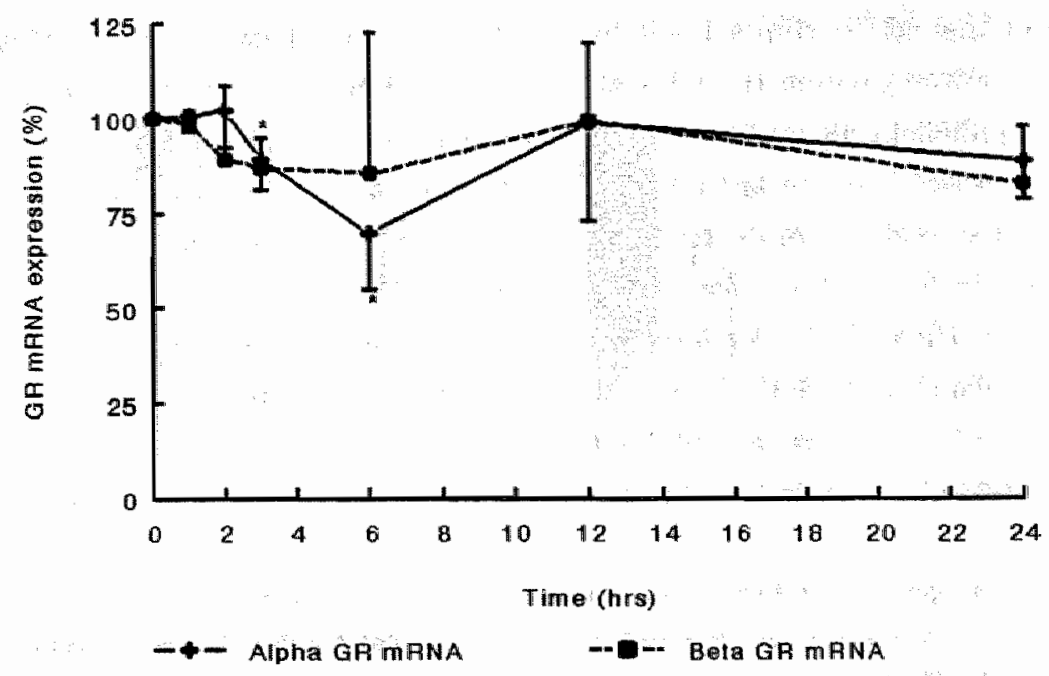

Figure 4: "Hit and run" time exposure of Bet1A cells to budesonide revealed a reversible and reduced downregulation of both $\alpha$ and $B$ GR mRNA $(*=p<0.05)$ compared to continuous exposure. The cells were exposed to budesonide for 1 hour and cultured for different periods of time after withdrawal of the corticosteroid. The data shown represent a mean of five experiments.

\section{In vivo budesonide inhalation:}

The distribution of the different cell types in the brush is shown in table 1 . Quantification of the cellular differentiation in the brushes and BAL obtained with the Giemsa stained smears demonstrated a $>93 \%$ purity of bronchial epithelial cells and alveolar macrophages in the cell samples.

Although we ran the Northern blots in vitro and in vivo with the same amount of total RNA, the bronchial epithelial cells showed in vivo slightly weaker signals ( $\pm 70 \%$ ) for the $\alpha$ and $\beta$ GR mRNA compared to the cell line samples. Alveolar macrophages showed more intense GR mRNA signals $(2-4 x)$ when compared to bronchial epithelial cells. In this study in all cases for bronchial epithelial cells and alveolar macrophages the $\alpha$ GR mRNA band was detected. On average no difference in $\alpha$ GR mRNA expression before or 
after 4 weeks of budesonide inhalation in either bronchial epithelial cells $(n=9)$ or alveolar macrophages $(n=10)$ was seen. Taking time between last inhalation and bronchoscopy into account a significant upregulation was observed in the bronchial epithelial cells $(p<0.05)$ when sampling was performed within two hours after inhalation $(n=4)$. However, a significant downregulation $(\mathrm{p}<0.05$ ) of the $\alpha$ GR mRNA to an average of $55 \%$ in the bronchial epithelial cells $(n=5)$ and $66 \%$ in the alveolar macrophages $(n=6)$ was observed when time passed between last inhalation and sampling of cells was more then 2 hours. Because of the weakness of the signal the $5 \mathrm{~kb}$ band could not be reliably quantified in all cases. Only in 6 out of 10 cases the $\beta$ GR mRNA could be measured in the alveolar macrophages. These results demonstrated a similar significant $(p<0.05)$ GR mRNA pattern of downregulation to $67 \%(\mathrm{n}=3)$, as obtained from the $\alpha$ GR mRNA in the macrophages (figure 5). With an average ratio of $2.3 \pm 0.4$ no difference between the $\alpha$ and $\beta$ GR mRNA expression was observed, indicating no effect of the steroid on alternative splicing.

Table 1: The frequency distribution (percentages) of the with bronchilal brushing ( $\mathrm{n}=18$ ) recovered cells is shown for four types of epithelial cells and for the different inflammatory cells combined. Damaged cells are cells that cannot be classified as either epithelial or inflammatory cells $(140,141)$. No significant difference in cell distribution was observed before or after the four weeks of budesonide inhalation.

\begin{tabular}{|l|l|l|}
\hline \hline Cell type & Mean & SD \\
\hline Ciliated & 63.8 & 6.7 \\
\hline Basal & 11.4 & 5.2 \\
\hline Secretory & 6 & 3.9 \\
\hline Undetermined epithelial cell & 12.4 & 5.9 \\
\hline Damaged cells & 3.1 & 2 \\
\hline Inflammatory cells & 3.3 & 4.1 \\
\hline
\end{tabular}




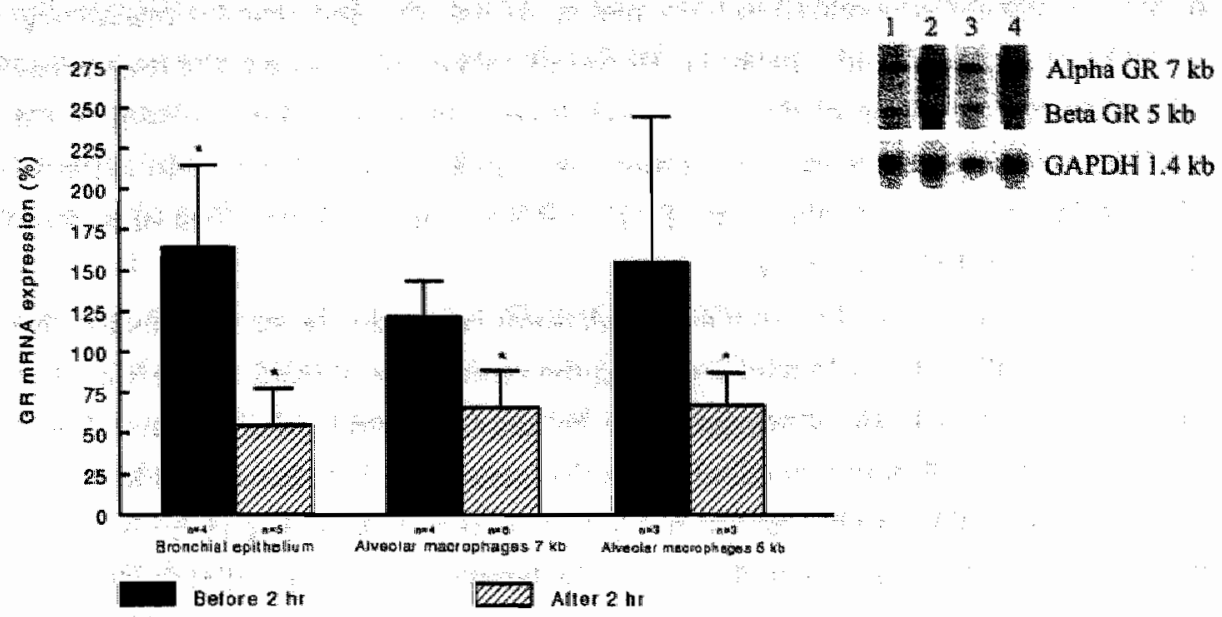

Figure 5: Effect of budesonide on the $\alpha$ and $\beta$ GR gene expression in vivo in bronchial epithelial cells and alveolar macrophages $(*=p<0.05)$. A separation has been made in time passed between the last inhalation and the sampling of the cells in "within two hours" (open bars) and "after two hours" (hatched bars). GR levels obtained after the first bronchoscopy were set at $100 \%$. Inserted is an example of a Northern, with RNA from bronchial epithelial cells (lane 1 and 3 ) and alveolar macrophages ( 2 and 4 ) of two volunteers before steroid use.

\subsection{Discussion}

We investigated the effect of the glucocorticoid budesonide on the $\alpha$ and $\beta$ glucocorticoid receptor gene expression in human bronchial epithelial cells in vitro and in vivo. In vitro the $\alpha$ and $\beta$ GR mRNAs revealed a downregulation after glucocorticoid treatment, in a dose and time dependent manner. Compared to continuous exposure, the 1 hour "hit and run" exposure resulted in a shorter duration and in a reduction of the percentage of downregulation of GR mRNA. In vivo, on average no difference in GR 
gene expression was observed in bronchial epithelial cells and alveolar macrophages after 4 weeks of corticosteroid inhalation. However, taking into account the time between last inhalation and sampling of the cells, a significant downregulation for both $\alpha$ and $\beta$ GR mRNA was observed when time passed was more than 2 hours. No difference was observed in ratio between the $\alpha$ and $\beta$ GR mRNAs, indicating no effect of budesonide on the alternative splicing process:

Despite the fact that the bronchial epithelium is a major target for inhaled therapy in asthma, no studies are performed regarding the modulation of the GR levels in vitro and in vivo in these cells. In this study however, human bronchial epithelial cells of high purity are investigated with a similar cellular distribution as described before $(140,141)$

The downregulation observed in the GR gene expression is explained by the effect of budesonide, since upregulation of metallothionein was found in parallel in all experiments, excluding general cell breakdown as an explanation for the GR downregulation. This downregulation of the GR mRNA and protein has been seen before in vitro in different cell lines, ex vivo in humans and in vivo in rats $(50,89,111,129-132)$. Importantly, in the in vitro studies the corticosteroid concentration is usually constant, whereas in vivo, due to the pharmacokinetic properties of the corticosteroid, the concentration of budesonide in the lungs is high directly after inhalation followed by a rapid decline within the first hour (2,135-137). Subsequently only low doses of budesonide are found in the peripheral blood $(135,136)$. Therefore, binding of the corticosteroid to its receptor in bronchial epithelial cells is likely to take place within the first hour. For this reason we performed experiments with a 1 hour exposure to budesonide. After this "hit" the experiment was continued without the corticosteroid for several hours, i.e. the "run". Since the pattern of GR mRNA expression with the "hit and run" experiments is similar to the in vivo situation, it is more useful, for extrapolation to in vivo situations, to carry out in vitro experiments with brief exposures and not with continuous exposures as frequently performed until now.

Despite the equal amounts of total RNA ran on Northern blots in vitro and in vivo, weaker GR mRNA signals compared to GAPDH signals were observed in bronchial epithelial cells in vivo, indicating an increased expression in the Bet $1 \mathrm{~A}$ cells. In vivo a stronger expression of the $\alpha$ and $\beta$ GR mRNA in alveolar macrophages was observed compared to bronchial epithelial cells. In an in situ hybridization study from Adcock and colleagues (132), the highest gene expression of the GR was also found in alveolar walls and vascular endothelium, with lower signals in airway epithelium and smooth muscle cells. The data of both studies emphasize that variable GR gene expression is present in 
the different cell types of the lung. This opens the possibility of differential effects of corticosteroid treatment in various cell types.

Downregulation of the GR gene expression in vivo is found after 2 hours in bronchial epithelial cells as well as in the alveolar macrophages. This downregulation appears to continue for at least another 6 hours. Since no downregulation was observed when the epithelial cells and alveolar macrophages were sampled within 2 hours after inhalation, the effect of the corticosteroid inhalation the evening before bronchoscopy had faded. Thus a single dose of inhaled budesonide has a measurable effect on the GR mRNA after 2 hours up to maximally 10-12 hours. These findings support the notion that the effect of corticosteroid medication for longer use is not the result of a chronic effect, but merely a sum of direct, short term effects, due to repeated single doses. The observation that corticosteroids inhaled twice a day give the best clinical results $(3,24,121)$ strengthens this hypothesis. The results are also in keeping with in vitro data (130) showing reversibility up to 6 weeks. However, in the same in vitro study irreversible GR downregulation has been suggested after 2 years of cell culture (130). This apparently paradox result may be explained by genetic alterations, which are likely to occur in vitro in time. Therefore, we presume that the in vivo long term use of inhaled corticosteroids will remain a reversible process.

Downregulation of GR mRNA by steroids seems to be due to a decrease in transcription rate of the GR gene as shown by the group of Gustafsson with nuclear run-on assays (50). In addition they demonstrated a superinduction of the GR mRNA level by cyclohexamide. The precise mechanism of GR mRNA downregulation is not clear. One possibility could be an interaction of the $\beta$ GR with the $\alpha$ GR resulting in a disturbed signal transduction of the $\alpha \mathrm{GR}$. However, the ratio between both receptor forms was constant in our study. In addition, in the study of Bamberger and coworkers an increasing inhibition of $50 \%$ to $80 \%$ is shown at an $\alpha: \beta$ ratio of $20 \%$ to $10 \%$, respectively (60). Importantly, in the present study the $\alpha: \beta$ ratio is clearly higher then 2 . For both reasons it is unlikely that the $\beta$ GR interferes in a relevant way with the autoregulation of the GR and its ligand. Alternatively, due to the downregulation of the GR, relative differences to other transcription factors occur (111), providing a possible explanation for secondary steroid resistance in asthma (25). If the downregulating effect of glucocorticoids on the GR is more pronounced in asthmatics with steroid resistance compared to asthmatics who do respond to glucocorticoids, this may well be of functional relevance.

To summarize, downregulation of the glucocorticoid receptor gene expression after 
continuous budesonide exposure occurred in a dose dependent manner at 3 hours for as long as the budesonide was added. Results obtained with the "hit and run" experiments were similar to the results acquired with the in vivo tests, showing normalization of the downregulation within 10-12 hours. This may be explained by the pharmacokinetics of inhaled budesonide in the lung. 


\section{FOUR}

$\alpha$ AND $\beta$ GLUCOCORTICOID RECEPTOR MRNA EXPRESSION IN RAT LUNG AND SKELETAL MUSCLE AFTER INTRA-TRACHEAL INSTILLATION OF BUDESONIDE 


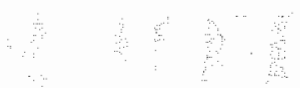

$\therefore \quad \therefore \quad \therefore \quad \square$ 
$\alpha$ AND $\beta$ GLUCOCORTICOID RECEPTOR IRNA EXPRESSION IN RAT LUNG AND SKELETAL MUSCLE AFTER INTRA-TRACHEAL INSTILLATION OF BUDESONIDE
4.1 Introduction
4.2 Materials and methods
4.3 Results
4.4 Discussion 


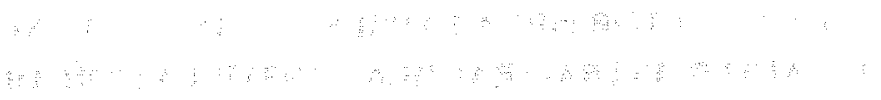




\section{Abstract}

In bronchial epithelial cells of healthy volunteers the glucocorticoid receptor (GR) mRNA expression is regulated in a biphasic way, resulting in an upregulated expression within the first 2 hours, followed by a downregulation. Present study was performed to better understand the pattern of the $\alpha$ and $\beta$ GR mRNA downregulation. 60 Rats were intra-tracheally instilled with $100 \quad \mu \mathrm{g}$ budesonide and sacrificed after 1,4 or 12 hours. Lungs and gastrocnemius muscle were removed. After Northern blot analysis, hybridization was performed with GR, GAPDH and glutamine synthetase probes. In the lungs a clear upregulation of the control glutamine synthetase mRNA was observed, demonstrating adequate delivery and functioning of budesonide. At all time points, the average $\alpha$ GR mRNA levels did not differ from controls. However, the $\beta$ GR mRNA was slightly reduced at 1 and 4 hours. In the gastrocnemius, at 4 hours, a marked downregulation of both $\alpha$ and $\beta$ GR mRNAs was found, indicating a slight systemic effect. $\alpha / \beta$ GR ratios were higher $(2.6 \pm 0.6)$ in the lungs than in the gastrocnemius $(1.1 \pm 0.2)$. In this study we observed no GR mRNA downregulation of both $G R$ in rat lungs after intra-tracheally instillation of budesonide, probably due to the diversity in cell population. The difference in $\alpha / \beta$ GR mRNA ratio and concentration between lung and gastrocnemius muscle, supports the hypothesis of a differential gene regulation by glucocorticoids in different cell types. 
$\therefore$ 


\subsection{Introduction}

Inhaled glucocorticoids are highly effective in controlling asthma and other inflammatory diseases. Despite their frequent use, the molecular mechanisms involved in the anti-inflammatory actions of glucocorticoids are not fully understood. A central role in the action of glucocorticoids is played by the glucocorticoid receptor (GR), which is present in the cytoplasm of cells as an inactive protein bound to a complex of different heat shock proteins (44). After binding of the ligand, the receptor becomes activated by dissociation of the heat shock proteins. By binding as a dimer to glucocorticoid responsive elements (GRE) in the DNA, the GR regulates the transcription of genes. The activated GR can also modulate gene transcription by binding to other transcription factors, such as activator protein-1 (AP-1) (99), nuclear factor $\mathrm{kB}$ (NFkB) (102), cAMP-responsive element binding protein (CREB) (104) and signal transducer and activator of transcription 5 (Stat5) (108).

Glucocorticoid hormone receptors contain a 5 ligand binding $\mathrm{C}$-terminal end, a central DNA binding domain, and a $3^{\prime}$ transactivating $\mathrm{N}$-terminal end. Due to alternative splicing, two functionally distinct receptors $\alpha$ and $\beta$ are formed, differing at their carboxyterminal end. Only the $\alpha$ GR has ligand binding capacity (58) and therefore; is the most intensively studied form of the two splice variants. The presence of both GR mRNAs has been demonstrated in several tissues $(57,60)$, but on protein level no clear separation between the $\alpha$ and $\beta$ form has yet been made. Recently an antibody recognizing the $\alpha$ form has become commercially available; however, this has not yet been the case for the $\beta \mathrm{GR}(4)$. In a recent study of Oakley and colleques (57), three GR mRNA isoforms have been described. With Northern blot analysis an $\alpha 1$ of $7 \mathrm{~kb}$, an $\alpha 2$ of $5.5 \mathrm{~kb}$ and a $\beta$ GR mRNA form of $4.3 \mathrm{~kb}$ was demonstrated. The $\alpha .1$ and $\alpha 2$ forms result in the same protein with ligand binding capacity. In contrast the $\beta$ GR has no steroid binding domain and is considered as a dominant negative inhibitor of the $\alpha \mathrm{GR}$, influencing its gene regulatory function after activation by glucocorticoids $(57,60)$. In view of this inhibitory function it is of interest to study the $\beta$ GR form, its relation to the $\alpha$ GR form and transcriptional regulation by different modulators.

Because of the direct correlation between glucocorticoid receptor number and cellular responsiveness to glucocorticoids $(30,47,48)$ and because of the inhibitory effect of the $\beta$ GR on the $\alpha G R$, it is important to thoroughly understand the mechanisms responsible for 
maintaining $\alpha$ and $\beta$ receptor levels and ratios. Several studies $(130,131,144-146)$ have shown that the $\alpha$ GR is downregulated after exposure to glucocorticosteroids. This downregulation is due to shortening of the half-life time of the protein and reduction of the mRNA transcription rate (131). In a previous study we demonstrated a downregulation of both $\alpha$ and $\beta$ GR mRNA in human bronchial epithelial cells in vitro (147). Compared to a constant downregulation observed after continuous exposure, a reversible downregulation was seen with a "hit and run" method, starting 2 hours after addition of the budesonide and being reversed within 12 hours. The same effect was also observed in vivo in bronchial epithelial cells and alveolar macrophages of healthy volunteers, even after inhalation of $800 \mu \mathrm{g}$ budesonide 2 times daily for 4 weeks. An $\alpha / \beta$ GR ratio above 2 was measured in bronchial epithelial cells both in vitro and in vivo. At this ratio no inhibitory function of the $\beta$ form on the $\alpha$ GR function is reported $(57,60)$. No information is available about $\alpha / \beta$ ratios in vitro or in vivo in other cells or tissues.

In the previous study (147) downregulation of the GR mRNA expression observed in the bronchial epithelial cells of the volunteers, was preceded by a short upregulated GR mRNA expression within the first 2 hours. This biphasic pattern has been described before in rat hepatoma tumor cells and human lung parenchyma $(50,148,149)$. In the human bronchial epithelial cells a similar effect might have occurred in vivo. However, an alternative explanation may be that this short term upregulation is a delayed effect of the inhaled budesonide dose the evening before the sampling of the cells, since all volunteers inhaled budesonide twice a day. The aim of the present study was therefore to investigate the reversibility of the GR downregulation in vivo 12 hours after exposure to budesonide. In addition, the $\alpha / \beta$ GR $\mathrm{mRNA}$ ratios were determined in lung and skeletal muscle. To this end $100 \mu \mathrm{g}$ budesonide was instilled in the rat trachea and at different time points $(1$, 4, and $12 \mathrm{hr}$ ) after exposure to budesonide the rats were sacrificed. Both left and right lungs were sampled. In order to study possible systemic effects of budesonide after inhalation, the gastrocnemius was sampled, because of the known catabolic effects of glucocorticoids on skeletal muscles.

\subsection{Materials and methods}

Animals and tissues:"

65 Male Wistar rats weighing 200-250 g (Harlan-Winkelmann, Borchen, Germany) 
were anesthetized by subcutaneous injection of $0.2 \mathrm{ml} 100 \mathrm{mg} / \mathrm{ml}$ ketamin (Nimatek, AUV Cuijk, the Netherlands) and $0.2 \mathrm{ml} 5$ times diluted $23 \mathrm{mg} / \mathrm{ml}$ Sedamun (AUV Cuijk, the Netherlands) in the neck. 5 Animals were used to optimize the instillation technique by aerosolation of black ink. The other 60 rats were included in the study. After intubation the animals were ventilated mechanically with $\mathrm{O}_{2}$ and $\mathrm{N}_{2} \mathrm{O}$ at a frequency of 40 breaths/minute. Under visual inspection the tube ending was localized a few millimeters above the carina. Within this ventilation tube a small tube was inserted, through which the budesonide solution was administered. $10 \mathrm{mg}$ Budesonide was dissolved in $250 \mu 170 \%$ alcohol and diluted in $50 \mathrm{ml}$ PBS to a final concentration of $200 \mu \mathrm{g} / \mathrm{ml}$. Either $0.5 \mathrm{ml}$ budesonide solution or $0.5 \mathrm{ml}$ dilutant (control) was injected in aliquots of $50 \mu 1$, administered during the inspiratory phase. Since the animals were similar in weight (range $200-250 \mathrm{~g}$ ), the budesonide dosage was equal in all rats: $100 \mu \mathrm{g}$ of budesonide intratracheally. Animals regained consciousness and were sacrificed 1,4 , or 12 hours later with $1.5 \mathrm{ml} 60 \mathrm{mg} / \mathrm{ml}$ pentobarbital administered intraperitoneally. Both lungs and the right gastrocnemius muscle were sampled. The lungs were embedded in tissue-tex (Milles Inc., Elkhart, $\mathrm{N}, \mathrm{USA}$ ) and immediately frozen in liquid nitrogen. The gastrocnemius muscle was put into $4 \mathrm{ml} 4 \mathrm{M}$ guanidinium isothiocyanate (GTC) and frozen immediately to $-70^{\circ}$ $C$ without homogenization. The whole animal experiment was performed in two days, and control and budesonide exposed animals were handled simultaneously ( 10 per group).

\section{Histology:}

From the frozen lung specimens $6 \mu \mathrm{M}$ sections were cut and mounted on gelatinechromium(III)-potassium sulfate coated slides. Sections were stained with hematoxylineosin. Morphologic examination on sections from right and left lung was performed to investigate possible traumatic or inflammatory changes in all animals.

\section{RNA-isolation:}

For part of the samples the method of total RNA extraction was similar as described

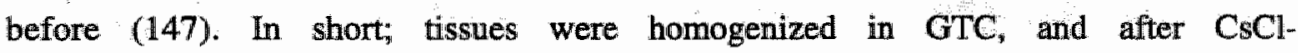
ultracentrifugation RNA was recovered. The second, faster approach was based on the method described by Chomczynski et al. (150), using an RNA isolation kit, TRIzol Reagent (Life Technologies, Breda, the Netherlands). Tissue samples were homogenized in $1 \mathrm{ml}$ TRIzol Reagent per $100 \mathrm{mg}$ tissue. After adding $0.2 \mathrm{ml}$ chloroform, the tubes were vigorously shaken, incubated at room temperature for 3 minutes and centrifuged at $4{ }^{\circ} \mathrm{C}$ 
and $12,000 \mathrm{~g}$ for 15 minutes. The aqueous phase was mixed with $0.5 \mathrm{ml} \mathrm{2}$-propanol per 1 $\mathrm{ml}$ TRIzol and RNA was recovered by centrifugation at $12,000 \mathrm{~g}$ and $4^{\circ} \mathrm{C}$ for 10 minutes. The pellet was washed with $75 \%$ ethanol and recovered again by centrifugation for 5 minutes at $7,500 \mathrm{~g}$ and $4^{\circ} \mathrm{C}$. This wash step was repeated once. RNA pellets were dissolved in $10 \mu$ distilled water. Total RNA concentration was determined visually, by comparison to RNA samples with known concentrations on a $1 \%$ agarose gel.

\section{Northem blot analysis:}

Northern blot analysis was performed as described before (147) with slight modifications. RNA $(20 \mu \mathrm{g})$ was dissolved in sample buffer (1.3xMOPS, $0.5 \mathrm{M}$ formaldehyde ( $\mathrm{pH}$ 6.5) and $16.3 \mathrm{M}$ formamide) (10xMOPS: $200 \mathrm{mM}$ morpholinopropane sulfonic acid, $80 \mathrm{mM}$ sodium acetate and $10 \mathrm{mM}$ EDTA) and fractionated by electrophoresis in an $1.2 \%$ agarose gel $(1.2 \mathrm{mg} / \mathrm{ml}$ agarose in $1 x M P S$ and 1 M formaldehyde (pH 6.5) with a 1xMPS running buffer) at $110 \mathrm{~V}$ and room temperature for $2 \mathrm{~h}$. The gel was rinsed 3 times for $15 \mathrm{~min}$ in RNAse free water, colored with ethidium bromide, washed in RNAse free water 3 times $15 \mathrm{~min}, 20 \mathrm{~min}$ in $0.05 \mathrm{M} \mathrm{NaOH}$, rinsed shortly in water and finally washed $30 \mathrm{~min}$ in $1 \mathrm{M}$ ammonium acetate. The RNA was transferred onto a Nytran membrane (Schleicher and Schuell; Dassel, Germany) by overnight ( $17 \mathrm{hrs}$ ) capillary blotting with $1 \mathrm{M}$ armmonium acetate. After blotting the RNA was fixed to the membrane by UV-crosslinking and $1 \mathrm{hr}$ baking at $80^{\circ} \mathrm{C}$. Per gel 10 samples were loaded, 5 budesonide exposed animals and their simultaneously handled controls, so for each time point 2 Northern blots were run.

\section{Hybridization:}

Northern blots were hybridized with the rat GR, human glyceraldehyde-3-phosphate dehydrogenase (147) and rat glutamine synthetase (a generous gift from Prof. Dr. W.H. Lamers, AMC, Amsterdam, the Netherlands) probes in the same order. Since glutamine synthetase is upregulated by glucocorticoids $(151,152)$, this probe was used as a positive control. All probes were labeled with $\left[\alpha-{ }^{32} \mathrm{P}\right]$-dCTP (Amersham, Buckinghamshire, England) using the random primed labeling method Northern blots were hybridized at 65

${ }^{C} \mathrm{C}$ in $0.5 \mathrm{M}$ phosphate, $1 \mathrm{mM}$ EDTA, $70 \mathrm{mg} / \mathrm{ml} \mathrm{SDS}$ and $5 \mathrm{mg} / \mathrm{ml} \mathrm{BSA}$. All blots were washed at room temperature with $2 x S S C, 3.5 \mathrm{mM}$ SDS and $0.5 \mathrm{xSSC}, 3.5 \mathrm{mM}$ SDS and at $65^{\circ} \mathrm{C}$ with $0.1 \times S S C, 3.5 \mathrm{mM}$ SDS for $15 \mathrm{~min}$ each. The sample signals were analyzed visually as well as semiquantitatively with a phosphorimaging system (Molecular 
Dynamics, Sunnyvale, CA, USA). GR and glutamine synthetase mRNA expression levels were determined relative to the control gene glyceraldehyde-3-phosphate dehydrogenase (GAPDH). These relative expression levels were compared to control animals (100\%), receiving only dilutant.

\section{Statistics:}

For all studies mean \pm standard deviation (SD) was calculated and the Mann-Whitney $U$ test performed. A difference of $\mathrm{p}<0.05$ was considered statistically significant.

\subsection{Results}

\section{Aerosol instillation and lung morphology:}

In a pilot study, the circumstances in which the best distribution of the steroid in both lungs was obtained, were tested by aerosoling black ink in the lungs of 5 rats (figure 1).

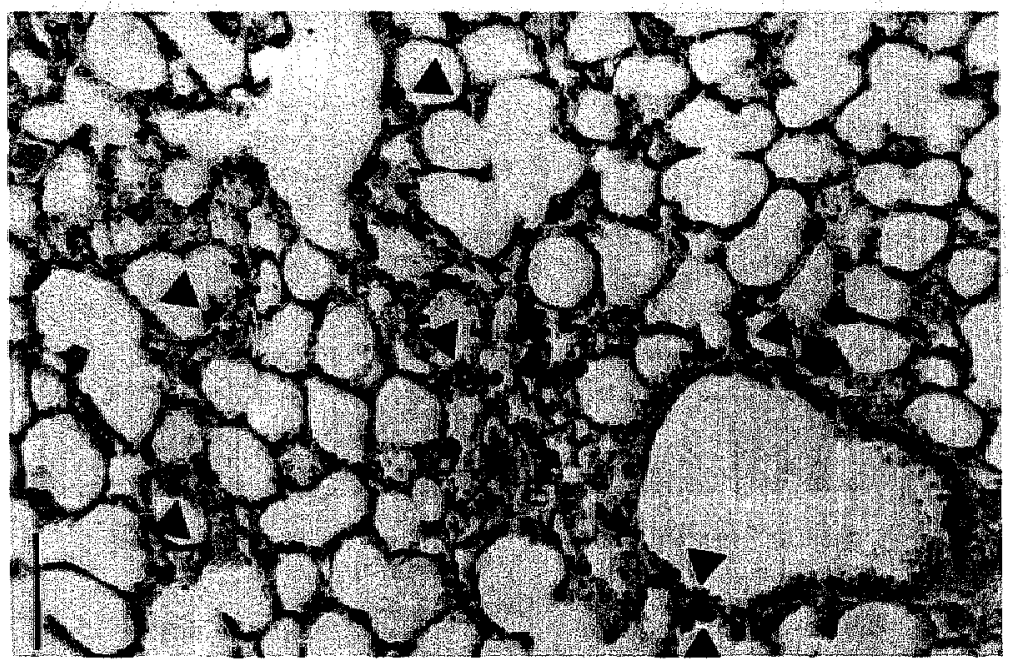

Figure 1: Photo micrograph of a rat lung showing the deposition of black ink after instillation into the alveolar level (arrow heads). Bar: $100 \mu \mathrm{M}$. 
By staining $6 \mu \mathrm{M}$ sections of frozen lung specimens, the distribution of the ink was determined by visualization. With morphologic examination of the treated and control rats no signs of bleeding or inflammation were found in the lungs. During the experiment 2 rats died after being anesthetized, one in the budlesonide exposed group (12 hr), and one in the control group ( $1 \mathrm{hr}$ ), which reduced the total number from 60 to 58 .

\section{Northem blot hybridization:}

The glucocorticoid receptor mRNA expression levels in the lung were 5-8 times higher than in muscle. The GR mRNA signals from the gastrocnemius in a few rats were too weak for a reliable quantification. The GR mRNA expression variations in time are shown in figure 2 and 3. No difference in $\alpha$ GR gene expression was observed in the lungs after 1,4 or 12 hours (figure 2 ).

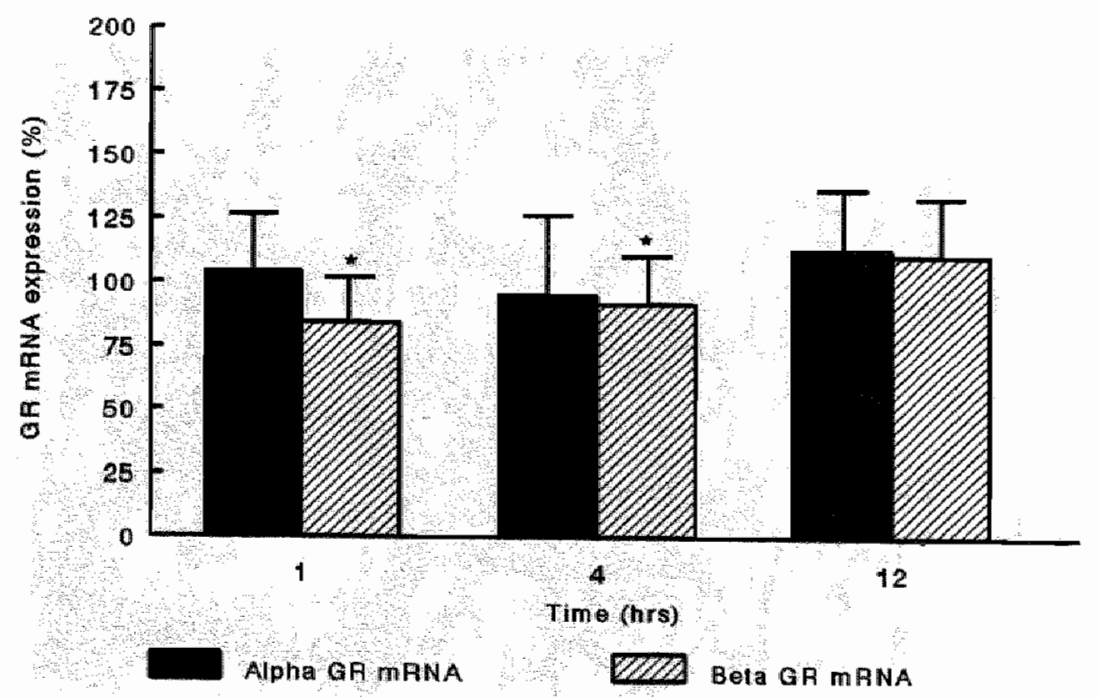

Figure 2: GR mRNA expression in rat lung after intra-tracheal instillation of budesonide. Rats were sacrificed after 1,4 , and 12 hours. Both $\alpha$ and $\beta$ GR mRNAs are displayed relatively to the GAPDH value. 
The average $\alpha$ GR mRNA levels at 1,4 , and 12 hours were $104 \%$, 95\% and 113\%, respectively. For the $\beta$ GR mRNA a slight downregulation was observed at 1 and 4 hours to $84 \%$ and $91 \%$, respectively. At 12 hours no change was seen compared to the control $(110 \%)$. The GR mRNA expression in the gastrocnemius showed a clear downregulation (p<0.05) of both $\alpha$ and $\beta$ glucocorticoid receptor types 4 hours after the addition of budesonide, to $64 \%$ and $67 \%$, respectively (figure 3 ). Within the first hour no change in $\alpha$ and $\beta$ GR mRNA expression took place (95\% and 101\%, respectively). After 12 hours the gene expression no longer differed from the control animals, although, a trend towards an upregulated expression was observed. The mRNA expression for the $\alpha$ GR was $133 \%$ and for the $\beta$ GR $125 \%$.

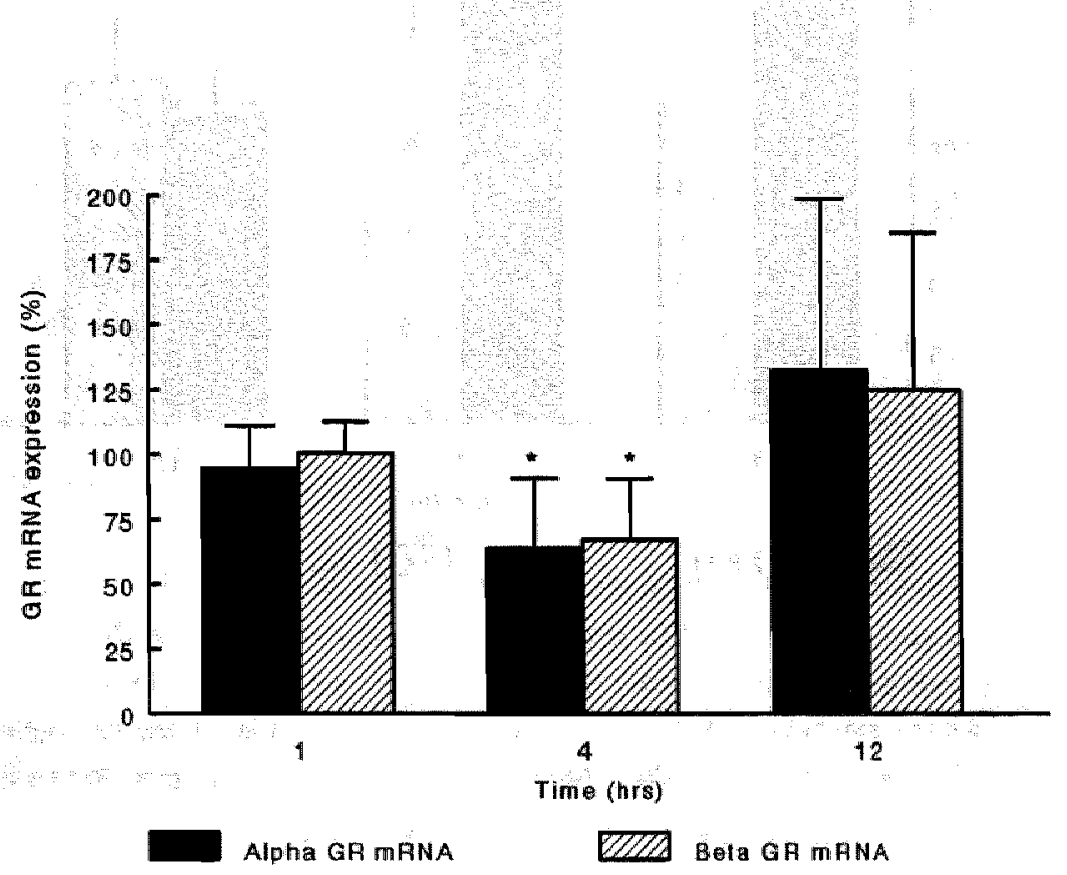

Figure 3: GR mRNA expression in rat gastrocnemius after intra-tracheal instillation of budesonide. After 4 hours a downregulation was observed for both $\alpha$ and $\beta$ GR mRNAs:

To demonstrate the pharmacological activity of budesonide in the lung, glutamine synthetase mRNA expression was studied as a control gene. The effect of budesonide on the glutamine synthetase gene expression in the lungs is shown in figure 4 . Both glutamine 
synthetase mRNA forms were at all time points upregulated by budesonide. The $2.8 \mathrm{~kb}$ mRNA expression was elevated to $165 \%, 164 \%$, and $112 \%$ at 1,4 , and $12 \mathrm{hr}$, respectively (p<0.05). For the $1.4 \mathrm{~kb}$ form the upregulation was less strong, but also significant (p<0.05) to $116 \%, 138 \%$, and $126 \%$ at 1,4 , and $12 \mathrm{hr}$, respectively.

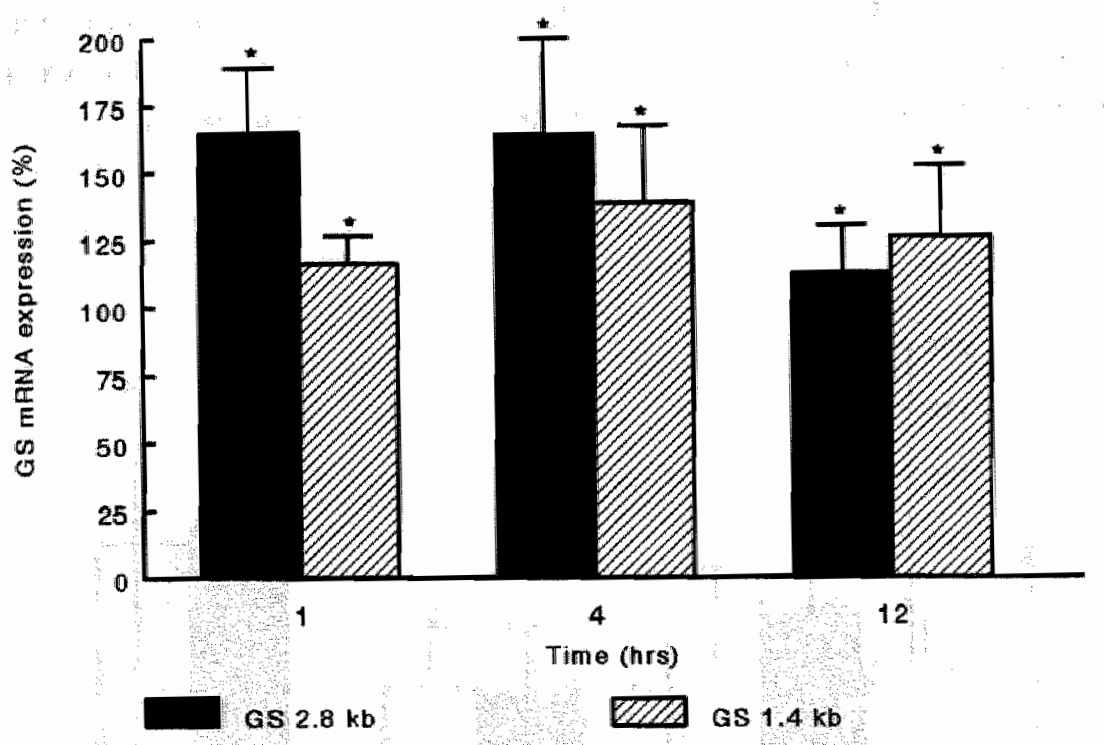

Figure 4: Glutamine synthetase mRNA expression in the rat lung. Both glutamine synthetase forms are displayed relatively to the GAPDH value. At all times an upregulated expression is observed.

A difference in $\alpha / \beta$ GR ratio was observed between the lungs and gastrocnemius, resulting in a higher ratio in the lungs of $2.6 \pm 0.6$, compared to a ratio of $1.1 \pm 0.2$ in the muscle $(p<0.05)$. In figure 5 an example is shown of a Northern blot hybridisation with the GR probe. Also higher $\alpha$ and $\beta$ GR mRNA amounts are detected in the lungs compared to the gastrocnemius muscle. For the $\alpha$ GR mRNA, the amount in the gastrocnemius muscle is $12 \%$ of that in the lungs. For the $\beta$ GR mRNA the expression is slightly higher, namely $20 \%$ of that in the lungs. 


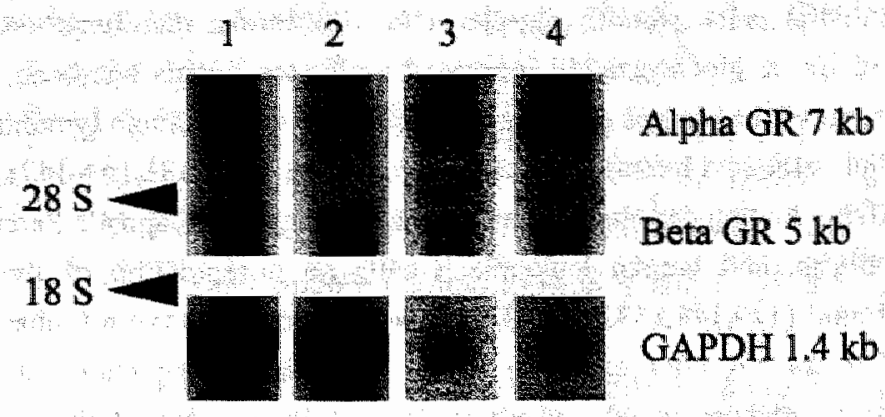

Figure 5: Northem blot presentation of the GR mRNA from rat lung and gastrocnemius. Both $\alpha$ and $\beta$ GR are shown. Lane 1 and 2 represent RNA from the gastrocnemius, lane 3 and 4 represent RNA from the lungs. In the odd lanes a control animal is shown, 4 hours after instillation. The even lanes represent an exposed animal after 4 hours. $A$ elear difference in $\alpha / \beta$ GR mRNA ratio is observed between the lung and gastrocnemius. The positions of the $\alpha$ and $\beta$ GR mRNA bands are determined by the $28 \mathrm{~S}$ and $18 \mathrm{~S}$ ribosomal bands.

\subsection{Discussion}

The purpose of this study was to investigate the short and long term regulation of the $\alpha$ and $\beta$ glucocorticoid receptor mRNA levels as well as the $\alpha / \beta$ GR ratios in lung and muscle Both mRNA levels were present in the rat. No downregulation of both receptor forms was observed in the lung, after exposure to budesonide, except for the $\beta$ GR mRNA after 1 and 4 hours. As demonstrated by the upregulation of the control gene glutamine synthetase, the steroid was adequately delivered and pharmacologically active. Remarkably, the gastrocnemius showed a reversible downregulation of both $\alpha$ and $\beta$ GR mRNAs 4 hours after instillation of the budesonide. Concerning the $\alpha / \beta$ GR mRNA ratio, a lower ratio was observed in the gastrocnemius as compared to the lung.

Surprisingly, despite the higher GR amounts and $\alpha / \beta$ GR ratios, and the broader availability of glucocorticoids in the lungs, no change in GR gene expression was observed in this tissue. In a previous study (147) a clear downregulation of the $\alpha$ and $\beta$ GR MRNA was observed in human bronchial epithelial cells. Since it is not possible to obtain enough bronchial epithelial cells of such high purity from rats, whole lung tissue was investigated. 
This tissue contained a mixture of different cells like epithelial cells, alveolar macrophages, mast cells, endothelial cells, smooth muscle cells, fibroblasts, and lymphocytes. A clear downregulation of the $\alpha$ glucocorticoid receptor by glucocorticoids has been demonstrated before in rat liver, cervix carcinoma cells, rat lung epithelial cells, human lymphocytes, human bronchial epithelial cells, and human alveolar macrophages $(130,131,144-147)$. However, in other reports studying human peripheral blood mononuclear cells, Kaposi's Sarcoma cells, rall pulmonary fibroblasts, and human leukemic T-cells an upregulation of the GR $\mathrm{mRNA}$ expression was found $(129,144,153,154)$. Other investigations observe a biphasic expression pattern of the GR mRNA after exposure of rat hepatoma tumor cells and human lung parenchyma cells to glucocorticoids, resulting at first in an upregulation followed by a downregulation of the GR mRNA expression $(50,148,149)$. This diversity of transcriptional responses in different cells to glucocorticoids, is determined by the concentrations of various transcription factors and their interactions in the cell, clearly varying from one cell type to another. Opposite reactions in GR mRNA expression between different cell types to glucocorticoids can result in absence of an overall measurable effect, as seen in this study. One of the options to study the GR mRNA expression solemnly in bronchial epithelial cells would be the use of mRNA in situ hybridisation. However, to be able to reliably determine differences in $\alpha$ and $\beta$ GR mRNA expression between control and exposed animals with in situ hybridisation, these differences must exceed a factor of 2 . Since in our studies changes in $\alpha$ and $\beta$ GR mRNA levels are less than 50\% after exposure to budesonide, it is not likely to detect these differences with mRNA in situ hybridisation. An improper spread of budesonide through the lungs could be another explanation for the unchanged GR mRNA expression found in the lungs in this study. From figure 1 , however, it can be concluded that the distribution of the glucocorticoid in the lungs was good. Also, the observed upregulated glutamine synthetase mRNA expression indicates proper steroid function in the lungs $(151,152)$.

The side effects that occur after oral glucocorticoid use are well documented. Controversial are the possible systemic side effects which talke place after a long period inhalation of glucoconticoids (155). A clear relationship, though, is observed with the administered dose, the pharmacokinetics of the steroid, and the method for inhaled drug delivery (156). Recently. a downregulation of the GR mRNA after topical glucocorticoid application has been shown in vivo in peripheral lymphocytes of humans (145). In this publication by Knutsson and coworkers, a downregulated $\alpha$ GR mRNA expression was observed after intranasal inhallation of budesonide and fluticasone propionate. By demonstrating a downregulation of both GR mRNA levels in the gastrocnemius muscle, 4 hours after instillation of $100 \mu \mathrm{g}$ budesonide, it can be supposed that the amount of budesonide entering the systemic circulation was high 
enough $\left(210^{-8} \mathrm{M}\right.$, see (147)) to create a similar change in both $\alpha$ and $\beta$ GR mRNA patterns as seen before in bronchial epithelial cells and alveolar macrophages (147). No change in gastrocnemius muscle GR mRNA was demonstrated 1 and 12 hour after instillation. In the present study the amount of steroid per $\mathrm{kg}$ body weight instilled in the rats was approximately 25 times more than the amount inhaled by the human volunteers. Since the occurrence of systemic effects is related to the administered dose, this could be an explanation for the observed downregulation of both $\alpha$ and $\beta$ GR mRNA expression at 4 hours.

It has long been known that the response of cells to glucocorticoids is positively correlated to the availability of the ligand and the amounts of receptor present in cells, and that both vary strongly between different tissues $(30,47,48)$. Because of the known inhibitory function of the $\beta$ on the $\alpha \operatorname{GR}$ form $(57,60)$, it is also important to take $\alpha / \beta$ GR ratios into consideration in studying these responses. In the present study 5 to 8 times higher $\alpha$ and $\beta$ GR mRNA levels were demonstrated in the lungs compared to the gastrocnemius. Also a tissue dependent variation in $\alpha / \beta$ GR ratio was observed, resulting in a ratio of 2.6 in the lungs compared to a ratio of 1.1 in the gastrocnemius. The $\alpha / \beta$ GR mRNA ratio in the lungs of rats is similar as observed in human bronchial epithelial cells and alveolar macrophages (147). In theory, because of the lower amounts of GR mRNA and $\alpha / \beta$ ratio in the gastrocnemius, less effect of glucocorticoids on gene transcription might be expected in the gastrocnemius compared to the lungs. Nevertheless, we observed a change in gene transcription of the GR. This is similar to the results obtained before in bronchial epithelial cells and alveolar macrophages (147) and in agreement with the in vitro model system where $\alpha / \beta$ ratios equal to or lower than 0.5 were clearly inhibiting.

In a recent study of Oakley and coworkers (57), the $\beta$ GR was investigated. As described before in a study of Bamberger et al. (60), the $\beta$ GR has a dominant negative inhibitory effect on the activity of the $\alpha$ form. Striking was the observation that, with Northern blot analysis, three GR mRNA forms were present. Instead of the routinely demonstrated $\alpha$ (7 kb) and $\beta$ (5 kb) GR mRNA $(58,89,157,158)$, an $\alpha 1$ band of $7 \mathrm{~kb}$, an $\alpha 2$ band of $5.5 \mathrm{~kb}$ and a $\beta$ band of $4.3 \mathrm{~kb}$ was demonstrated (57). These three forms have also been demonstrated in the past in rats. In a study by Kalinyak and coworkers (159) only the $7 \mathrm{~kb}$ form was reported in detail, but all three isoforms are in retrospect visible on the Northern blot analysis. Similar results can be observed in the study of Brönnegard et al. (160). In the present study we investigated both $\alpha 1$ and $\beta$ GR mRNA forms. The identity of these isoforms was determined by the location of the 28 and $18 \mathrm{~S}$ ribosomal 
bands. In a previous study in patients and in a bronchial epithelial cell line (147), the third isoform was occasionally seen. In contrast in rats, no sign of the third $\propto 2$ band was observed.

In conclusion, in rats the $\alpha$ and $\beta$ GR mRNA forms are present. No GR mRNA downregulation of intra-tracheally instilled budesonide in rat lung was observed, probably due to the diversity of the cell population. The $\alpha / \beta$ GR mRNA ratios and concentrations were higher in the lungs as compared to the gastrocnemius, which suggest a possible difference in gene regulation by glucocorticoids between these tissues. 
S.

25

कर $+\cdots$

$\ldots$ 


\section{FIVE}

IS THE $\beta$ GLUCOCORTICOID RECEPTOR (GR) MRNA LEVEL HIGH ENOUGH FOR INHIBITION OF THE GR FUNCTION IN COPD? 
IS THE $\beta$ GLUCOCORTICOID RECEPTOR (GR) MRNA LEVEL HIGH ENOUGH FOR INHIBITION OF THE GR FUNCTION IN COPD?

5.1 Introduction

5.2 Materials and methods

5.3 Results

5.4 Discussion 


\section{Abstract}

In patients with asthma the beneficial effects of oral and inhaled glucocorticoids are well established, but their effectiveness in COPD is limited. The glucocorticoid receptor (GR), which exists as an $\alpha$ and a $\beta$ form, plays a central role in the function of glucocorticoids. Significant inhibition of the GR-activity by the $\beta$ from occurs at an $\alpha / \beta$ ratio lower than 1 . We investigated whether patients with COPD have basically lower $\alpha / \beta$ GR mRNA ratios and levels in their bronchial epithelial cells and alveolar macrophages compared to an agematched non-obstructive control group.

All subjects underwent bronchoscopy and cells were sampled through brushing and bronchoalveolar lavage (BAL). Northern blot hybridizations were performed with $\mathrm{GR}$ and control probes.

A lower $\alpha$ GR mRNA expression was demonstrated in patients with COPD compared to the non-obstructive control group. No difference was observed in $\beta$ GR mRNA expression between both groups. In the BAI samples a higher $\alpha$ and $\beta$ GR gene expression was present than in the brush samples. The $\alpha / \beta$ GR mRNA ratio did not differ between subjects with COPD and controls, nor between brush and BAL samples, averaging 1.7.

In conclusion, the $\alpha$ and $\beta$ GR mRNA ratios did not differ between subjects with COPD and controls. However, a lower expression of the $\alpha$ form was seen in patients with COPD. These findings suggest that the limited effect of glucocorticoids in patients with COPD cannot be attributed to $\beta$ GR MRNA. 


\subsection{Introduction}

Several short and long term studies on the effects of oral and/or inhaled glucocorticoids have been performed in patients with chronic obstructive pulmonary disease (COPD), showing little or no effect on airflow obstruction $(32,33)$. In a meta-analysis by Callahan and colleagues, only $10 \%$ of the patients responded to oral corticosteroid therapy with a $20 \%$ increase in baseline FEV1 (34). The reason for this limited response in COPD is not elucidated yet, but to be able to distinguish between responders and non-responders, long term studies are necessary with well defined patient populations. In asthma, glucocorticoids form the mainstay of treatment, reducing symptoms and airway hyperresponsiveness, suppressing inflammatory responses, improving airway function and restoring airway integrity (24), Despite their frequent use, the molecular mechanisms involved in the anti-inflammatory actions of glucocorticoids are not fully understood.

The glucocorticoid receptor (GR) mediates the pharmacological effect of glucocorticoids. Binding of a glucocorticoid activates the receptor and enables it to translocate to the nucleus and bind to glucocorticoid responsive elements in the promotor region of genes (161). Which genes are modulated not only depends on the presence or absence of these responsive elements, but also on the interaction with other transcription factors within the cell (25). Until now direct protein-protein interaction of the GR is described with activator protein-1 (AP-1) (99), nuclear factor $\mathrm{kB}$ (NFKB) (101), cAMPresponsive element binding protein (CREB) (104) and signal transducers and activators of transcription 5 (Stat5) (108). In asthma, a small proportion of patients does not respond to glucocorticoids. This steroid resistance is not due to any abnormality in glucocorticoid clearance, absorption or receptor binding (26). It has been suggested that a reduced binding of the activated glucocorticoid receptor to DNA, due to high AP-1 concentrations, results in this non-response (162).

Alternative splicing of the glucocorticoid receptor leads to an $\alpha$ and $\beta$ form (58). The $\alpha$ form has always been the primary target in research, because of its predominant expression and ligand binding capacity $(57,58)$, despite the observation that both $\alpha$ and $\beta$ GR mRNAs are present in all tissues investigated $(57,60)$. The fact that the $\beta$ mRNA form is so widely expressed throughout the body, indicates that it may play a role in the cellular response to glucocorticoids. However, almost no information is available about this 
receptor form. Recently, Oakley and coworkers (57), reported the existence of $2 \propto \mathrm{GR}$ isoforms, called $\alpha 1$ and $\alpha 2$ with Northerm blot analysis. The $\alpha 1, \alpha 2$, and $\beta$ bands were demonstrated at $7 \mathrm{~kb}, 5.5 \mathrm{~kb}$, and $4.3 \mathrm{~kb}$, respectively. The $\beta$ GR acts as a dominant negative inhibitor on the action of the $\alpha$ GR at an $\alpha / \beta$ ratio well below $1(60)$. So hypothetically, a predominant expression of the $\beta$ GR mRNA over the $\alpha$ GR mRNA could explain the lack of response to steroils in COPD, due to an inhibitory effect of the $\beta$ GR on the GR-activity. The levels of GR expression are cell type dependent, but so far, all cell types consistently show a higher expression of the $\alpha$ GR mRNA over the $\beta$ GR mRNA (57). In a previous study by our group the $\alpha$ and $\beta$ GR mRNA levels were examined in healthy volunteers and an average $\alpha / \beta$ ratio of 2.3 was found in alveolar macrophages (147).

In this study we investigated the $\alpha$ and $\beta$ GR mRNA in vivo in human bronchial epithelial cells and alveolar macrophages. Since the amount of cells obtained from human bronchial epithelial cells in vivo is limited and no antibodies are available to separately investigate both GR forms, we chose to study the $\alpha$ and $\beta$ GR on mRNA level. Therefore, the aim of this study was to investigate $\alpha / \beta$ glucocorticoid receptor mRNA ratios and levels in bronchial epithelial cells and alveolar macrophages of patients with COPD and an age-matched control group. Since cigarette smoking is the most important etiological factor in the pathogenesis of COPD and because cigarette smoke contains cadmium and other heavy metals, the metallothionein gene expression, upregulated by heavy metals and glucocorticoids, was also studied. For control of cellular composition of brush and BAL samples, smears were Giemsa stained and the cell differentiation was performed.

\subsection{Material and methods}

\section{Patients:}

We studied patients with COPD $(n=6)$, as defined by the American Thoracic Society (35) and used an age matched control group $(n=14)$ with no history of obstructive pulmonary diseases and normal lung function. None of the subjects were treated with glucocorticoids or $\beta_{2}$-agonists at least 6 weeks before the study, except for 2 patients in the COPD-group, who received $\beta_{2}$-agonists. Pulmonary function tests and bronchoscopies were performed according to the guidelines of the European Respiratory Society (163) and American Thoracic Society (139), respectively. Smoking status was recorded and a 
subdivision was made between smokers and non-smokers, i.e. people who stopped smoking more than 5 years ago. Bronchial epithelial cells and alveolar macrophages were collected via fiberoptic bronchoscopy by brushing and lavage. From the 10 subjects of the control group diagnosed with lung cancer in one side of the lung, samples were taken from the healthy, contralateral side. The protocol was approved by the local ethical committee.

\section{RNA-isolation, Northern blotting and hybridization:}

RNA was isolated from the cells as described before by Korn et al. (147). In short: cells of 10 brush samples collected from second to fourth order bronchi were firmly shaken in $4 \mathrm{ml}$ DMEM to which immediately an equal amount of $8 \mathrm{M}$ GTC was added. Bronchoalveolar lavage was performed 3 times with $50 \mathrm{ml} 0.9 \% \mathrm{NaCl}$. The last two fractions were pooled and centrifuged and the pellet was dissolved in $8 \mathrm{ml} 4 \mathrm{M} \mathrm{GTC}$. Total RNA was isolated with the GTC/CsCl-method and $20 \mu \mathrm{g}$ was run on Northern blot. The glucocorticoid receptor, glyceraldehyde-3-phosphate dehydrogenase (GAPDH) and metallothionein (MT2) probes were subsequently hybridized. Both $\alpha$ and the $\beta$ form are detected with the GR-probe. Sample signals were analyzed visually as well as semiquantitatively with a phosphorimaging system (Molecular Dynamics, Sunnyvale, CA). GR and MT2 mRNA levels were expressed relative to GAPDH levels of the same sample.

\section{Cytology:}

To determine the cellular composition of the brushes, smears were made and air dried. Morphology was obtained by immediately smearing one additional brush on an object glass. The BAL-fluid was centrifuged for 15 minutes at $1500 \mathrm{rpm}$, the pellet dissolved in $0.5 \mathrm{ml}$ PBS and $5 \mu \mathrm{l}$ of this cell suspension was used for smears and air dried. Object slides from brush and BAL were Giemsa stained, and cellular composition analyzed as described before $(140,141)$.

\section{Statistics:}

For all results mean \pm standard deviation (SD) was callculated. To determine differences the Mann-Whitney $U$ test was performed. Differences of $p<0.05$ were considered to be statistically significant. 


\subsection{Results}

Clinical characteristics of the subjects:

Clinical characteristics of the COPD-patients and controls are shown in table 1. Age, gender, and smoking status did not differ significantly between the two groups. FEV1 was significantly lower in patients with COPD $(\mathrm{p}<0.001)$ compared to the control group ( $61.0 \pm 10.1$ vs $95.2 \pm 15.2 \%$ predicted). The percentage FEV1 reversibility obtained from the patients with COPD was $4.2 \pm 3.2 \%$, well below the $12 \%$ as determined by the ATS. None of the patients received glucocorticoid medications within 6 weeks before bronchoscopy.

Table 1: Clinical characteristics of the COPD-patients and controls.

\begin{tabular}{|c|c|c|c|c|c|}
\hline Patient & Indication & $\begin{array}{l}\text { Age } \\
\text { yr }\end{array}$ & Sex & $\begin{array}{l}\text { FEV1 } \\
\% \text { pred }\end{array}$ & Smoking \\
\hline 1 & COPD & 64 & $\mathbf{M}$ & 72 & $y$ \\
\hline 2 & COPD & 52 & $\mathbb{F}$ & 66 & $y$ \\
\hline 3 & COPD & 72 & $\mathbf{M}$ & 47 & $y$ \\
\hline 4 & COPD & 74 & $\mathrm{M}$ & 71 & $y$ \\
\hline 5 & COPD & 74 & $\mathbf{M}$ & 48 & $\mathrm{n}$ \\
\hline 6 & COPD & 73 & $\mathbf{M}$ & 62 & $\bar{y}$ \\
\hline 7 & Haemoptysis: & 61 & $\mathbf{M}$ & nd & $y$ \\
\hline 8 & Haemoptysis & 72 & $\mathrm{M}$ & 111 & $n$ \\
\hline 9 & Haemoptysis & 49 & $\mathrm{M}$ & 136 & $\mathrm{n}$ \\
\hline 10 & Unexplained & 61 & $\mathbf{M}$ & 96 & $\mathrm{n}$ \\
\hline 11 & Lung cancer & 48 & $\mathbf{M}$ & 77 & $y$ \\
\hline 12 & Lung cancer & 58 & $\mathrm{M}$ & 87 & $y$ \\
\hline 13 & Lung cancer & 77 & $\mathrm{M}$ & 84 & $y$ \\
\hline 14 & Lung cancer & 61 & $F$ & 81 & $y$ \\
\hline 15 & Lung cancer & 63 & $\mathbf{M}$ & 83 & $y$ \\
\hline 16 & Lung cancer & 36 & $\mathbb{F}$ & 103 & $y$ \\
\hline 17 & Lung cancer & 69 & $\mathrm{M}$ & 100 & $y$ \\
\hline 18 & Lung cancer & 73 & $\mathbf{M}$ & 86 & $\mathrm{n}$ \\
\hline 19 & Lung cancer & 74 & $\mathbf{M}$ & 93 & $y$ \\
\hline 20 & Lung cancer & 52 & $\mathrm{M}$ & 100 & $y$ \\
\hline
\end{tabular}

nd $=$ not determined 


\section{Cell counts.:}

In table 2 the cellular distribution from brushes and BAL specimens is presented. The main cell types observed in the brush were bronchial epithelial cells ( $>78 \%$ in the COPDs and $>91 \%$ in the controls) and in the BAL alveolar macrophages ( $>90 \%$ in the COPDs and $>71 \%$ in the controls). No significant difference was observed in cell differential counts obtained from brushes and BAL of patients with COPD and controls and from brushes and BAL of smokers $(n=15)$ and non-smokers $(n=5)$, except for a higher number of eosinophils observed in brushes from non-smokers $(\mathrm{p}=0.02)$.

Table 2: Cellular distribution of epithelial and various inflammatory cells from brush and BAL samples. Mean and standard deviations are given for each patient group.

\begin{tabular}{|l|l|l|l|l|}
\hline Cell types & COPD brush & Control brush & COPD BAL & Control BAL \\
\hline Epithelial cells & $78 \% \pm 18$ & $91 \% \pm 8$ & $6 \% \pm 0$ & $8 \% \pm 9$ \\
\hline Macrophages & $4 \% \pm 7$ & $1 \% \pm 1$ & $90 \% \pm 0$ & $71 \% \pm 13$ \\
\hline Neutrophils & $10 \% \pm 13$ & $4 \% \pm 5$ & $5 \% \pm 0$ & $18 \% \pm 18$ \\
\hline Eosinophils & $<1 \%$ & $<1 \%$ & $<1 \%$ & $<1 \%$ \\
\hline Lymphocytes & $7 \% \pm 9$ & $4 \% \pm 4$ & $<1 \%$ & $3 \% \pm 1$ \\
\hline Basophils & $<1 \%$ & $<1 \%$ & $<1 \%$ & $<1 \%$ \\
\hline
\end{tabular}

\section{Gene expression:}

The $\alpha$ GR mRNA levels were higher than the $\beta$ GR mRNA levels in all subjects "In 11 patients ( 8 controls and 3 COPDs) BAL could not be sampled during bronchoscopy. In the brush of 2 patients with COPD and 1 control, GR mRNA expressions could not be determined because the signals were too weak for reliable quantification. Inserted in figure 1 is an example of the $\alpha$ and $\beta$ GR, GAPDH and MT2 mRNA hybridizations.

Means and standard deviations of the $\alpha$ and $\beta$ GR mRNA expression in brush and BAL cells are shown in figure 1 . In the brush, for both receptor forms the MRNA expression was lower in patients with COPD, but only to a significant extent for the $\alpha \mathrm{GR}$ ( $\mathrm{p}<0.05$ for the $\alpha$ GR and $p=0.14$ for the $\beta$ form). On average, alveolar macrophages expressed 1.9 times higher $\alpha$ and 1.5 times higher $\beta$ GR mRNA levels as compared to the bronchial epithelial cells, being significant in the COPDs $(p<0.05)$, but not in the controls $(p=0.054$ for the $\alpha$ and 
$p=0.27$ for the $\beta$ GR). No difference in $\alpha$ and $\beta$ GR mRNA levels was observed between smokers and non-smokers.

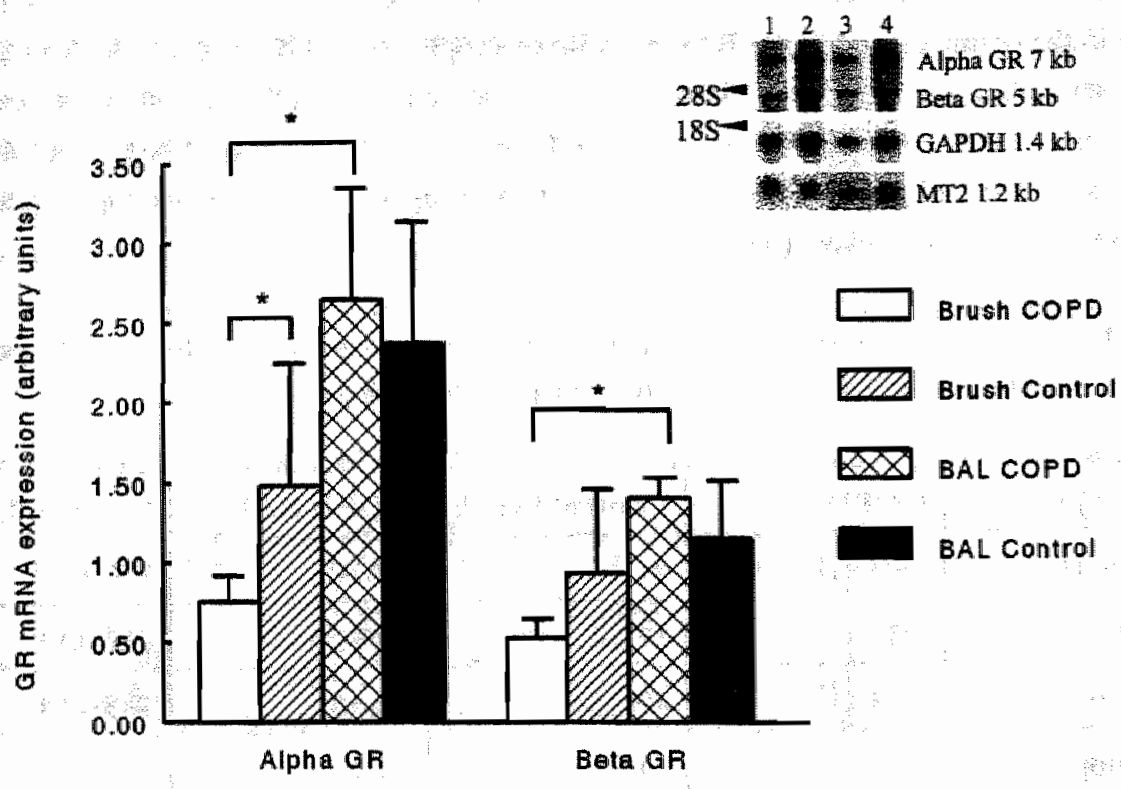

Figure 1: The mean $\pm S D$ of $\alpha$ and $\beta$ GR mRNA expression in brush and BAL cells is shown for COPD-patients and controls. Inserted is a Northern blot presentation of bronchial epithelial cells (odd numbers) and alveolar macrophages (even numbers) from a patient with COPD (lanes 3 and 4) and an age-matched control (lanes 1 and 2). Hybridization signals of the a and $\beta$ GR, GAPDH and MT2 are shown.

As shown in figure 2 , no significant difference was observed in $\alpha / \beta$ GR mRNA ratio between patients with COPD and controls, nor between brush and BAL samples. The mean and standard deviation of the $\alpha / \beta$ GR mRNA ratio for the brush was $1.6 \pm 0.4$, ranging from $1.1-2.5$. For the BAL the ratio was slightly higher, $1.9 \pm 0.5$, ranging from $1.2-2.7$. 


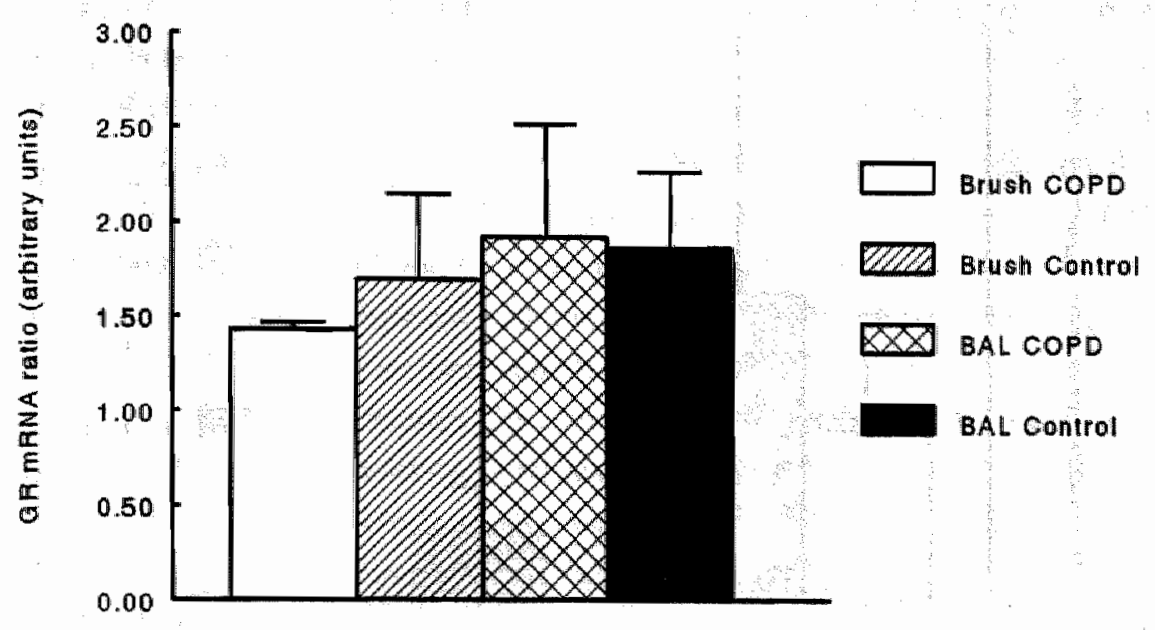

Figure 2: $\alpha / \beta$ GR mRNA ratios in brush and BAL of patients with COPD and controls. Shown are mean values $\pm \mathrm{SD}$ of every group.

In figure 3 MT2 mRNA expression is shown. For MT2 mRNA levels a 4 times higher expression was found in bronchial epithelial cells than in alveolar macrophages, which was significant in the controls ( $p<0.05$ ), but not in the COPDs $(\mathrm{p}=0.08$ ). Comparison of MT2 mRNA expression between patients with COPD and controls revealed no differences in either brush or BAL samples. 


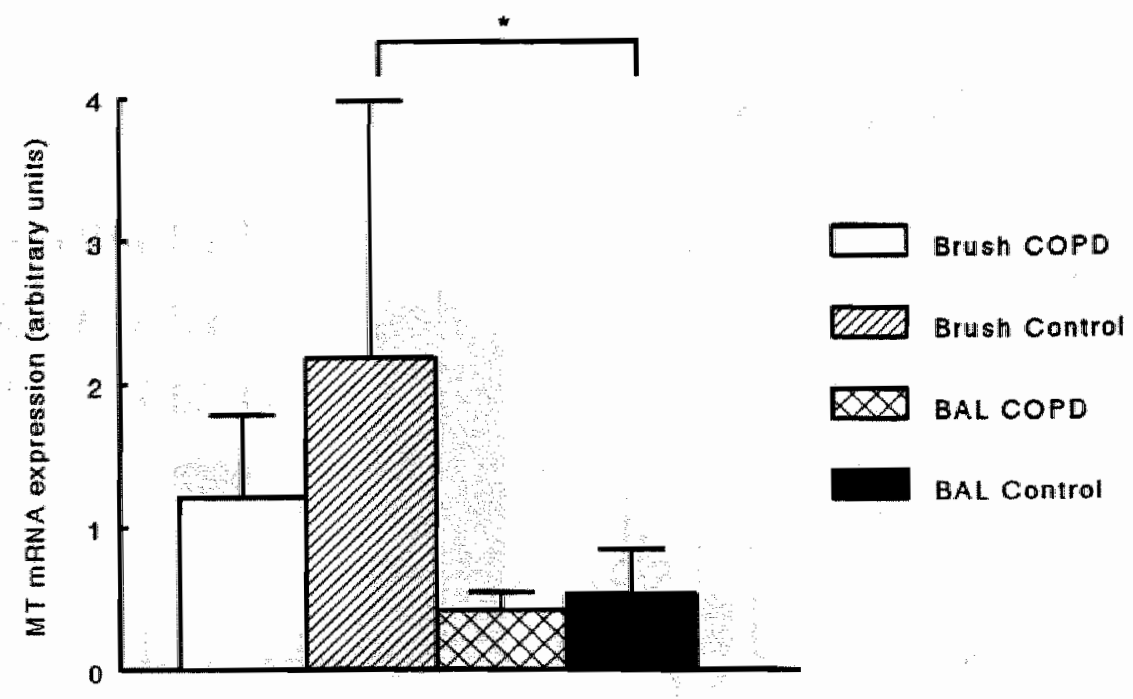

Figure 3: MT2 mRNA expression in brush and BAL of patients with COPD and a control group. Shown are mean values $\pm \mathrm{SD}$.

\subsection{Discussion}

In this study, a lower $\alpha$ GR mRNA expression was observed in brushes from patients with COPD compared to an age matched non-obstructive control group. No difference in $\alpha / \beta$ GR mRNA ratio was observed between the patients and their controls, in neither brush or BAL samples. In both groups, alveolar macrophages had a higher $\alpha$ and $\beta$ GR gene expression compared to bronchial epithelial cells, although only significantly in the patients with COPD. Smoking did not appear to influence the $\alpha$ and $\beta$ GR gene expression in brush or BAL samples. The MT2 mRNA expression did not differ between patients with COPD and controls, but was significantly higher in bronchial epithelial cells compared to alveolar macrophages in the controls. Smoking did not influence the MT2 mRNA expression in either brush or BAL samples. 
In a previous study (147) we investigated $\alpha$ and $\beta$ GR mRNA levels in human bronchial epithelial cells and alveolar macrophages. In healthy volunteers aged 23.43 years, a higher expression of GR mRNA was found in alveolar macrophages compared to bronchial epithelial cells, as also demonstrated in this study. In addition, the $\alpha / \beta$ GR mRNA ratio was also similar to that observed in the present study in COPD-patients and controls, 36 to 77 years of age. Until now, no studies have been performed on the GR mRNA expression in patients with COPD. However, the recent discovery of the $\beta$ GR as a negative inhibitor of the $\alpha$ GR might be an important element in the poor response to glucocorticoids in steroid resistant asthma or COPD. Bamberger and coworkers demonstrated in a model study an increasing inhibition of $50 \%$ to $85 \%$ on $\alpha / \beta$ ratios from 0.2 to 0.07 , respectively. Importantly the $\alpha / \beta$ ratio in the patients with COPD was 1.4 , more than 10 fold higher, rendering a possible inhibitory effect of the $\beta$ GR on GRfunction unlikely in COPD. This is supported by the fact that we found no difference in $\alpha / \beta$ GR-ratio between COPD-patients and age-matched controls. However, the fact that lower $\propto$ GR $\mathrm{mRNA}$ levels were demonstrated in patients with COPD in contrast to similar $\beta$ GR mRNA levels might be an essential observation regarding the steroid resistance of these patients. Because a lower expression of the active GR form could result in a reduction of response to glucocorticoids. Since these results are on mRNA level and it is not known whether translation of both mRNAs is equally effective, protein levels need to be studied when separate antibodies for both $\alpha$ and $\beta$ GR proteins become available. Also no separation was made between responders and non-responders to glucocorticoids in the group of patients with COPD. Therefore, it might be possible that all 6 COPD patients belonged to those $10 \%$ responding to oral glucocorticoids. Thus, it is important that $\alpha$ and $\beta$ GR ratios and levels are studied both on $\mathrm{mRNA}$ and protein level, in larger groups of patients with COPD and coupled to responses to glucocorticoids, so a separation can be made between responders and non-responders.

In a recent study of Oakley and coworkers (57), the GR $\beta$ isoform was studied. Similar findings as compared to the study of Bamberger et al. (60) were found regarding the negative inhibitory function of the $\beta$ GR on the activity of the $\alpha$ form. Striking in this article was the observation that with Northern blot analysis three GR mRNA forms were present. Instead of the previously frequently mentioned $(58,89,157,158) \alpha$ GR $\mathrm{mRNA}(7$ $\mathrm{kb})$ and $\beta$ GR mRNA (5 kb), an $\alpha 1$ band of $7 \mathrm{~kb}$, an $\alpha 2$ band of $5.5 \mathrm{~kb}$ and a $\beta$ band of $4.3 \mathrm{~kb}$ was demonstrated (57). In the present study we investigated the $1 \mathrm{GR} \mathrm{mRNA}$ form, which was very abundantly expressed in both bronchial epithelial cells and alveolar 
macrophages and the $\beta$ band, which was also expressed in these cell types, although to lesser extent. We determined the identity of these isoforms by the location of the $28 \mathrm{~S}$ and $18 \mathrm{~S}$ ribosomal bands. Occasionally in cells expressing high amounts of $\mathrm{GR}$, a third hybridization signal could be discerned, although in much lower levels as compared to the other two GR mRNA forms. This band appeared to be located just above the $28 \mathrm{~S}$ band; whereas the $\beta$ form was situated below the $28 \mathrm{~S}$ band. This is in agreement with the study of Oakley and coworkers.

Asthma and chronic bronchitis are both characterized by airway inflammation, although the type of inflammation seems to be different (17). In studies with BAL and (induced) sputum a higher number of eosinophils in the airways of asthmatics has been observed, in contrast to a larger number of neutrophils present in the airways of COPDs (18-20). A clear correlation exists between the amount of neutrophils and the airway obstruction and decline in lung function $(18,21)$. On the contrary, in the bronchial mucosa higher amounts of macrophages and T-lymphocytes have been reported in patients with COPD $(22,23)$. Since the GR mRNA expression varies between the different cell types (see below), it is important to check the cellular composition of the sampled material, to prevent at misplaced GR gene expression in the cell type investigated. The cellular distribution obtained in this study is highly comparable with the results obtained in a previous study with healthy, young volunteers (147) and not significantly different between patients with COPD and the controls, for neither brush and BAL samples. The stronger expression of the $\alpha$ and $\beta$ GR mRNA occurring in alveolar macrophages compared to bronchial epithelial cells is in line with findings of Adcock and colleagues (149), in which the highest gene expression of the GR was found in alveolar walls and vascular endothelium, with lower signals in airway epithelium and smooth muscle cells. This variable GR gene expression present in different cell types of the lung opens the possibility of differential effects of glucocorticoids in these cell types, since the effects of glucocorticoids are positively correlated to the amount of GR in the cell. Therefore, a higher effect of glucocorticoids might be expected in patients with larger numbers of macrophages in the lungs. Since we found no difference in any cell type amounts between COPDs and controls, no conclusions can be drawn from this investigation, regarding the correlation between the amount of cell types and response to glucocorticoids.

Smoking is known to induce neutrophilic inflammation in the airways of patients with COPD (164), either by direct chemotactic effects of cigarette components, such as nicotine, or by the release of chemokines by alveolar macrophages (165). Therefore, 
smoking results in a reduced response to glucocorticoids (166). In this study no difference was observed in cell samples obtained from smokers or non-smokers. In this investigation we also studied MT2 mRNA levels, since glucocorticoids and heavy metals, present in cigarettes, increase the transcription of the MT2 gene (143). No difference was observed in MT2 mRNA levels between patients with COPD and the controls. A higher MT2 gene expression was observed in bronchial epithelial cells compared to alveolar macrophages in the controls. This expression was inversely correlated to the GR mRNA expression. Since none of the patients used glucocorticoids, the effects of glucocorticoids on MT2 mRNA expression in bronchial epithelial cells and alveolar macrophages could not be determined. Nor were we able to determine differences between COPDs and controls in transcriptional responses to glucocorticoids. No correlation was found between smoking status and MT2 mRNA expression in bronchial epithelial cells and alveolar macrophages, despite the fact that heavy metals, like cadmium, are present in cigarette smoke (167).

In conclusion, a lower $\alpha$ GR mRNA expression was demonstrated in human bronchial epithelial cells of patients with COPD, compared to non-obstructive controls. The $\alpha$ and $\beta$ GR mRNA ratio did not differ between subjects with COPD and controls. These findings suggest that the limited response to glucocorticoids in patients with COPD cannot be attributed to $\beta$ GR mRNA. 


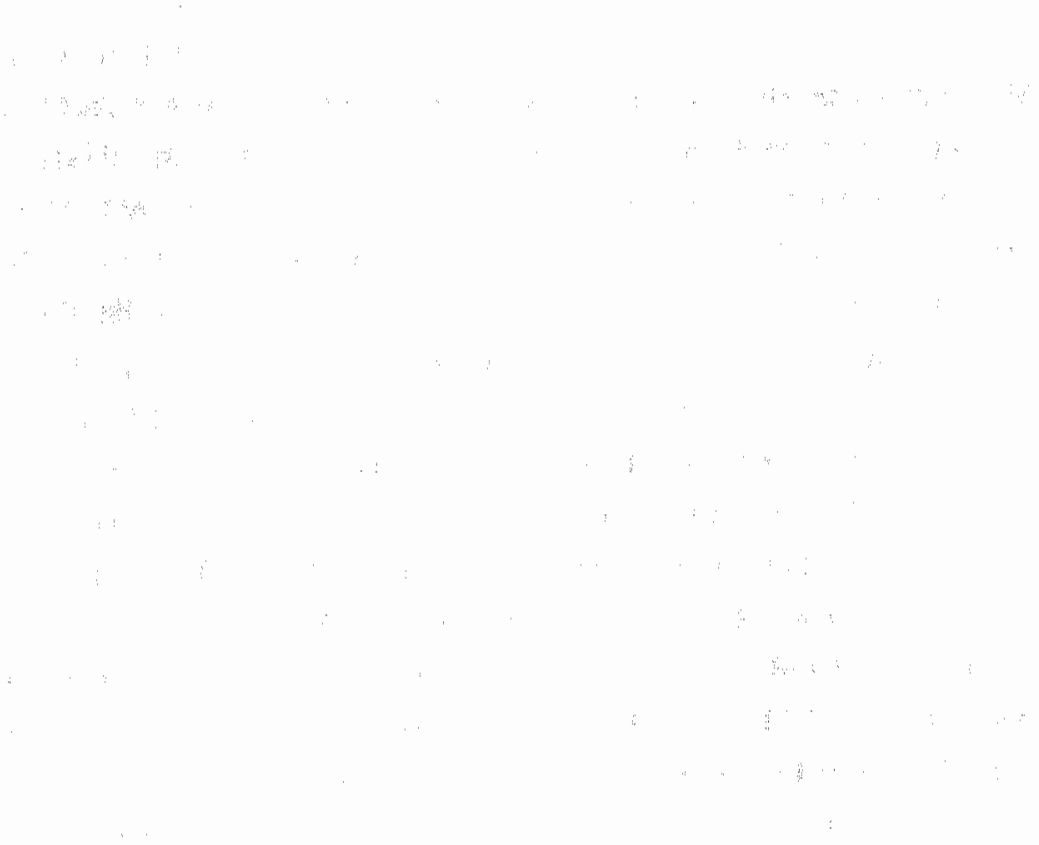




\section{SIX}

GLUCOCORTICOID RECEPTOR MRNA LEVELS IN BRONCHIAL EPITHELIAL CELLS OF PATIENTS WITH COPD: INFLUENCE OF GLUCOCORTICOIDS 
3 
GLUCOCORTICOID RECEPTOR MRNA LEVELS IN BRONCHIAL EPITHELIAL CELLS OF PATIENTS WTTH COPD: INFLUENCE OF GLUCOCORTICOIDS
6.1. Introduction
6.2 Materials and methods
6.3 Results
6.4 Discussion 


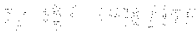

a 
Abstract

Glucocorticoids are known to be effective in the treatment of asthma. In COPD, however, no beneficial effects are demonstrated in most of the patients. Hypothetically, this may be explained by an over expressed $\beta$ glucacorticoid receptor (GR) compared to the $\alpha \mathrm{GR}$. The aim of this study was to investigate $\alpha$ and $\beta$ GR mRNA levels and ratios in patients with COPD and a non-COPD control group after glucoconticoid use.

GR and as control metallothionein (MT) 2 mRNA levels were compared between patients with COPD receiving glucocorticoids and nonCOPD patients not using glucocorticoids. Bronchoscopy was performed and bronchial epithelial cells were sampled with brushing. To study the short term response of the GR to glucocorticoids, controls undergoing pneumectomy were used. Bronchial epithelial cells were sampled by brushing the lung resection at a predetermined interval after budesonide inhalation.

GR and MT2 levels did not differ between patients with COPD receiving glucocarticoids and the non-COPDs using no glucocorticoids. $\alpha 1 / \beta$ GR mRNA ratios were $1.7 \pm 0.4$ in the patients with COPD compared to $1.7 \pm 0.5$ in the controls, indicating no inhibitory effect of the $\beta$ $G R$ on the $a 1$ form. $A$ short term downregulation of the GR mRNA expression was observed after glucoconticoid inhalation in non-COPDs.

In conclusion, in contrast to the non-COPD patients, no evidence of GR mRNA downregulation was found in patients with COPD after chronic use of glucocorticoids, which is not explained by low GR. mRNA levels or $\alpha / \beta$ mRNA ratios. 


\subsection{Introduction}

Glucocorticoids have proven to be effective in the long-term management of asthma. Symptoms and airway hyperresponsiveness are reduced, airway functions improved and airway integrity restored (24). Only a small proportion of the asthma patients does not respond to glucocorticoids. In contrast, their effectiveness in patients with chronic obstructive pulmonary disease (COPD) is controversial $(32,33)$. Callahan and colleagues demonstrated in only $10 \%$ of the patients a response to oral corticosteroid therapy. measured as a $20 \%$ increase in baseline FEV1 (34). The beneficial effects of glucocorticoids in COPD are at present still under study (36), and the results of this investigation will be gained soon. The reason for the limited response to glucocorticoids in patients with COPD is not elucidated yet.

The molecular mechanisms involved in the anti-inflammatory actions of glucocorticoids are not completely understood. Glucocorticoids enter the cell by passive diffusion and bind to a cytoplasmic glucocorticoid receptor (GR). This receptor mediates the effect of glucocorticoids by translocating into the nucleus, binding to glucocorticoid responsive elements (GRE) in the DNA and modulating the transcription of genes (161). Another way of regulating the transcription of genes does not involve binding of the GR to DNA but interaction of the GR with other transcription factors. Cross-talk between the GR and proinflammatory transcription factors, like activator protein-1 (AP-1) $(98,99)$ and nuclear factor $\times B$ (NFkB) $(102,103)$, has been demonstrated within the cell. This interaction is believed to be important for the anti-inflammatory effect of glucocorticoids (96). Direct protein-protein interaction of the GR has not only been described with AP-1 and NFxB, but also with cAMP-responsive element binding protein (CREB) $(104,106)$ and signal transducers and activators of transcription 5 (Stat5) (108). In asthma, steroid resistance might be due to a reduced binding of the activated glucocorticoid receptor to DNA, caused by high AP-1 concentrations (162). No information is available about the GR expression and interactions with other transcription factors in patients with COPD.

As a result of alternative splicing, the glucocorticoild receptor exists in two forms, $\alpha$ and $\beta,(58)$. Both $\alpha$ and $\beta$ GR mRNAs are present in all tissues investigated $(57,60)$, but because of its ligand binding capacity, the $\alpha$ form has been the primary target in research $(57,58)$. The levels of GR expression vary between cell types and individuals, but in all 
cases higher $\alpha$ GR mRNA expression levels have been observed compared to $\beta$ GR mRNAs (57). Recently, Oakley and coworkers (57), reported the existence of $2 \alpha$ GR isoforms, $\alpha 1$ and $\alpha 2$ with Northern blot analysis. The $\alpha 1, \alpha 2$, and $\beta$ bands were demonstrated at $7 \mathrm{~kb}, 5.5 \mathrm{~kb}$, and $4.3 \mathrm{~kb}$, respectively. However, translation of both $\alpha$ forms results in the same GR protein. The fact that the $\beta$ form is widely expressed in many cell types, indicates that it may play a role in the cellular response to glucocorticoids. It has been demonstrated that the $\beta$ GR acts as a dominant negative inhibitor on the transcriptional activity of the $\alpha$ GR at an $\alpha / \beta$ ratio well below 1 (60). Thus, a predominant expression of the $\beta$ GR mRNA over the $\alpha$ GR mRNA could explain a lack of response to steroids as observed in steroid resistant asthma and COPD. Therefore, it is important to study both GR forms in COPD.

In a previous study $\alpha$ and $\beta$ GR mRNAs were investigated in patients with COPD and an age-matched control group. The average $\alpha$ and $\beta$ GR mRNA levels did not differ between patients with COPD and the controls. Also $\alpha / \beta$ GR mRNA ratios were similar between both groups. Since these $\alpha / \beta$ ratios were well above 1 , no inhibitory function of the $\beta$ GR on the $\alpha$ activity was expected. None of these patients received glucocorticoid medication, so basal $\alpha$ and $\beta$ GR mRNA levels and ratios could not explain the lack of response of patients with COPD to glucocorticoids. How the GR mRNA is modulated by glucocorticoids in patients with COPD is not known.

The short term $\alpha$ and $\beta$ GR mRNA regulation has been studied before in bronchial epithelial cells of healthy volunteers (147). An average $\alpha / \beta$ ratio of 2.3 was found, which was not affected by glucocorticoids (147). However, the $\alpha$ and $\beta$ GR mRNA levels were downregulated 2 hours after inhalation and normalized within 12 hours in bronchial epithelial cells. Before the downregulation an upregulated a GR mRNA expression appeared to be present. The question remained whether this upregulation was due to a direct effect of the inhaled budesonide in the morning, just before bronchoscopy, or a delayed effect of the dose inhaled the evening before, 12 hours before bronchoscopy.

The aim of the present study was twofold. Firstly, to investigate $\alpha$ and $\beta$ glucocorticoid receptor mRNA levels and ratios in bronchial epithelial cells of patients with COPD receiving glucocorticoid therapy. Secondly, to study the reversibility of the short term time-dependent GR mRNA downregulation. As a control, metallothionein mRNA levels were studied, since this gene is known to be upregulated by glucocorticoids. 


\subsection{Material and methods}

\section{Patients:}

Patients with COPD and non-COPD controls were divided in 4 groups stratified for smoking status: patients with COPD that smoked $(n=8)$, non-smoking COPDs $(n=4)$, control patients that smoked $(n=10)$ and non-smoking controls $(n=4)$. COPD $(n=12)$ was defined according the standards of the American Thoracic Society (35). Pulmonary function tests and bronchoscopies were performed according to the guidelines of the European Respiratory Society (163) and American Thoracic Society (139), respectively. Smoking status was recorded and non-smoking was defined as "stopped smoking for more than 5 years". The control group existed of patients with lung cancer $(n=10)$, patients with haemoptoe $(n=3)$ and 1 patient with chronic cough. From the patients with lung cancer, bronchial brushings were performed from second to fourth order bronchi of the non-malignant contralateral lung. The patients with COPD all used glucocorticoids and $\beta_{2}$-agonists. The controls did not receive glucocorticoids nor $\beta_{2}$-agonists.

For investigation of the short term effect of steroids on GR mRNA regulation, 2 brush samples from each subject were required. To avoid performing two bronchoscopies within a short time in the same individual, an alternative method was chosen. Patients from the nonCOPD control group with lung cancer undergoing pneumectomy were included $(\mathrm{n}=6)$. The first brush sample was used as a $100 \%$ control value, since it was taken during diagnostic bronchoscopy, when the patients did not use glucocorticoids (see above). After a recovery period of at least 1 week, a single dose of $1600 \mu \mathrm{g}$ budesonide was inhaled and the second sample of bronchial brushings was obtained from the lung resection in a bronehus not related to the tumor. Three patients inhaled about 5 hours before sampling of the cells, the other three inhaled more than 12 hours before sampling. The results from these patients were combined with the results obtained before (147) from 9 healthy volunteers. The protocol was approved by the local ethical committee.

\section{RNA-isolation, Northern blotting and hybridization:}

RNA was isolated from the cells as described before by Korn et al. (147). In short: 10 brush samples were taken from the second to fourth order bronchi and cells were firmly shaken into $4 \mathrm{ml}$ DMEM. Immediately after collection, an equal amount of $8 \mathrm{M}$ GTC was added. Total RNA was isolated with the GTC/CsCl-method and $20 \mu \mathrm{g}$ was run on gel for 
Northern blot analysis. The glucocorticoid receptor, Glyceraldehyde-3-phosph dehydrogenase (GAPDH) and metallothionein (MT2) probes were subsequently hybridiz Both $\alpha$ forms and the $\beta$ form are detected with the GR-probe. Sample signals were analy visually as well as semiquantitatively with a phosphorimaging system (Molecular Dynami Sunnyvale, CA): GR and MT2 mRNA levels were expressed relative to GAPDH levels of saime sample.

\section{Cytology:}

To determine the cellular composition of the brushes, smears were made by spreading additional brush on an object glass. Cells were Giemsa stained, and cellular composit analyzed as described before $(140,141)$.

\section{Statistics:}

For all results mean \pm standard deviation (SD) was calculated. To determine differences Mann-Whitney $U$ test or Chi-square test were performed. Differences of $p<0.05$ considered to be statistically significant.

\subsection{Results}

Clinical characteristics of the patients:

Clinical characteristics and smoking status of the patients with COPD $u$ glucocorticoids and the control group receiving no glucocorticoids are shown in tabl Age and gender did not differ between the two groups. The FEV 1 was lower $(p<0.05$ patients with COPD compared to the control group, $46 \%$ and $95 \%$, respectively. percentage $\mathrm{FEV}_{1}$ reversibility obtained from the patients with $\mathrm{COPD}$ was $3.0 \pm 2.4 \%$. DLCO was significantly lower $(\mathrm{p}<0.05)$ in patients with COPD as compared to controls: $68 \%$ and $105 \%$, respectively. 
Table 1: Clinical characteristics of the patients.

\begin{tabular}{|c|c|c|c|c|c|c|c|}
\hline Patient & Steroids & Age & Sex & Disease & FEV1 & DLCO & Smoking \\
\hline 1 & + & 67 & $\mathbf{M}$ & COPD & 33 & 43 & $y$ \\
\hline 2 & 8 & 73 & $\mathrm{~F}$ & COPD & 41 & nd & $y$ \\
\hline 3 & + & 62 & $\mathrm{M}$ & COPD & 65 & 68 & $y$ \\
\hline 4 & + & 67 & $F$ & COPD & 32 & 59 & $y$ \\
\hline 5 & + & 68 & $\mathrm{M}$ & COPD & 32 & 62 & $\mathrm{n}$ \\
\hline 6 & + & 62 & $\mathbf{M}$ & COPD & 45 & 70 & $y$ \\
\hline 7 & + & 73 & $F$ & COPD & 69 & 74 & n \\
\hline 8 & + & 67 & $F$ & COPD & 38 & 93 & $\mathrm{n}$ \\
\hline 9 & + & 71 & $\mathrm{M}$ & COPD & 70 & 85 & $y$ \\
\hline 10 & + & 57 & $\mathrm{M}$ & COPD & 51 & nd & $y$ \\
\hline 11 & + & 67 & $\mathrm{~F}$ & COPD & 41 & 51 & $y$ \\
\hline 12 & + & 72 & $\mathbf{M}$ & COPD & 34 & 72 & n \\
\hline 13 & - & 61 & $\mathbf{M}$ & Haemoptoe & nd & nd & $y$ \\
\hline 14 & $\therefore$ & 72 & $\mathbf{M}$ & Haemoptoe & 111 & 94 & in \\
\hline 15 & $\infty$ & 49 & $\mathrm{M}$ & Haemoptoe & 136 & 123 & $n$ \\
\hline 16 & - & 61 & $M$ & Cough & 96 & 147 & $\mathrm{n}$ \\
\hline 17 & - & 48 & $\mathrm{M}$ & Cancer & 77 & 124 & $y$ \\
\hline 18 & $-\quad \mathrm{a}$ & 58 & $\mathbf{M}$ & Cancer & 87 & 133 & $y$ \\
\hline 19 & 3 & 77 & $\mathrm{M}$ & Cancer & 84 & 54 & $y$ \\
\hline 20 & - & 61 & $\mathbf{F}$ & Cancer & 81 & nd & $y$ \\
\hline 21 & - & 63 & $\mathbf{M}$ & Cancer & 83 & 86 & $y$ \\
\hline 22 & - & 36 & $F$ & Cancer & 103 & 91 & $\bar{y}$ \\
\hline 23 & - & 69 & $M$ & Cancer & 96 & 108 & $y$ \\
\hline 24 & 3 & 73 & $M$ & Cancer & 86 & 90 & $\mathrm{n}$ \\
\hline 25 & - & 74 & $M$ & Cancer & 93 & 89 & $y$ \\
\hline 26 & - & 52 & $\mathrm{M}$ & Cancer & 100 & 120 & $y$ \\
\hline
\end{tabular}

$\mathrm{nd}=$ not determined

\section{Cell counts:}

In table 2 the cellular composition from the brush specimens is presented. The majority of the cell types were epithelial of origin (average $>86 \%$ ). No difference was observed in cell differential counts obtained from brushes of patients with COPD and the nonobstructive control group. Aithough the patients with COPD tended to have higher 
amounts of neutrophils in the brush sample this difference was not significant $(p=0.3)$. Neither was there a significant difference in cell types between brushes from smokers and non-smokers.

Table 2. The relative cellular distribution of the cellular composition in given in percentages.

\begin{tabular}{|l|l|l|}
\hline Cell types & $\begin{array}{l}\text { COPD brush } \\
(\text { mean } \pm \text { SD })\end{array}$ & $\begin{array}{l}\text { Control brush } \\
\text { (mean } \pm \text { SD })\end{array}$ \\
\hline Epithelial cells & $81 \pm 20$ & $91 \pm 8$ \\
\hline Macrophages & $1.5 \pm 2$ & $1.1 \pm 1$ \\
\hline Neutrophils & $11.8 \pm 21$ & $3.7 \pm 5$ \\
\hline Eosinophils & $0.1 \pm 0.2$ & $0.2 \pm 0.3$ \\
\hline Lymphocytes & $5.7 \pm 4$ & $4.1 \pm 4$ \\
\hline Basophils & 0 & 0 \\
\hline
\end{tabular}

\section{Gene expression:}

The means and standard deviations of the $\alpha 1$ and $\beta$ GR mRNA levels in bronchial epithelial cells are shown in figure 1, In 3 patients ( 2 with and 1 without glucocorticoids) the GR mRNA signal was too weak for reliable quantitation. The $\alpha 2$ band was not detectable in these blots. No difference in both $\alpha 1$ and $\beta$ GR mRNA expression levels was observed between smoking patients with COPD receiving glucocorticoid therapy and smoking controls using no glucocorticoids. Similar results were obtained when the nonsmoking patients with COPD were compared to the non-smoking controls. No difference was observed in $\alpha 1$ or $\beta$ GR mRNA levels between smokers and non-smokers. Inserted is an example of a Northem blot hybridization with the GR and GAPDH probe. Total RNA from bronchial epithelial cells of 2 patients with COPD is shown. A clear band at 7 kb ( $\alpha 1)$ was visible and a less pronounced $\beta$ GR band on the low site of the 285 band was observed. 


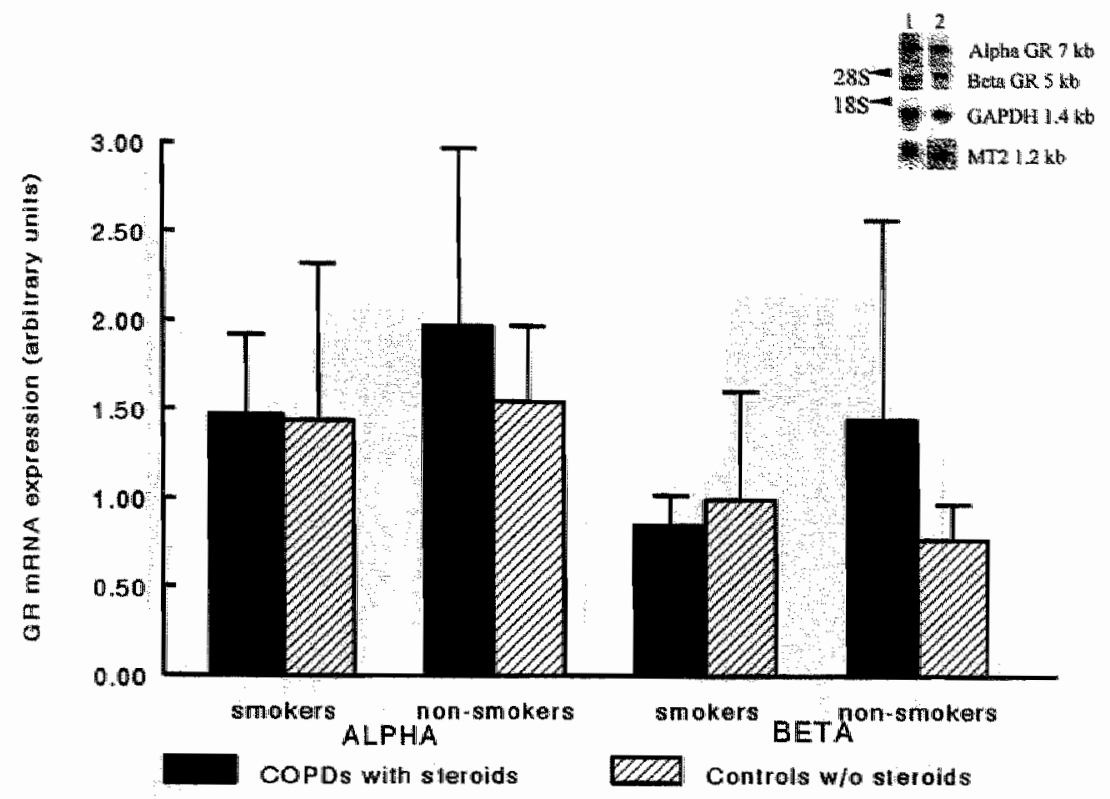

Figure 1: The mean \pm SD of $\alpha$ and $\beta$ GR mRNA expression in brush of patients with COPD and the age-matched controls. Glucocorticoid therapy did not downregulate either $\alpha$ or $\beta$ GR mRNA in parients with COPD. Inserted is a Northern blot presentation of bronchial epithelial cells from 2 patients with COPD. Both ( $\alpha 1$ and $\beta$ ) GR bands are observed. The position of the $28 \mathrm{~S}$ and $18 \mathrm{~S}$ bands is shown.

The $\alpha 1 / \beta$ ratios in smoking and non-smoking patients with COPD receiving glucocorticoids were $1.8 \pm 0.4$ and $1.7 \pm 0.5$, respectively. As shown in figure 2, these were not different from the ratios obtained from the smoking controls without glucocorticoids $(1.6 \pm 0.5)$ and in non-smoking controls without glucocorticoids $(2.0 \pm 0.2)$. 


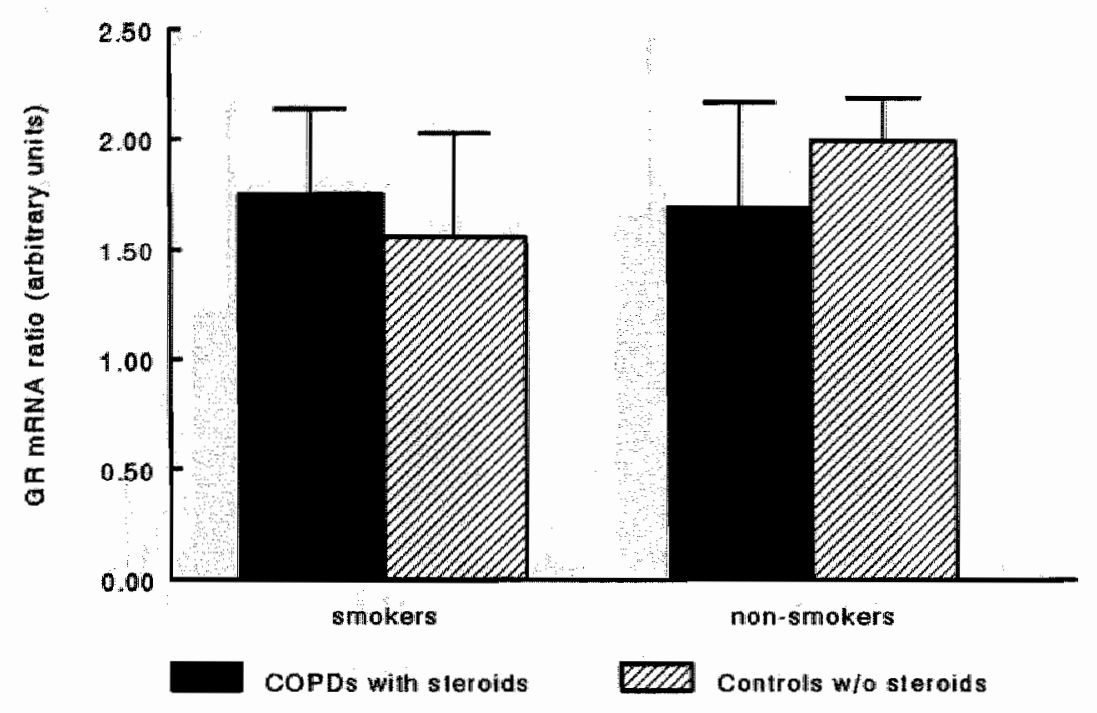

Figure 2: $\alpha / \beta$ GR mRNA ratios in brush samples of patients with COPD receiving glucocorticoids. Shown are mean values \pm SD of every group.

Since glucocorticoids induce MT2 gene transcription, higher levels of MT2 mRNA were expected in the patients with COPD using glucocorticoids. However, as shown in figure 3, MT2 mRNA levels were not influenced by glucocorticoids, neither in the smokers ( $p=0.7$ ) or non-smokers ( $p=0.2$ ). No effect of smoking on MT2 mRNA levels wat demonstrated in the controls $(\mathrm{p}=0.3)$ and patients with $\operatorname{COPD}(\mathrm{p}=0.6)$. 


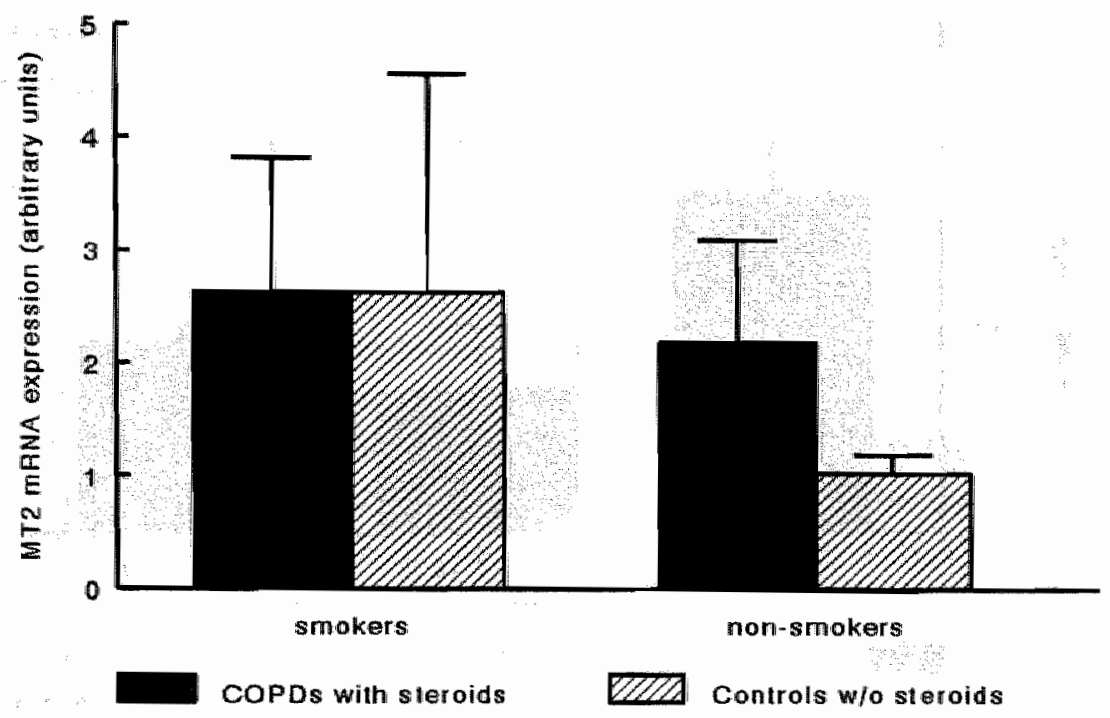

Figure 3: MT2 mRNA expression in brush samples of patients with COPD and an age-matehed control group. No upregulation of MT2 mRNA was seen in the patients with COPD using glucocorticoids, compared to the controls receiving no glucocorticoids. Shown are mean values $\pm \mathrm{SD}$.

The short term regulation of the $\alpha 1$ and $\beta$ GR mRNA was studied in patients with lung cancer and healthy volunteers and in figure $4 \mathrm{a}$ graph is shown. A clear upregulation of the Q1 GR mRNA was seen in the bronchial epithelial cells, when sampling occurred within 2 hours. A downregulation was observed after 2 hours being normalized after 10 hours. Conversely, MT2 mRNA levelis were upregulated to $152 \%(\mathrm{p}=0.04), 5$ hours after budesonide inhalation, and normalized to $93 \%, 12$ hours after inhalation. 


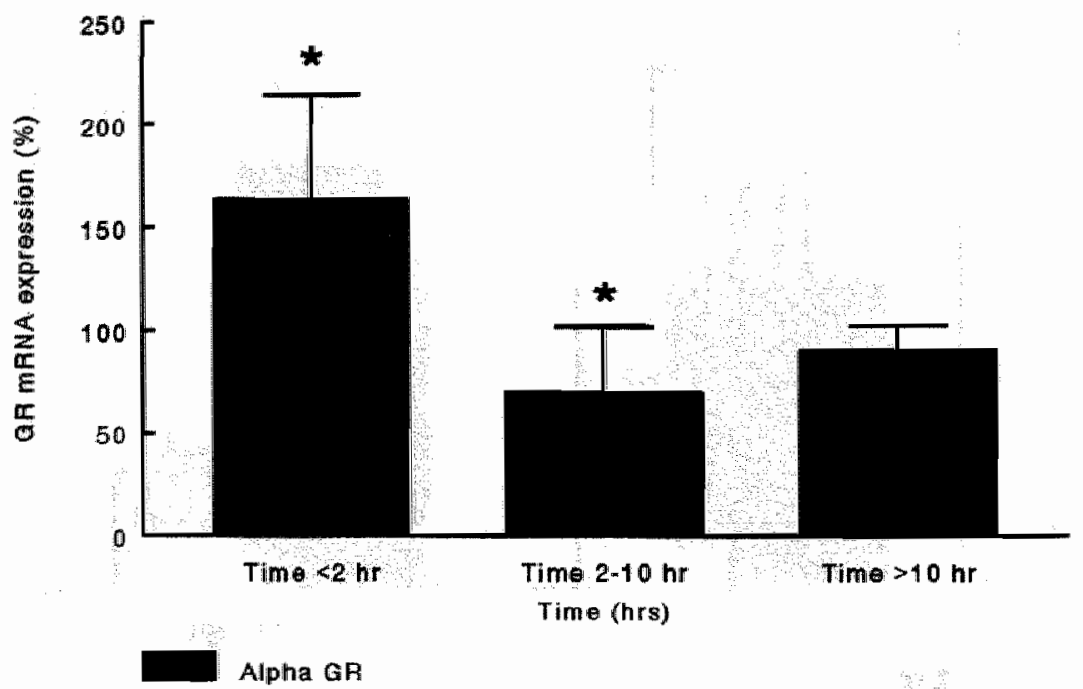

Figure 4: GR mRNA levels in patients with lung cancer and healthy volunteers in time after inhalation of budesonide. A downregulation was observed between 2 and 10 hours.

\subsection{Discussion}

Because of the lack of response of patients with COPD to glucocorticoids, the $\alpha 1$ and $\beta$ GR mRNA levels and ratios were investigated after use of glucocorticoids. In patients with COPD, the use of glucocorticoids did not result in modulation of gene transcription: no difference in $\alpha 1$ and $\beta$ GR mRNA levels and ratios was observed. Neither were the MT2 mRNA levels higher in patients using glucocorticoids than in controls. In both groups, a 1.7 times higher $\alpha 1$ GR mRNA expression was seen compared to the $\beta$ GR mRNA levels. Smoking did not appear to influence $\alpha 1$ and $\beta$ GR and MT2 mRNA levels in the bronchial epithelial cells. In contrast, in non-COPD controls and healthy volunteers, reversible downregulated GR mRNA and upregulated MT2 mRNA levels were demonstrated.

It has been shown, in healthy volunteers, that $\alpha 1$ and $\beta$ GR mRNA levels are 
downregulated by glucocorticoids, 2 hours after inhallation (147). This downregulation was preceded by an upregulation within the first 2 hours. Unclear was whether this upregulation was due to a direct effect of the inhaled budesonide, or to a delayed effect from the dose inhaled the evening before. In the present study it was demonstrated that the downregulation occurring after 2 hours was normalized within 10 hours. This indicates that the upregulation seen in the previous study (147) was due to a direct effect.

In a previous study we compared the $\alpha 1$ and $\beta$ GR mRNAs and ratios between patients with COPD and an age matched control group with no obstructive pulmonary disease. None of these subjects used glucocorticoids or $\beta_{2}$-agonists (except for 2 COPD patients) within 6 weeks before the bronchoscopy and we demonstrated that basal $\alpha$ GR mRNA levels were lower in patients with COPD. As shown in the present study, no downregulation in $\alpha 1$ and $\beta$ GR mRNA levels was observed in the bronchial epithelial cells of patients with COPD after exposure to ghucocorticoilds. Also no upregulation of MT2 mRNA levels was seen in these patients, indicating a lack in response to glucocorticoids. Since in patients with lung cancer and healthy volunteers, a reversible downregulated $\propto 1$ GR mRNA and upregulated MT2 mRNA expression was observed, the followed methodology is adequate.

In a recent study of Oakley and coworkers (57), the GR $\beta$ isoform was studied. Similar findings as compared to the study of Bamberger et al. (60) were found regarding the negative inhibitory function of the $\beta$ GR on the activity of the $\alpha$ form. Striking in this article was the observation that with Northern blot analysis three GR mRNA forms were present. Instead of the previously frequently mentioned $(58,89,157,158) \alpha$ GR mRNA (7 $\mathrm{kb})$ and $\beta$ GR mRNA ( $5 \mathrm{~kb}$ ), an $\alpha 1$ band of $7 \mathrm{~kb}$, an $\alpha 2$ band of $5.5 \mathrm{~kb}$ and $\mathrm{a} \beta$ band of $4.3 \mathrm{~kb}$ was demonstrated (57). In a previous study (147) we investigated the $1 \mathrm{GR}$ mRNA form, which was very abundantly expressed in both bronchial epithelial cells and alveolar macrophages and the $\beta$ band, which was also expressed in these cell types, although to a lesser extent. We determined the identity of these isoforms by the location of the $28 \mathrm{~S}$ and $18 \mathrm{~S}$ ribosomal bands. Occasionally in alveolar macrophages expressing higher amounts of GR, a third hybridisation signal could be discerned, although in much lower levels as compared to the other two GR mRNA forms. This band was located just above the $28 \mathrm{~S}$ band, whereas the $\beta$ form was situated on the low site of the $28 \mathrm{~S}$ band, in agreement with the study of Oakley and coworkers (57).

The recent discovery of the $\beta$ GR as a negative inthibitor of the $\alpha$ GR might be an important element in the poor response to glucocorticoids in steroid resistant asthma or 
COPD (57,60): Bamberger and coworkers (60) demonstrated in a model stady increasing inhibition of $50 \%$ to $85 \%$ on $\alpha / \beta$ ratios from 0.2 to 0.07 , respectively. Importantly the $\alpha 1 / \beta$ mRNA ratio in the present study was 1.7 , more than 10 fold bighe: rendering a possible inhibitory effect of the $\beta$ GR on GR-function unlikely in COPD. Therefore, the fact that no change in GR and MT2 mRNA levels was observed can not be explained by low $\alpha 1 / \beta$ mRNA ratios.

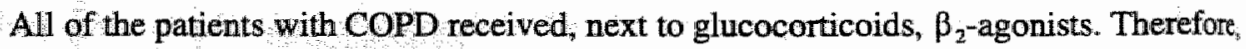
an interaction between transcription factors is a possible explanation for the non-response to glucocorticoids observed in patients with COPD. Cross-talk between CREB and GR, as described by Barnes and coworkers $(104,168,169)$, might result in capture of activated GR, unabling it to bind to DNA and proinflammatory transcription factors like AP-1 and NFFB in a functional way. Also the phosphorylated CREB is unable to bind DNA and this intermuption is probably of importance in the vanished GR downregulation. The GR promotor region consists of 5 CREs, 1 AP-1 and no GREs (91). Reduction of the GR gene transcription is likely to be caused by inhibition of the positive regulating effects of transcription factors like AP-1 or CREB instead of negative regulation of the GR itself (through negative GREs).

Inflammatory stimuli, like $I L 1 \beta, \Pi L 2, \amalg 4, I F N \gamma$ and LPS increase the number and decrease ligand binding affinity of GRs in vitro (170-173). It is known that in smokers and patients with COPD a general inflammatory process is present in the lungs (174), resulting in increased levels of inflammatory mediators like IL8 and TNF $\alpha(17,18)$. This may suggest that in vivo in patients with COPD and smokers, GR characteristics can be affected. In this study no correlation was found between GR mRNA levels and smoking or COPD. However, it is important to notice that no inflammatory mediators were measured. Therefore, in this study, it can not be excluded that the non-response of patients with COPD is due to the fact that we measured the GR downregulation from an upregulated position, caused by inflammatory mediators not present in the controls (174).

In the present study it is demonstrated that lack of responise to glucocorticoilds of patients with COPD is not due to an intrinsic problem of $\alpha 1$ and $\beta$ mRNA levels and ratios. What has not been examined, but might be an explanation for the non-response, is the amount of proinflammatory transciiption factors present in the cells. As demonstrated by Keatings et al. patients with COPD express higher amounts of IL 8 and TNF $\alpha$ in induced sputum (18). These cytokines are, as other inflammatory indices measured, not redueed after budesonide inhalation and prednisolone intake (175). Since both II\& and 
TNF $\alpha$ activate $A P 1$ and $N F K B$, an increased activation of these transcription factors in patients with COPD might be present. Like in steroid asthma (162), this may result in intra-cytoplasmic scavenging of all the activated GR, due to a disbalance in transcription factor amounts.

Smoking is known to induce neutrophilic inflammation in the airways (164), either by direct chemotactic effects of cigarette components, such as nicotine, or by the release of chemokines by alveolar macrophages (165). COPD is characterized by airway inflammation, represented by larger numbers of neutrophils in the bronchoalveolar lavage and induced sputum (18-20). A clear correlation exists between the amount of neutrophils present in induced sputum and the airway obstruction and decline in lung function $(18,21)$. Since the GR mRNA expression varies among different cell types, it is important to determine the cellular composition in the brush specimens. However, in this study, no increase in neutrophils or other inflammatory cell types was found in patients with COPD and smokers, indicating no misplaced GR gene expression in the cell type investigated. MT2 mRNA levels were also investigated, since heavy metals, present in cigarettes, increase the transcription of the MT2 gene (143). No change in MT2 gene expression was observed in bronchial epithelial cells of smokers compared to non-smokers, despite the fact that heavy metals, like cadmium, are present in cigarette smoke (167).

In conclusion, in contrast to the non-COPD patients, no evidence of GR mRNA downregulation was found in patients with COPD after chronic use of glucocorticoids, which is not explained by low GR mRNA levels or $\alpha 1 / \beta$ mRNA ratios. 



\section{SEVEN}

INTERACTION BETWEEN GLUCOCORTICOIDS AND $\beta_{2^{-}}$ AGONISTS: $\alpha$ AND $\beta$ GLUCOCORTICOID RECEPTOR mRNA EXPRESSION IN HUMAN BRONCHIAL EPITHELIAL CELLS 
$\begin{array}{lllll}3 & \vdots & \\ 4 & & \vdots\end{array}$

$\begin{array}{lll}\cdots & \vdots\end{array}$

$\therefore$. 
INTERACTION BETWEEN GLUCOCORTICOIDS AND $\beta_{2}$-AGONISTS: $\alpha$ AND $\beta$ GLUCOCORTICOID RECEPTOR MRNA EXPRESSION IN HUMAN BRONCHIAL EPITHELIAL CELLS

7.1 Introduction

7.2 Materials and methods

7.3 Results

7.4 Discussion 
1)

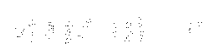




\section{Abstract}

Recent studies have suggested that regular use of $\beta_{2}$-agonists has adverse effects on asthma control. due to the cross-talk between AMP response element binding proteins (CREB) and glucocorticoid receptors (GR). The aim of this study was to investigate the interaction between GR and CREB on cytoplasmic protein level with a gel mobility shift assay and to determine the effect of this interaction on gene transcription by Northern blot analysis. After exposing human bronchial epithelial cells for 1 hour to either $\mathbb{L} \mu \mathrm{M}$ terbutaline or budesonide, more binding of CREB and GR, respectively, was observed to their responsive elements in DNA. Exposure to terbutaline and budesonide simultaneously, also increased the binding of CREB and GR to DNA. After 4 hours, both $\alpha$ and $\beta$ GR mRNAs. were downregulated by $1 \mu \mathrm{M}$ budesonide. Addition of $1 \mu \mathrm{M}$ terbutaline simultaneously, prevented this downregulation. Adding 100 times more budesonide compared to terbutaline, again downregulated both GR forms, although significantly less compared to the downregulation induced by $1 \mu \mathrm{M}$ budesonide alone. Addition of terbutaline to cells already exposed to budesonide did not reverse the GR mRNA expression within 44 hours. Similar results were obtained with MT2 mRNA levels. From our data we conclude that B2-agonist exposure interferes with the GR function in human bronchial epithelial cells when given simultaneously, which may be overcome by sequential administration of glucoconticoids and B2-agonist. 



\section{Introduction}

Inhaled $\beta_{2}$-adrenergic agonists are the most effective bronchodilators at present, and bave long been used as primary therapy for the treatment of asthmatics. However, since the awareness of asthma as being a chronic inflammatory disease of the airways emerged, inhaled glucocorticoids have become the mainstay of treatment. Today, $\beta_{2}$-adrenergic agonists and glucocorticoids are often used in combination for the treatment of asthma. However, despite the more widespread use of inhaled $\beta_{2}$-agonists and glucocorticoids, mortality and morbidity from asthma has increased. It is thought that glucocorticoids and $\beta_{2}$-adrenergic agomists function antagonistic in their control of asthma (176). However, glucocorticoids sometimes appear able to diminish or reverse the negative effects of $\beta_{2}$ agonists on asthma control, but reports on this are limited $(177,178)$. Therefore, the underlying mechanisms remain to be elucidated.

Exposure of cells to glucocorticoids or $\beta_{2}$-adrenergic agonists, results in the activation of two separate signal transduction pathways in these cells. The glucocorticoid receptor (GR), which exists in an $\alpha$ and a $\beta$ form, plays a central role in the function of glucocorticoids (45). After entering the cell by passive diffusion, glucocorticoids bind to an inactive GR which then becomes activated (44). Gene transcription is regulated by binding of a GR dimer to glucocorticoid responsive elements (GRE) in the DNA (128). The $\beta_{2}$-adrenergic agonists on the other hand, bind to a cell membrane bound receptor, which, after binding of the ligand, activates the receptor-associated stimulating $\mathrm{G}$-protein (179). Subsequent production of cyclic $3^{\prime}-5^{\prime}$-adenosine monophosphate (cAMP) leads to phosphorylation of the cAMP response element binding proteins (CREB) (180), which can regulate gene transcription by binding to cAMP responsive elements (CRE) in the DNA (181). The modulation of gene transcription not only depends on the presence or absence of responsive elements in the genes, but also on the direct interaction between transcription factors (25). Direct protein-protein interaction of the GR is described with CREB $(104,106,107)$. In addition, the activated GR is also capable of binding with other transactivation proteins such as activator protein-1 (AP-1) $(98,99)$, nuclear factor $\mathrm{kB}$ (NFKB) (102,103), and signal transducers and activators of transcription 5 (Stat5) (108). Especially crosstalk of the GR with AP-1 or NFKB is now believed to play an essential role in the reduction of cytokine production, an important aspect of the anti-inflammatory action of glucoconticoids $(1,96)$. 
Scavenge of the GR by CREB before binding to DNA may be one explanation for a possible anti-glucocorticoid activity of $\beta_{2}$-adrenergic agonists. Cross-talk between CREB and GR has been demonstrated before in rat and human lung $(104,168)$, rat hepatoma cells (105), placental cells $(106,107)$, and human pulmonary and bronchial epithelial cells (169). In three studies $(104,168,169), \beta_{2}$-adrenergic agonists were used to demonstrate interactions between GR and CREB. No studies have been performed in which changes in mechanisms occurring on a cellular level or in gene transcription are demonstrated, after exposing cells simultaneously to glucocorticoids and $\beta_{2}$-adrenergic agonists.

The purpose of this study was to investigate a possible effect of $\beta_{2}$-adrenergic agonists on the action of glucocorticoids. To this end we exposed a human bronchial epithelial cell line to terbutaline and budesonide separately as well as simultaneously. Gel mobility shift assays were performed to determine the binding of GR and CREB to their responsive elements in the DNA. The effect of this interaction was studied by measuring the $\alpha$ and $\beta$ GR mRNA expression.

\subsection{Materials and methods}

\section{In vitro experiments:}

Bet1A, a human bronchial epithelial cell line transformed by the SV40 virus (133), was cultured in LHC-8 medium containing $2 \times 10^{-7}$ M hydrocortisone (LHC-8+, Biofluids, Rockville, MD) and an addition of $3.30 \mathrm{mM}$ retinoic acid and $5.46 \mathrm{mM}$ epinephrine (134). During the experiments LHC-8 medium without hydrocortisone (LHC-8-, Biofluids, Rockville, MD) was used without the additives. Budesonide (Astra, Zoetermeer, the Netherlands) was dissolved in $10 \mathrm{ml} 100 \%$ alcohol to a concentration of $10^{-2} \mathrm{M}$. Terbutaline (Astra, Zoetermeer, the Netherlands) was dissolved in $10 \mathrm{ml}$ DMSO to $10^{-2} \mathrm{M}$. Before addition of the $\beta_{2}$-adrenergic agonist terbutaline, or the glucocorticoid budesonide, cells were preincubated during 24 hours with the LHC-8- medium in order to create a balanced startpoint. Separate experiments were performed to investigate the gene transcription and the transcription factor-DNA binding. The experiments were planned with harvesting of the cells at approximately $70-85 \%$ confluency and were performed in two to fourfold. Controls for terbutaline contained equivalent amounts of DMSO. To the controls for budesonide equal amounts of $100 \%$ alcohol were added. 


\section{Gene transcription:}

Hit and Run. In order to mimic the in vivo situation, a short term exposure to terbutaline was performed. With this "hit and run" phenomenon (147) cells were incubated with $1 \mu \mathrm{M}$ terbutaline for one hour in fresh LHC-8- medium and subsequently cultured in LHC-8-medium alone for different incubation times $(1,2,3,4,5,6,12 \mathrm{hrs})$. Incubation of the control samples was performed at every time point sampled.

Continuous exposure: During the continuous time experiment incubation times of 1,2 , $3,4,5,6$ and 12 hours with a terbutaline concentration of $1 \mu \mathrm{M}$ were used. Control samples consisted of only DMSO and were taken at equal time points.

Intervention: To study the interaction of terbutaline and budesonide both hormones were simultaneously added to Bet $1 \mathrm{~A}$ cells for 4 hours. The compounds were added to the cells in an equimolar concentration of $1 \mu \mathrm{M}$ or with 100 times lower concentration of terbutaline. In a separate experiment the reversibility of the known GR mRNA downregulation by budesonide (147) was studied by adding, after four hours, terbutaline to the cells for different lenghts of time. Thus after 4 hours, budesonide and terbutaline were simultaneously present in the culture medium. In the controls DMSO was added without removing the budesonide.

\section{RNA-isolation, Northern blotting and hybridization:}

RNA was isolated from the cells as deseribed before by Kom et al (147). In shont: After removal of the culture medium Bet1A cells were harvested by adding $8 \mathrm{ml}$ of a $4 \mathrm{M} \mathrm{GTC}$ solution directly into the tissue culture plates. Total RNA was isolated by the GTC/CsClmethod and $20 \mu \mathrm{g}$ was run on Northern blot. The GR, Glyceraldehyde-3-phosphate dehydrogenase (GAPDH) and metallothionein (MT2) probes were subsequently hybridized. Both $\alpha$ and the $\beta$ form are detected with the GR probe. Sample signals were analyzed visually as well as semiquantitatively with a phosphorimaging system (Molecular Dynamics, Sunnywale, CA). GR and MT2 mRNA levels were expressed relative to GAPDH levels of the same sample and were compared to control samples at each time point.

\section{Electrophoretic mobility shifi assays (EMSA):}

Intervention: To study the binding of GR and CREB to DNA, cells were exposed for 1 hour to budesonide and terbutaline, respectively. As in the previous experiments, concentrations of $1 \mu \mathrm{M}$ terbutaline and budesonide were used. 
Protein isolation and mobility shift assays:

Gel mobility shift studies were performed as described before by Adcock an coworkers (129), with slight modifications: Cytoplasmic proteins were isolated ; described and $5 \mu \mathrm{g}$ was used for the EMSA. Double stranded GREs (5 $5^{\prime}$-TCGACTGTA AGGATGTTCTAGCTACT-3) and CREs (5'-AGAGATTGCCTGACGTCAGAG GCTAG-3) were endlabeled with ( $\left.\gamma-{ }^{32} \mathrm{P}\right) \mathrm{ATP}$ and $50 \mathrm{ng}$ GRE and $80 \mathrm{ng}$ CRE wes added per reaction. Proteins and labeled responsive elements were incubated for 2 minutes at room temperature in $30 \mu \mathrm{l}$ buffer containing $4 \%$ glycerol, $100 \mathrm{mM} \mathrm{NaCl}, 1 \mathrm{ml}$ EDTA, $1 \mathrm{mM}$ DTT, $10 \mathrm{mM}$ tris-HCL ( $\mathrm{pH} 7.5$ ), and $0.8 \mathrm{mg} / \mathrm{ml}$ sonicated salmon sper DNA. As negative control a sample was added without proteins. In order to check $t$ specificity of the binding, 100 times excess unlabeled, cold GRE or CRE was use respectively. As a control double stranded oligonucleotides of the MT2 gene (5"-GGGG GTCCTCACAATGGTGTA-3) were also added unlabeled. The samples were separat on a $6 \%$ polyacrylamide gel (29:1) for 4 hours at $200 \mathrm{~V}$ in $0.25 \times$ TRIS-borate EDT running buffer. After vacuum drying the samples for 2 hours at $80^{\circ} \mathrm{C}$, the gell w analyzed semi-quantitatively with a phosphorimaging system (Molecular Dynamics).

\section{Statistics:}

For all studies mean \pm standard deviation (SD) was calculated and the Mann-Whitn $\mathrm{U}$ test was performed to determine possible differences. Differences of $\mathrm{p}<0.05$ we considered statistically significant.

\subsection{Results}

\section{Gene transcription:}

To observe the effect of terbutaline on the GR gene transcription, two different ti experiments were performed with $1 \mu \mathrm{M}$ terbutaline. With the "hit and nun" experimen no difference in both $\alpha$ and $\beta$ GR mRNA expression was obtained, except for a sliq downregulation of the $\beta$ GR gene expression after 4 hours (figure 1 ). 


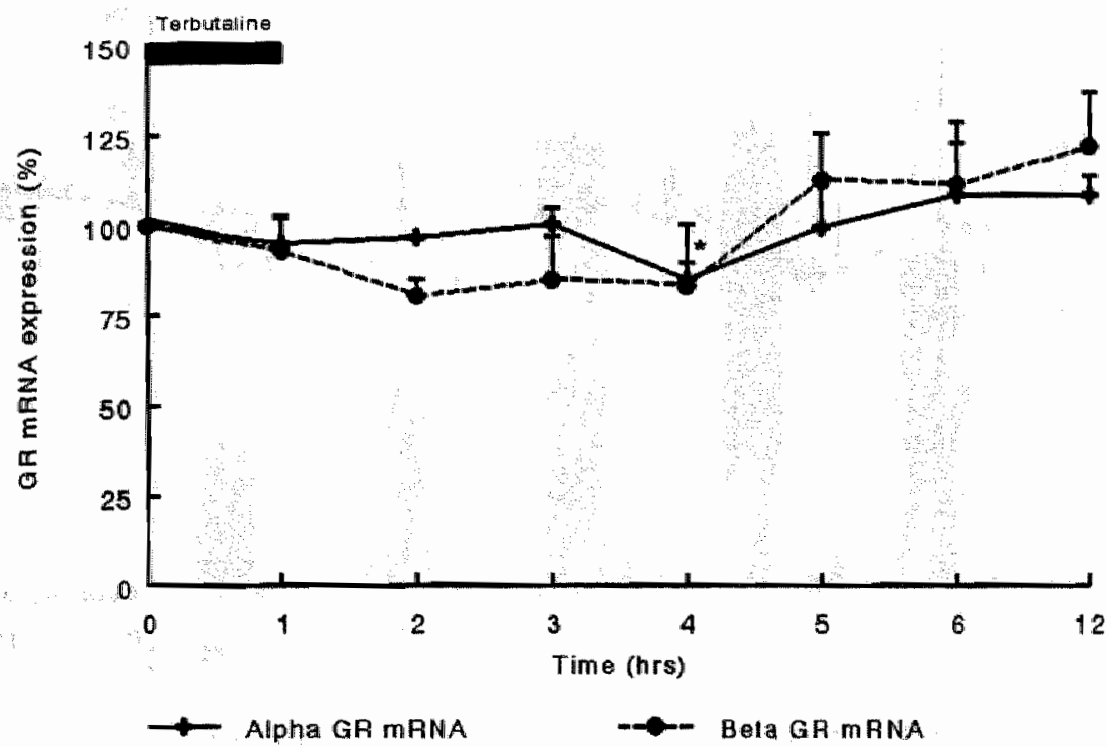

Figure 1: The glucocorticoid receptor mRNA expression is shown after exposure of bronchial epithelial cells for 1 hour to $1 \mu \mathrm{M}$ terbutaline. The cincles represent the $\alpha$ GR mRNA, the triangels the $\beta$ form. No change in both $\alpha$ and $\beta$ GR mRNAs is observed in time. Represented are the means \pm standard deviations of $2-4$ experiments $(*=p<0.05)$.

Since a 1 hour exposure might be too short to obtain transcriptional modification of the GR by terbutaline, a continuous time experiment was performed with $1 \mu \mathrm{M}$ terbutaline for up to 12 hours. GR mRNA levels varied slightly along baseline values (figure 2), with a small but significant upregulation after 3 hours for $\beta$ GR mRNA. Thus, terbutaline alone appears to have no essential effect on GR mRNA levels. 


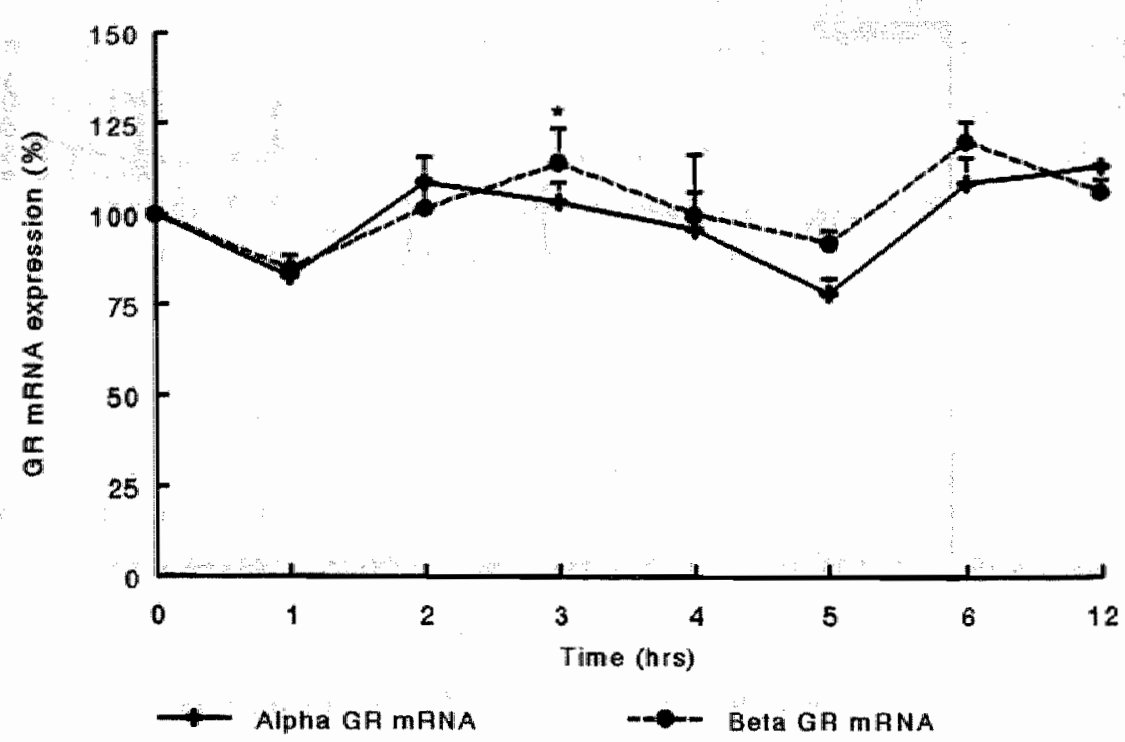

Figure 2: Continuous exposure of bronchial epithelial cells to $1 \mu \mathrm{M}$ terbutaline did not change both $a$ and $\beta$ GR mRNAs in time. Given are means and standard deviations of $2-4$ experiments ( ${ }^{*}=$ $\mathrm{p}<0.05$ ).

Exposure of the cellls to budesonide alone for 4 hours, downregulated both $\alpha$ and $\beta$ GR mRNAs $(p<0.05)$. Simultaneously exposing cells for 4 hours to terbutaline and budesonide, in equimolar concentrations, did not change GR mRNA levels (figure 3). Addition of 100 times more budesonide to terbutaline again significantly downregulated both GR mRNAs ( $\mathrm{p}<0.05$ ), but to a lesser degree than budesonide alone. The inhibition of the budesonide induced downregulation by terbutaline was thus dose dependent. 


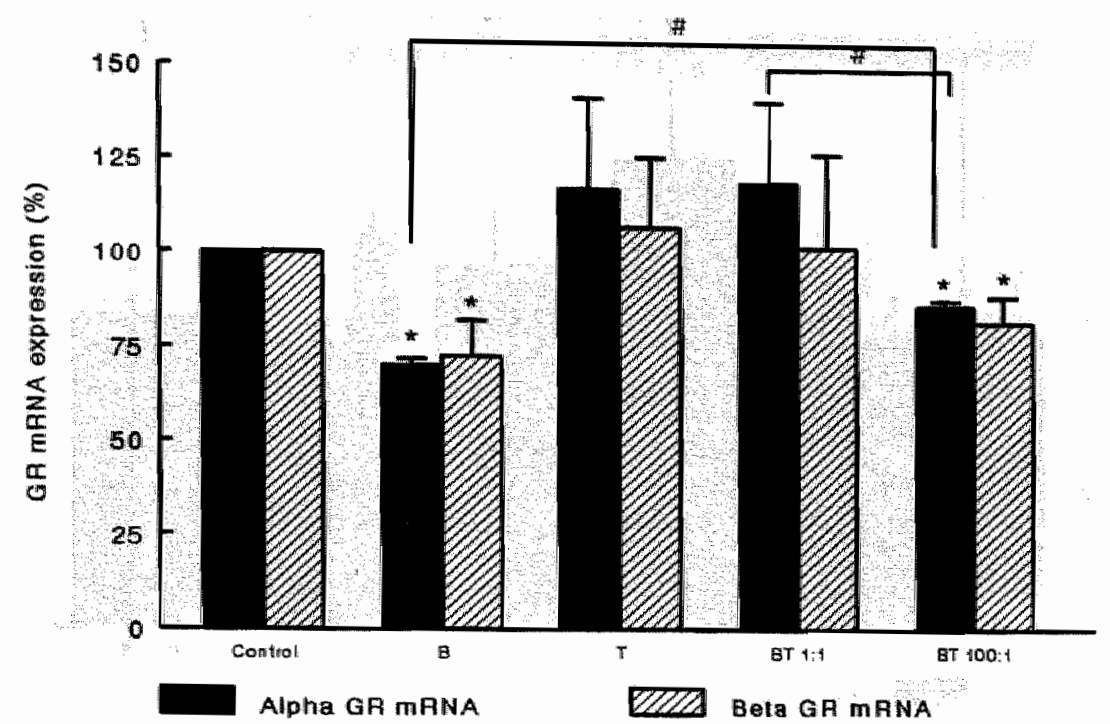

Figure 3: The intervention between budesonide (B) and terbutaline (T) is shown. After exposing cells to $1 \mu M$ budesonide for 4 hours a downregulated $\alpha$ and $\beta$ GR mRNA expression was observed. Simultaneously adding equal amounts of terbutaline to the cells prevented this GR mRNA downregulation. Addition of 100 times less terbutaline restored the downregulatory capacity of budesonide, although to a lower level than obtained with budesonide alone ${ }^{*}=$ $p<0.05$ compared to control), $\#=p<0.05$ ).

To demonstrate that this inhibition of GR function by budesonide was not limited to the GR gene, MT2 mRNA levels, usually upregulated by glucocorticoids, were determined. Similar results were obtained (figure 4): terbutaline alone had no effect on MT2 mRNA levels after 4 hour exposure of the cells. However, the budesonide induced upregulation of the MT2 mRNA was inhibited by terbutaline when added in equimolar concentrations. Exposure of the cells to 100 times more budesonide again upregulated MT2 mRNA levels $(\mathrm{p}<0.05)$, but to a lesser extent as with budesonide alone. 


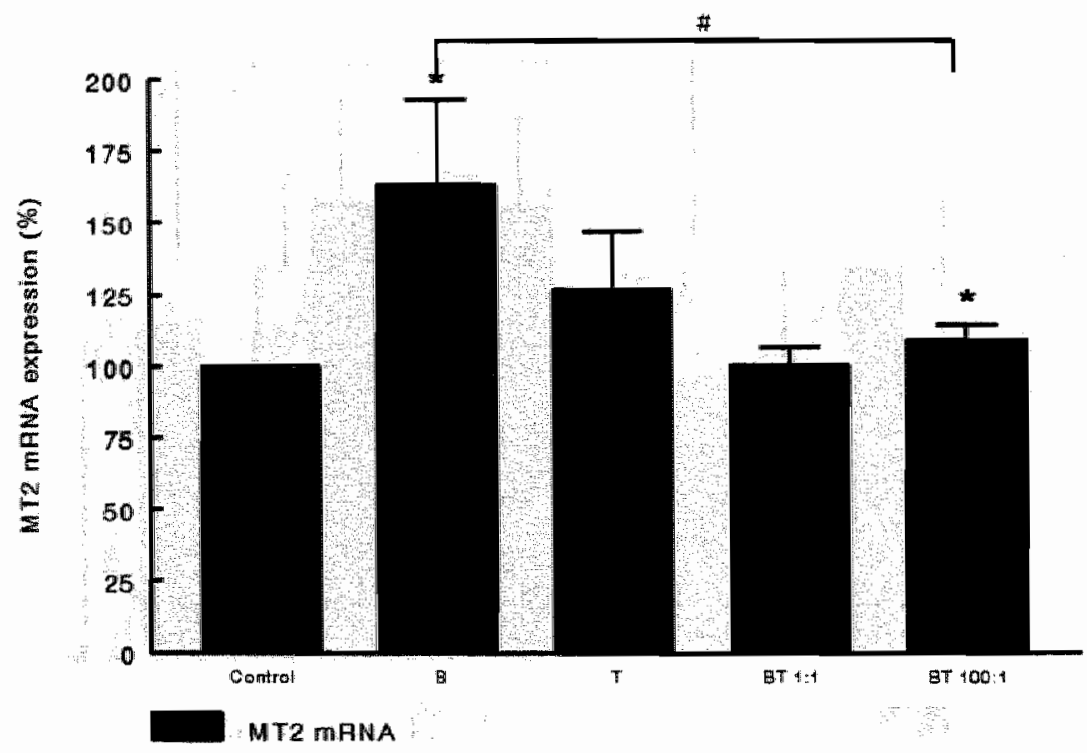

Figure 4: MT2 mRNA levels in cells exposed to budesonide and terbutaline separately and simultaneously for 4 hours. A dose-dependent inhibition of the budesonide induced upregulated MT2 mRNA level was demonstrated by terbutaline. For an explanation of the symbols see figure 3 .

To test whether this interaction would also occur after the budesonide induced GR mRNA downregulation had already taken place, terbutaline was added to the bronchial epithelial cells after 4 hours preincubation with budesonide alone. The GR mRNA downregulation induced by budesonide, present after 4 hours, was not reversed to preexposure levels by subsequent simultaneous incubation of the cells to budesonide and terbutaline up to 44 hours (figure 5). 


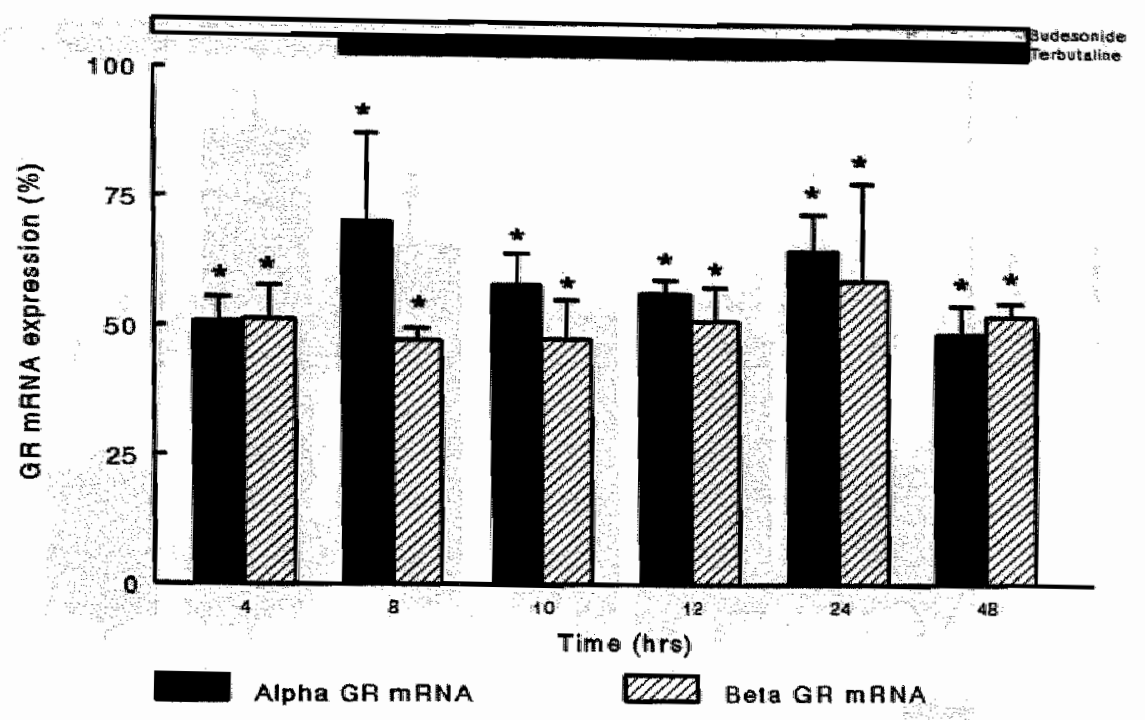

Figure 5: After establishing a downregulation of $\alpha$ and $\beta$ GR mRNA, by exposing bronchial epithelial cells for 4 hours to budesonide, incubation of terbutaline combined with budesonide did not reverse the downregulation up to 44 hours $(*=p<0.05)$.

Similar results were obtained for the MT2 mRNA levels (figure 6). The budesonide induced upregulation of the MT2 mRNA was not reversed by terbutaline within 44 hours. Although it seemed that after 44 hours the MT2 mRNA levels returned to the $100 \%$ preexposure level. 


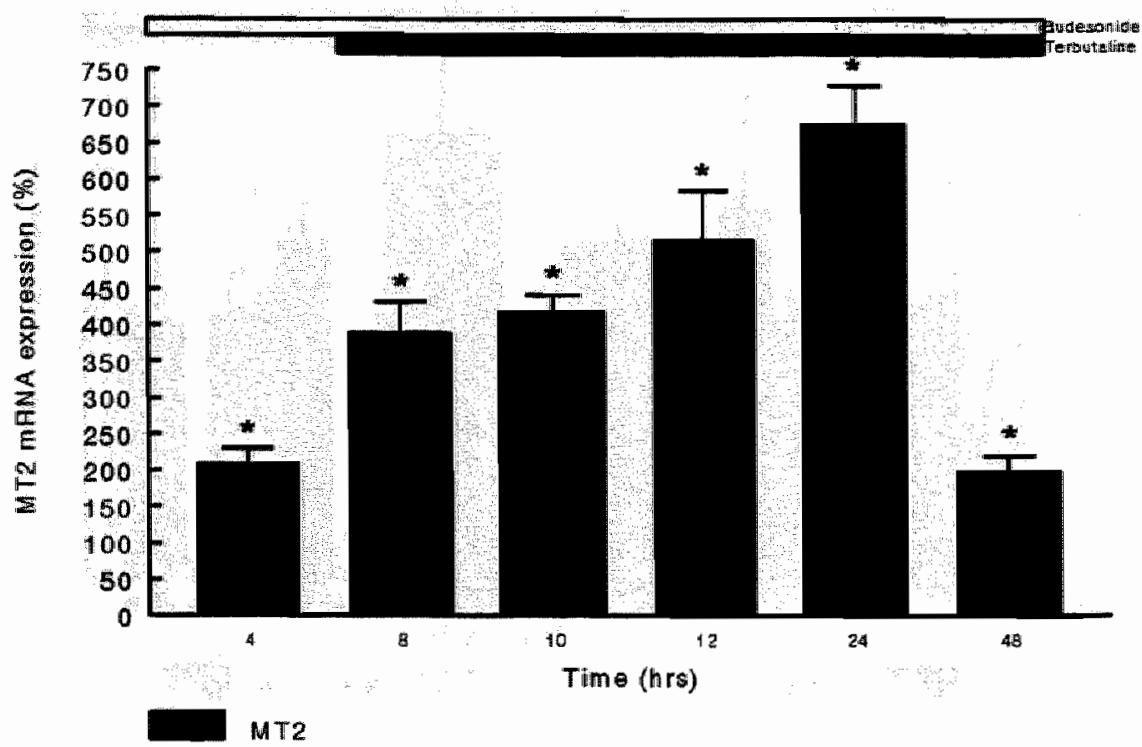

Figure 6: The budesonide induced upregulated MT2 mRNA levels after 4 hours were not reversed b? combined terbutaline and budesonide exposure up to 44 hours $(*=p<0.05$ ).

\section{EMSA:}

To test whether the disturbance of the GR and MT2 gene transcription observed afte addition of terbutaline and budesonide simultaneously to epithelial cells was due to at interaction of the transcription factors GR and CREB, an electrophoretic mobility shif assay was performed. To this end, cells were exposed to either budesonide or terbutalin or to budesonide and terbutaline simultaneously, for $\mathbb{1}$ hour and cytoplasmic proteins wen isolated. Specificity of the signal was tested by addition of unlabeled GRE, CRE or contro DNA not representing any responsive element (MT2 oligonucleotides). Cells exposed t budesonide showed an increased binding of GR to GRE. Exposure to terbutaline resulte in an increase of CREB binding to CRE. Simultaneous exposure to equimola concentrations of budesonide and terbutaline increased the binding of both transcriptio factors to GRE and CRE equally (figure 7), indicating protein interaction. Protein-GR] bindings were strongly inhibited by 100 times excess unlabeled GRE and CRE, but not $b$ the unspecific control DNA. Similar results were obtained for the protein-CRE bindin 
which was also inhibited by both responsive elements and not by MT2 oligonucleotides.

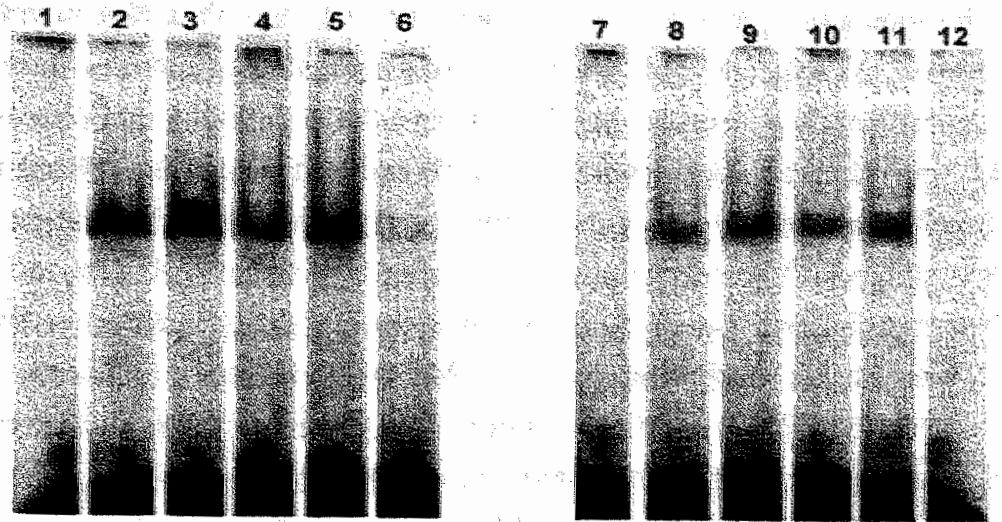

Figure 7: Gel mobility shift assays demonstrated a cross-talk between GR and CREB. In lanes 1-6 binding to GREs is shown. Lanes 7-12 represent binding of transcription factors to CREs. To lanes 1 and 7 no proteins are added. Lane 2 represents the control of the in lane 3 shown budesonide exposed cells, Lanes 4 and 10 represent the controls of the cells exposed to budesonide and terbutaline simultaneously, shown in lanes 5 and 11 . Lanes 6 and 12 are similar to lane 3 and 9, except for the addition of 100 times unlabeled GRE or CRE, respectively. Lane 8 represents the control of the terbutaline exposed cells, as seen in lane 9 . 


\subsection{Discussion}

In this study the interaction between glucocorticoids and $\beta_{2}$-agonists was investigated at transcriptional level. As expected (147), exposure of a bronchial epithelial cell line to 1 $\mu \mathrm{M}$ budesonide, significantly downregulated both $\alpha$ and $\beta$ GR mRNAs. No change in $\alpha$ and $\beta$ GR mRNA was observed after exposing the cells to $1 \mu \mathrm{M}$ terbutaline. Simultaneous incubation of bronchial epithelial cells with equimolar concentrations of budesonide and terbutaline, prevented the budesonide induced dose dependent downregulation, indicating an interaction between the two signal transduction pathways. This interaction between CREB and GR was further supported by the EMSA-experiments. However, initial downregulation of the $\alpha$ and $\beta$ GR mRNA by budesonide, was not reversed by subsequent treatment with a combination of budesonide and terbutaline. Similar results were obtained with the control gene, MT2, which is upregulated by glucocorticoids.

The downregulation of both GR mRNAs triggered by budesonide is a well known phenomenon and has been demonstrated before in this cell type (147). However, the physiologic significance of this downregulation is still not known and has to be further evaluated. Activation of cAMP may also lead to modulation of GR mRNA levels (182: since five CRE-sides have been demonstrated in the promotor region of the GR (91). In re: hepatoma cells, exposure to 8-bromo-cAMP for 5 hours resulted in an increase in GR mRNA, due to an increased GR mRNA stability (182). Since $\beta_{2}$-agonists increase intracellular cAMP levels, modulation of GR mRNA expression might be expected after exposing cells to $\beta_{2}$-adrenergic agonists. In this study no direct effect of terbutaline on the GR mRNA levels was observed. However, we demonstrated that simaltaneous incubation with equimolar concentrations of terbutaline resulted in an inhibition of the budesonide induced GR mRNA downregulation. This inhibition was dose dependent since addition of 100 times more budesonide again downregulated both GR mRNAs, but to a lesser extent than with budesonide alone. The inhibition of GR mediated gene transcription due to interaction with other transcription factors has been shown before for CREB (105-107), AP-1 $(98,99)$, NFkB $(102,103)$ and Stat5 (108). Interestingly, addition of terbutaline to cells already exposed to budesonide for 4 hours, did not reverse GR mRNA downregulation. Similar results were obtained with MT2 mRNA. The fact that GR mRNA downregulation and MT2 mRNA upregulation continued for a longer period of time, 
despite the addition of terbutaline, suggests that the activated DNA bound transcription factors present are not inhibited by binding to other transcription factors.

There is, at present, controversy as to whether regular treatment with $\beta_{2}$-agonists reduces overall asthma control, since despite the use of inhaled $\beta_{2}$-agonists and glucocorticoids, morbidity and mortality of asthma has increased worldwide (176). An explanation for the detrimental effects of $\beta_{2}$-adrenergic agonists on asthma control might be found in the interaction between CREB and GR, which has also been demonstrated by Barnes and coworkers $(104,168,169)$. Rat and human lung were exposed to albuterol and dexamethasone, which resulted in a reduced binding of both transcription factors to their responsive elements. In the present study we also demonstrate an interaction between CREB and GR in bronchial epithelial cells, since the proteins arising after exposure to terbutaline and glucocorticoids were able to bind both labeled GRE and CRE. Another support for this interaction is that the GRE and CRE signals not only disappeared with their own unlabeled responsive elements, but also with 100 times more of the other responsive element. However, contrary to the studies by Barnes and coworkers, an increased binding of this complex to DNA was demonstrated after simultaneous exposure to terbutaline and budesonide. These paradoxal results may be explained by the fact that in the above mentioned studies $(104,168,169)$ proteins were isolated from the nucleus and in the present study the proteins were of cytoplasmic origin. Combining these data strengthens the notion of a cross-talk between GR and CREB transcription factors in the cytoplasm and not in the nucleus, suggesting that cytoplasmic transcription factor complexes do not enter into the nucleus. This is supported by a study of Adcock et al. $(109,110)$, in which exposure of cells simultaneously to dexamethasone and PMA/TNF $\beta / \mathrm{IL} 1 \alpha$ results in cross-talk between the GR and NFKB and/or AP-1 in the cytoplasm. The surprising findings that 1) in the EMSA assays the GRE and CRE bands are on the same level and 2) the GRE and CRE are mutual inhibitors of GR and CREB DNA binding, suggest that these interacting proteins are part of a larger protein complex. An explanation for the cytoplasmic localization may be that the nuclear localization signals from the individual transcription factors, necessary for nuclear influx $(54,55)$ are blocked due to the protein-protein interactions. Alternatively, the size of the protein complex may be too large to enter the nuclear pores (183). In figures 8a-c schematic presentations are provided of the hypothesis about the interaction between CREB and GR. 
A:

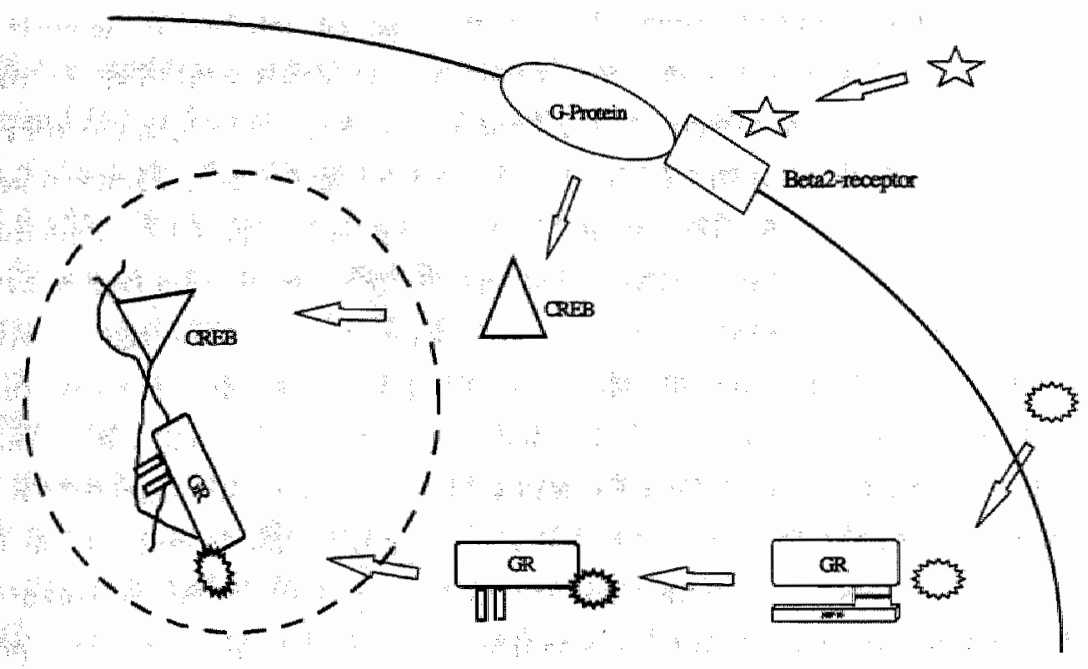

B:

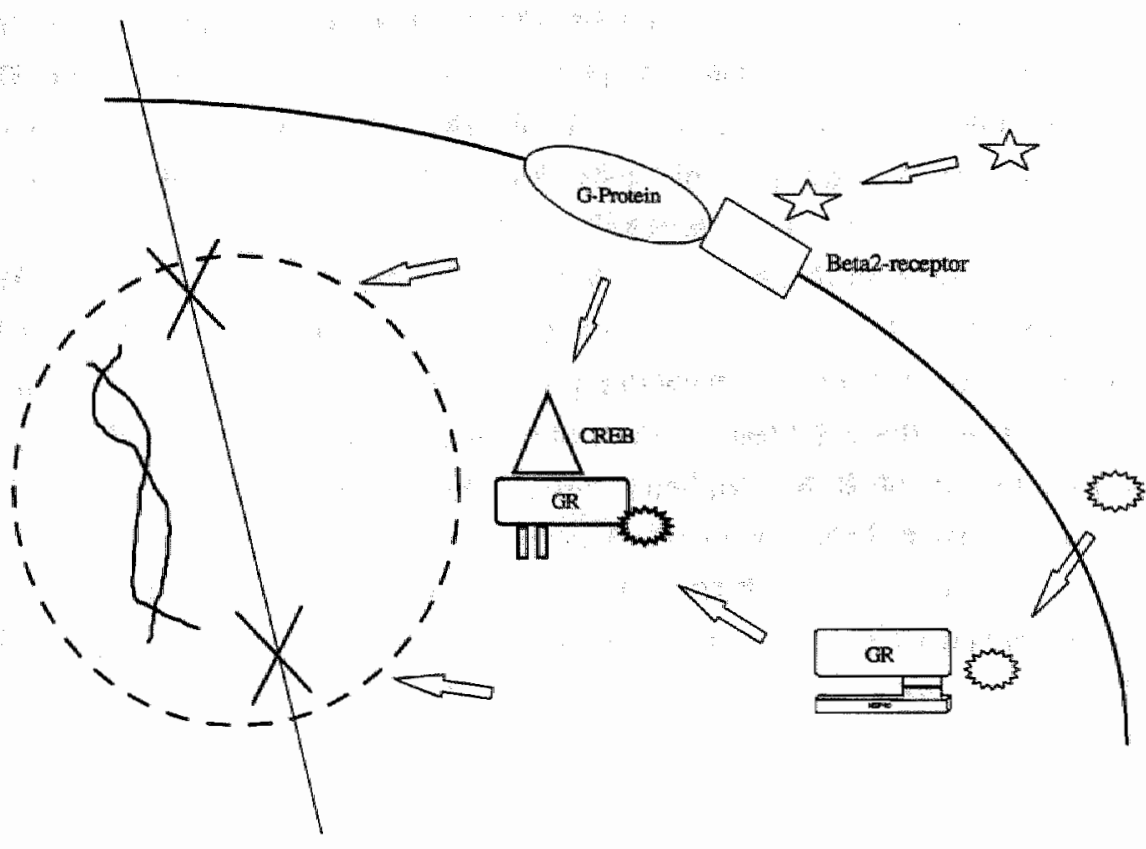


$\mathrm{C}$

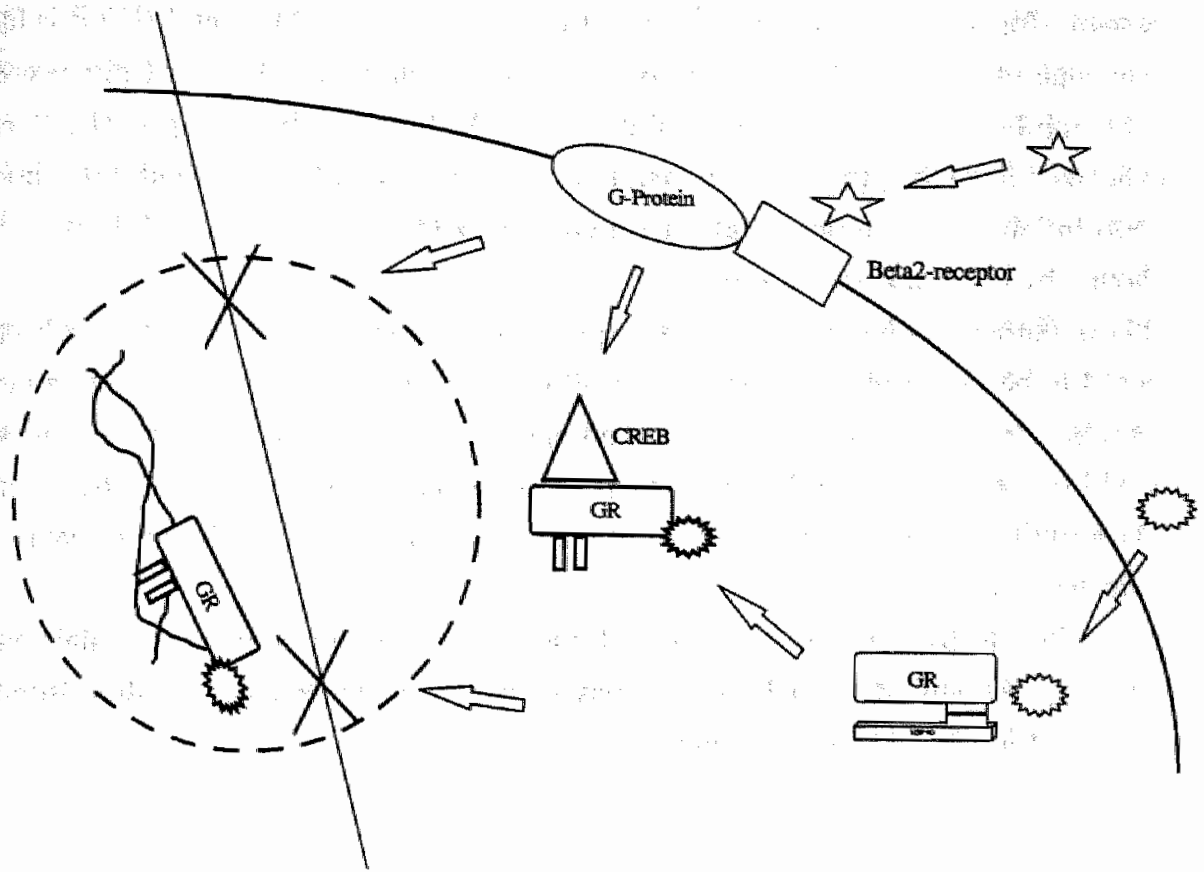

Figure 8: Proposed mechanism of cross-talk between CREB and GR: a) Signal transduction pathways after separate exposure of cells to budesonide or terbutaline. b) Interaction between CREB and GR after simultaneous exposure to budesonide and terbutaline. c) Exposure of cells to budesonide, followed by exposure to budesonide and terbutaline simultaneously.

Extrapolation of the results to the in vivo situation depends on the time span. On the long term, the effect of higher GR mRNA levels is as yet unclear and is dependent of the presence of several transcription factors, playing a pathophysiologic role in diseases like asthma. On the short term, simultaneous inhalation of glucocorticoids and $\beta_{2}$-adrenergic agonists induces an interaction of transcription factors, thereby disturbing the regulation of gene transcription caused by glucocorticoid treatment alone. In this, the modulation of GR and MT2 mRNA can be looked upon as one of the effects of glucocorticoid treatment. In asthma several cytokines play a role which are inhibited in their expression by glucocorticoids (for review see Brattsand (112)). This inhibition occurs by binding of the 
activated GR to transcription factors AP-1 and NFikB which induce the cytokine mRNA expression (for review see Barnes (96)). If the cross-talk with AP-1 and NFKB is blocked by scavenge of activated GR by CREB, the anti-inflammatory effects of glucocorticoids may be inhibited. To avoid the inhibition of GR function by $\beta_{2}$-agonists, it can be hypothesized from the present study that, to allow beneficial effects of both bronchodilator and anti-inflammatory agonists, glucocorticoids should be inhaled first, followed, after a few hours, by inhalation of $\beta_{2}$-agonists.

This hypothesis is based on in vitro experiments, where the dose of the medication is supposed to be uniformly distributed over all cells. However, in the human lung the drug deposition after inhalation will be non-homogeneous and it is not likely that all airway cells will be exposed to similar doses of $\beta_{2}$-agonists and glucocorticoids. Thus a mixture of transcription effects may occur in vivo. However, this hypothesis remains to be investigated in a clinical study.

In conclusion, $\beta 2$-agonists interfere with the GR function in human bronchial epithelial cells when given simultaneously, which may be overcome by sequential administration of first glucocorticoids and later $\beta 2$-agonists. 


\section{EIGHT}

\section{CONCLUDING REMARKS}


-

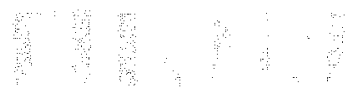

$\therefore$ 


\section{CONCLUDING REMARKS}

8.1 Introduction

8.2 Technical aspects

8.3 Glucocorticoid receptor mRNA in human bronchial epithelium

8.3.1 Time dependent downregulation of the glucocorticoid receptor $m R N A$

8.3.2 Glucocorticoid receptor mRNA levels in COPD

8.3.3 Interaction of the glucocorticoids with $\beta_{2}$-agonists

8.4 Transcription factor model

8.5 The future 


\subsection{Introduction}

It is generally accepted that the bronchial epithelium plays a central role in inflammatory processes of the lung. However, its function in the anti-inflammatory actions of glucocorticoids is less clear. Glucocorticoids are frequently used in the treatment of asthma to reduce inflammation, but the molecular mechanism behind this action is not elucidated yet. The GR mediates the action of glucocorticoids. It exists in an $\alpha$ and $\beta$ form, of which only the $\alpha$ GR has intensively been studied. Since it has been demonstrated, in a model system, that the $\beta$ GR can inhibit the activity of the $\alpha$ form, the non-ligand binding form has become a subject of interest. By studying the $\alpha$ and $\beta$ GR expression in bronchial epithelial cells and the modulation of both receptor forms by glucocorticoids, more insight can be gained in the role of this cell type in antiinflammatory processes and the molecular mechanism behind glucocorticoid action. Therefore, the aim of the present thesis was to investigate both $\alpha$ and $\beta$ GR in human bronchial epithelial cells.

This final chapter consists of several paragraphs, each addressing another subject. Firstly, technical aspects of the study are mentioned. Secondly, the most interesting results are summed up and discussed. Thirdly, a hypothetical model is given for the gene regulation of the GR, which is extended to gene transcription of transcription factors in general. Fourthly, ideas for further research are presented.

\subsection{Technical aspects}

A good approach to study the $\alpha$ and $\beta$ GR in bronchial epithelial cells would be to determine the GR expression on protein level. However, thusfar it has not been possible to separately investigate $\alpha$ and $\beta$ GR proteins in vivo in bronchial epithelial cells because of two restrictions. First of all, antibodies detecting either $\alpha$ or $\beta$ GR protein were not available at the beginning of this study. Recently, an antibody detecting the $\alpha$ form has become commercially available, but this is still not the case for the $\beta$ GR protein. Secondly, for the study of protein levels with Western blotting or receptor binding studies, large numbers of cells need to be sampled. In Western blot analysis often $100 \mu \mathrm{g}$ protein per lane is used, although occasionally less $(40 \mu \mathrm{g})$ protein is needed for a reliable signal 
$(57,111,131)$. Alternatively, the use of receptor binding studies usually requires over $10^{6}$ cells per assay $(146,170,171)$. Since, in the in vivo situation, we were restricted in the amount of brushes that can be obtained from a single patient, a choice in approach had to be made. However, EMSA analysis, which requires less proteins; was suitable for this study and used to determine differences in transcription factor binding to DNA after exposing cells to various stimuli.

In vivo studies performed so far, investigating gene expression in bronchial epithelial cells, have been limited in their methodology because of the small number of cells obtained. An option is the ex vivo culture of the specific cell types $(7,8)$. However, in these circumstances cells lack the influences from the original environment, which limits extrapolation of the results to the in vivo situation. To study mRNA from the $\alpha$ and $\beta$ GR, RT-PCR $(6,11)$ or Northern blot analysis can be performed. Northern blot analysis requires more total RNA compared to RT-PCR techniques but has technical advantages over RT-PCR. In this study (chapter 2) a method for isolating total RNA from brush samples was modified, resulting in a high yield of mRNA, which allowed investigation of mRNA directly from human bronchial epithelial cells. This modification was used for all in vivo experiments, described in the following paragraphs.

\subsection{Glucocorticoid receptor mRNA in human bronchial epithelium}

\subsection{1: Time dependent downregulation of the glucocorticoid receptor mRNA:}

At the start of this study, no information was available about the GR mRNA expression in bronchial epithelial cells, despite the fact that this cell type plays a central role in asthmatic reactions. Also no investigation had been performed regarding the $\beta \mathrm{GR}$ mRNA, which is known to negatively inhibit the function of the $\alpha$ GR. Additionally, in most studies, autoregulation of the GR in vitro was investigated by continuously exposing cells to glucocorticoids. However, after inhaling glucocorticoíds; a sharp increase and : subsequent rapid decline (75\% within 1 hour) of the glucocorticoid concentration occurs within the lung. In order to mimic the in vivo situation a new approach was used in vitrc (135-137). With this so called "hit and run" method, cells are exposed to budesonide for : short period, after which the experiment continues for several hours without the glucocorticoid. In this study, $\alpha$ and $\beta$ GR mRNA levels and ratios were determined in bronchial epithelial cells in vitro and in vivo before and after modulation with budesonide. 
In an in vitro as well as in vivo condition, a time dependent downregulation of both $\alpha$ and $\beta$ GR mRNAs was demonstrated. In vivo, in healthy volunteers a downregulation occurred after 2 hours, which was normalized within 12 hours. The downregulation observed with the "hit and run". method was shorter and less pronounced compared to the traditional continuous exposure to cells, which resulted in a constant downregulation. A strong resemblance was observed in GR gene response to glucocorticoids between the "hit and run"? method and the in vivo situation, indicating that this in vitro approach is better for the extrapolation to humans than continuous exposure. This "hit and run" technique should be used more often in in vitro studies when performing experiments with drugs rapidly transported out of the lungs. There was one difference between the "hit and run" experiment and the in vivo situation: in vivo, the $\propto$ GR MRNA downregulation was preceded by an upregulation within the first 2 hours. It was unclear whether this upregulation was due to a short-term direct effect of the budesonide inbaled just before the bronchoscopy, or due to a delayed effect from the dose inhaled the night before:

In order to better understand the biphasic GR mRNA expression pattern demonstrated in bronchial epithelial cells in vivo, an animal study model was used. Surprisingly, a similar pattern to the in vitro "hit and run" experiments was observed in the gastrocnemius muscle, i.e., a downregulated expression around 4 hours and no change 1 and 12 hours after the intra-tracheal instillation of budesonide. In contrast, in the lungs no effect of budesonide on the GR mRNA was found. Therefore, the manuscript was submitted in a modified form, emphasizing the GR mRNA expression in the skeletal muscle. Since exposure of cells to glucocorticoids can, depending on the cell type, result in either an upor downregulated GR expression, the lack of response is explained by the mixed cell population of the lung tissue sample $(50,129-131,144-149,153,154)$. In theory, mRNA in situ hybridization techniques might enable determination of GR mRNA levels from cell to cell, and also measure differences between exposed and control animals, when these differences exceed $100 \%$. Since in our studies changes in $\alpha$ and $\beta$ GR mRNA levels are less than $50 \%$ after exposure to budesonide, it is not likely that these can be detected by mRNA in situ hybridization. A remarkable finding was a difference in $\alpha / \beta$ GR mRNA ratio between peripheral lung tissue and gastrocnemius muscle. If these differences between tissues are also present on the protein level, this might indicate tissue specific responses to glucocorticoids, since the $\beta$ GR has a negative inhibitory function on the $\alpha$ form. Especially at ratios below 1 a reduced or diminished response of cells to glucocorticoids might occur. 
Since the animal study did not clarify whether the biphasic GR mRNA reaction partem observed in the bronchial epithelial cells of healthy volunteers was due to a short-tem direct effect or a delayed effect of budesonide, another study was performed. In patients with lung cancer, similar to the volunteers, bronchial epithelial cells were sampled duning diagnostic bronchoscopy. This sample served as a $100 \%$ control value since at that point the patients did not receive glucoconticoids. A second sample was obtained from resection specimens of these patients inhaling budesonide 5 or 12 hours before surgery. A downregulation around 5 hours was observed but a late effect, around 12 hours, was not found. Therefore, the upregulation seen in healthy volunteers within 2 hours, is likely to be an early effect of the budesonide treatment. $\mathrm{A}$ similar biphasic reaction pattern has been demonstrated before in other studies $(50,148,149)$.

We have demonstrated that the bronchial epithelium has a functional GR and therefore is liable to exert effects of inhaled glucocorticoids and participate in the anti-inflammatory actions of glucocorticoids in the lungs. Both $\alpha$ and $\beta$ GR mRNA forms have been observed and shown to be autoregulated by glucocorticoids in a similar fashion. No effect of budesonide on the alternative splicing process of the GR is demonstrated, indicating no interference on the autoregulation of the $\mathrm{GR}$.

\subsubsection{Glucocorticoid receptor mRNA levels in COPD:}

In patients with COPD a lack of response to glucacorticoids is observed. However, the reason for this impaired response is unknown. Because of the direct correlation between GR number and cellular responsiveness $(30,47,48)$ and because of the inhibitory effect of the $\beta$ GR on the $\alpha$ G, it is interesting to investigate both $\alpha$ and $\beta$ GRs in these patients in vivo.

We noticed no abnormal $\alpha$ and $\beta$ mRNA levels and ratios in bronchial epithelial cells and alveolar macrophages of patients with COPD compared to a non-obstructive agematched control group. Since none of these patients used glucocorticoids, these were basal mRNA levels, revealing no explanation for the lack of response of patients with COPD to glucocorticoids. Since it is not known if translation of both mRNAs is equally effective, protein levels need to be studied when separate antibodies become available. Also, because of the inter-individual variation, more age and gender-matched patients should be included.

As no "mpairment in basal $\alpha$ and $\beta$ GR mRNA levels was demonstrated, the question was raised about the response on gene transcription level of patients with COPD after 
receiving glucocorticoids. In a cross-sectional study in patients with COPD no change in the transcription of several genes was observed after glucocorticoid use. Both GR and MT2 mRNA levels were similar to the levels seen in non-obstructive patients receiving no glucocorticoids, indicating a disturbed regulation of glucocorticoid induced gene transcription. Because of the inflammatory similarities between smokers with normal lung functions and patients with COPD this control group was chosen. For further investigation a longitudinal study can be performed. Because the patients did not only use glucocorticoids, but were also treated with $\beta_{2}$-agonists, a cross-talk between CREB and GR could be a possible explanation for the lack of response. Alternatively, other transcription factors, like AP-1 and/or NFKB, may be upregulated in patients with COPD and interfere with the GR (162).

From this study it is clear that the lack of response of patients with COPD cannot be explained by deviating $\alpha$ and $\beta$ GR mRNA levels or ratios. However, it is suggested that a non-response appears to occur on gene transcriptional level. Whether this is due to high $\beta$ GR protein levels, activation of CREB by $\beta_{2}$-agonists (also used by COPD patients), inability of heat shock protein dissociation or nuclear translocation, or high levels of proinflammatory transcription factors (AP-1 and NFKB) is unclear and needs to be further elucidated.

\subsubsection{Interaction of the glucocorticoids with $\beta_{2}$-agonists:}

Glucocorticoids and $\beta_{2}$-agonists are both frequently used in the treatment of asthma. Recent studies have suggested that regular use of $\beta_{2}$-agonists has adverse effects on asthma control, due to the cross-talk between cAMP response element binding proteins (CREB) and GR. This cross-talk has been demonstrated in cells exposed to glucocorticoids and $\beta_{2}$-agonists, but no information is available on the consequence of this interaction on gene transcription.

Bronchial epithelial cells were exposed to glucocorticoids and $\beta_{2}$-agonists simultaneously and additionally. Indeed, after simultaneously exposing cells to budesonide and terbutaline, CREB inhibited the budesonide induced GR MRNA downregulation and MT2 mRNA upregulation. However, by applying glucocorticoids first, followed after four hours by $\beta_{2}$-agonists, downregulation of GR mRNA levels was observed for a prolonged period. The disturbance of the budesonide induced gene transcription was due to a cytoplasmic interaction between CREB and GR, as demonstrated by EMSA experiments. The complex formed in the cytoplasm probably existed of more proteins than CREB and 
GR alone. This was based on the observation that the glucocorticoid responsive element (GRE) and cAMP responsive element (CRE) bands are located on the same height, regardless whether the cells were treated with terbutaline, budesonide or both. Probably other transcription factors and central binding proteins are involved in this complex. In addition, a stearic hindrance seems to be present in this complex between GRE and CRE; as the radioactive labeled GRE band can be faded by the addition of cold CRE and vise verse. This indicates that both transcription factors may be situated closely to each other in this protein complex.

Cross-talk between CREB and GR, either with or without the involvement of other transcription factors, may be a theoretical explanation for a decreased therapeutic response in patients with asthma. In clinical practice, it is generally advised to inhale $\beta_{2}$-agonists first, based on the assumption that bronchial constriction is reduced, enabling the subsequently inhaled glucocorticoids to enter more deeply in the conducting airways and reduce inflammation. However, for a more optimal effect, glucocorticoids should be inhaled first and $\beta_{2}$-agonists can be inhaled a few hours later.

\subsection{Transcription factor model}

For years it has been thought that negative gene regulation by the GR occurred through negative GREs (nGRE). This concept was born in mind to explain the phenomenon of downregulation occurring in certain genes after treatment of cells with glucocorticoids $(14,114,131,184-186)$. In the promotor region of these genes a search was performed for a responsive element with common characteristics (nGREs). These 'consensus' sites were quite variable. Since 1) most genes that are downregulated by glucocorticoids do not have the 'consensus' sequence of nGRE or GRE in their promotor region, and 2) positive and negative GREs differ in many bases making it unlikely that the GR protein binds both responsive elements, it is necessary to think about an alternative mechanism to explain negative regulation. Still, even recent reviews mention the existence of a nGRE (25). From the findings of this study (chapter 7 ) and other investigations $(1,96,98,129,187)$, it is conceivable that transcription factor interactions play a pivotal role in the downregulation of genes by glucocorticoids. On the basis of this conception we generated the following hypothesis about gene regulation by glucocorticoids and the regulation of gene transcription in general: 
a) The first assumption is that binding of a full length transcription factor to its responsive element on the DNA results in a stimulation of gene transcription, whereas negative responsive elements that downregulate gene transcription, do not exist. According to this concept, in a homeostatic situation an increase in DNA bound transcription factors will result in upregulation of the mRNA transcription, whereas on the other hand a decrease of DNA bound transcription factors will lead to a reduction in transcription rate (i.e. downregulation). A peculiar situation is formed by transcription factors binding closely to or partly over responsive elements of other transcription factors. In this case, steric hindrance may occur resulting in an inability of a stimulating transcription factor to bind the DNA. Nevertheless, the protein that binds will stimulate transcription, possibly at a different rate

Binding to a responsive element will usually occur in the promotor region close to the adjacent transcription start site of a gene. However, in a model system it was shown that, binding of the protein to its responsive element could activate a gene $1.5 \mathrm{~kb}$ or more away, ewen on the other strand (188).

b) In biological systems positive signals are normally followed by immediate negative feedback controls to prevent overshoot. Therefore, in ordier to prevent continuous gene transcriptional stimulation and thus overproduction of proteins, the activation of transcription factors must somehow be terminated. Since in our hypothesis, binding of a transcription factor results in transcriptional induction (see above), a positive feedback loop would occur, if a responsive element was present in the promotor region of the corresponding transcription factor gene and no posttranslational modification would take place. This should especially be true for transeription factors which take part in the first messenger step of the signal transduction process, like the GR. Therefore, transcription factor genes should have no "self" responsive elements in their promotor regions as demonstrated for the GR gene, unless some essential form of posttranslational modification occurs. Remarkably, several genes of other transcription factors have in their promotor regions "self" responsive elements, like CREB, c-Fos, c-Jun, P50, and the retinoic acid receptor (189-196). Binding of CREB, AP-1 and NFKB to their own genes results in upregulated CREB, c-Jun and P50 mRNA and protein leveis (189-196). This supports the assumption mentioned above. However, modifying steps must be present to avoid overshoot. At least three different mechanisms with a negative feedback function have been described:

1) Activation of a transcription factor results in an increased gene transcription of a 
transcription factor binding protein that inactivates the transcription factor, as demonstrated for $N F \kappa B$. NFKB induces $I K B$, a protein that binds and thereby inactivates NFkB $(195,196)$.

2) Inactivation of protein kinases that phosphorylate and thereby activate transcription factors, like protein kinase $A$ for the activation for CREB and protein kinase $\mathrm{C}$ for the activation of $c-J u n$ and possibly other jun kinases.

3) Dephosphorylation of activated transcription factors by phosphatases might play a role. This has been demonstrated for the CREB protein $(192,197)$ and is thought to be especially important in the phenomenon of downregulation of gene activity after the first burst of activation by cAMP.

c) Interactions between transcription factors that prevent binding to the DNA, obviously will interfere with gene transcription. Depending on the previous level of transcription this may result in a downregulation (as seen in chapter 7). Interactions between transcription factors probably occur both within the cytoplasm and in the nucleus. In figure 1 a schematic drawing is presented about this hypothesis. Which proteins are involved is not clear, but CREB Binding Proteins (CBPs) might play a role in this capture of transcription factors (198-200). Until now, however, this protein has only been described in the nucleus. d) Important in the interactions between transcription factors is the competition for binding places. Competition for responsive elements on the DNA, binding regions of central binding proteins like CBPs, or for binding to other transcription factors may play a role in gene regulation. The affinity of the binding is important in these interactions and determines which transcription factors interact with each other, CBPs and/or DNA. If protein-protein interactions are stronger than protein-DNA interactions, this might play a role in the removal of the transcription factor from the DNA. 


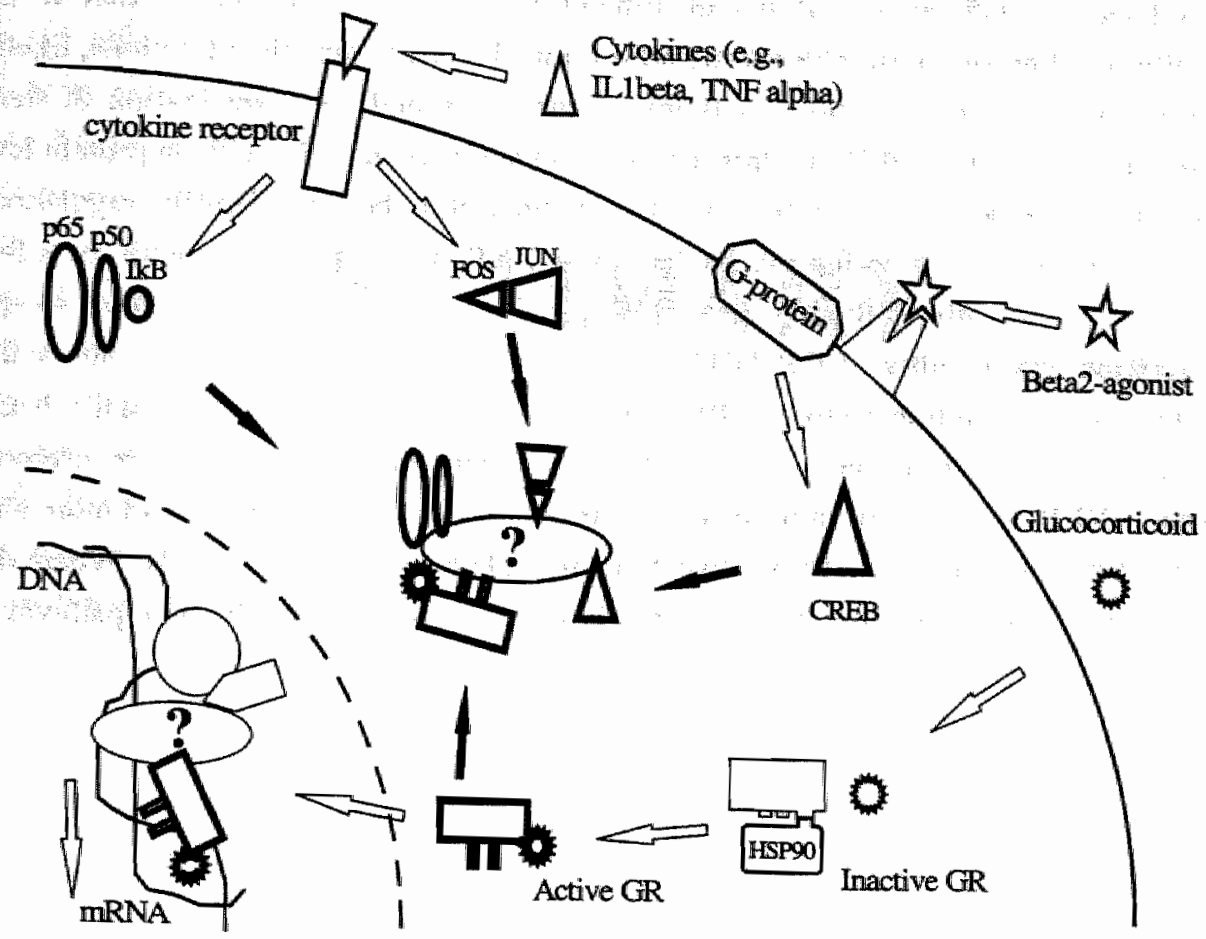

Figure 1: Interactions of transcription factors, $\rightarrow=$ interaction, $\Rightarrow=$ stimulation.

\subsection{Suggestions for further research}

Further research needs to be performed to get more insight into the mechamism behind glucocorticoid therapy, transcription factor interactions and gene regulation. First of all it is important to know the physiological significance of the GR downregulation. Some studies report a potential risk of long-term glucocorticoid treatment on the development of steroid resistance (130), because of the non-reversibility of the downregulated GR levels in the exposed cells. However, in this and other studies, withdrawal of the glucocorticoids 
reestablished the GR levels within short time $(130,131,201-203)$, indicating that the non. reversibility after long-term glucocorticoid use may be due to genetic alterations, likely to occur in time in vitro. Secondly, it is interesting to expand the investigation of steroid resistent patients with COPD to a larger group and study the $\alpha$ and $\beta$ GR on protein levels and test the activity of other transcription factors present in the cells. Thirdly, regulation of gene transcription, the working mechanism of anti-inflammatory drugs, should be a focus of future investigation. Studies into the processes of HSP dissociation, receptor dimerization, reversibility of GR-DNA binding, function of the $\beta \mathrm{GR}$, and interactions with known transcription factors (CREB, AP-1, NFKB, STAT5) may eventually lead to new and better ways to modulate cell functions with glucocorticoids. The cross-talk between CREB and GR is of importance in this context. In order to understand more about regulating gene transcription, these cross-talks should be studied more widely. Where does it take place, what proteins are involved, how can a signal transduction pathway be blocked? 
SUMMARY 


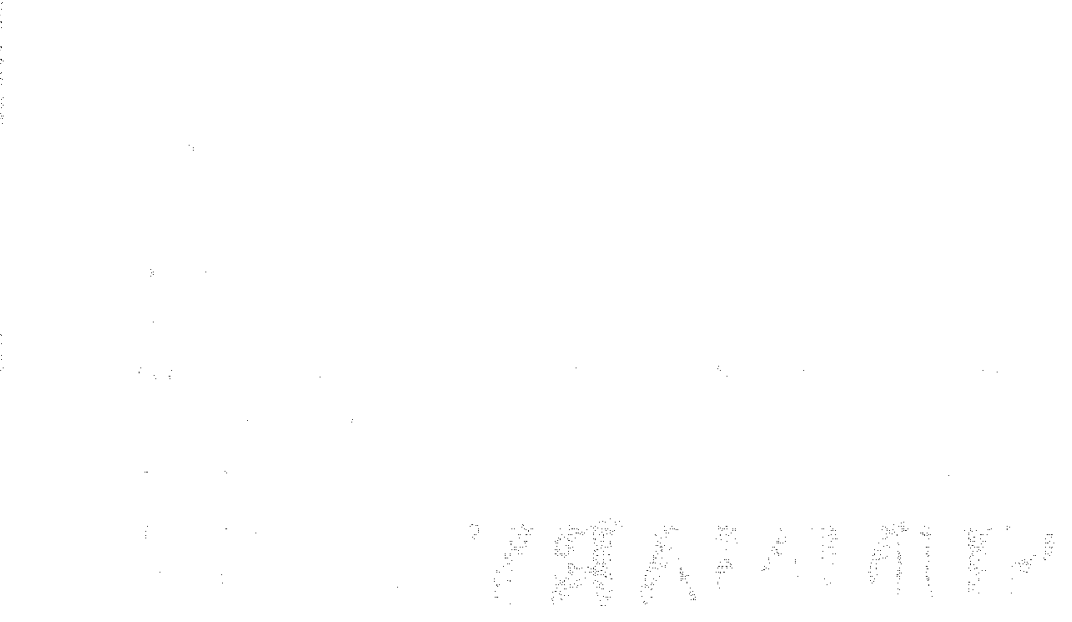

.


SUMMARY 


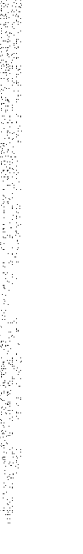

.

(3) 
Despite the central role bronchial epithelial cells play in asthmatic reactions and the widespread use of inhaled corticosteroids in asthma, no information is available about the effect of glucocorticoids on its receptor gene expression in this cell type. Neither are studies performed concerning the $\alpha / \beta$ glucocorticoid receptor (GR) mRNA ratios, despite the fact that the $\alpha$ GR activity is known to be dominant negatively influenced by the $\beta$ form, when the latter is excessively present in cells. Therefore, in this thesis the $\alpha$ and $\beta$ GR mRNA levels and ratios are studied in human bronchial epithelial cells after exposure to the glucocorticoid budesonide.

In chapter 1, the introduction, literature of the molecular mechanism behind glucocorticoid action is summarized. It presents an overview of glucocorticoids, the GR and their anti-inflammatory functions. The purpose of the study is outlined and concerns investigation of the $\alpha$ and $\beta$ GR mRNA expression in bronchial epithelial cells in vitro and in vivo.

Investigation of gene expression in human bronchial epithelium with Northern blot analysis is often impeded by difficulties in collecting enough material. As described in chapter 2, modification of an existing method increased the amount of isolated total RNA by 5 times. This modification allows Northern blot analysis of several genes such as the GR. Therefore, the procedure may facilitate the research on diseases of the human bronchial epithelium such as asthma, smoking related diseases and cystic fibrosis.

In chapter 3 the effect of budesonide on $\alpha$ and $\beta$ GR gene expression in human bronchial epithelial cells was investigated in vitro and in vivo. Both receptor forms were dose and time dependently downregulated by budesonide in a human bronchial epithelial cell line. The $\alpha / \beta$ GR mRNA ratios were similar in vitro and in vivo, $2.6 \pm 0.7$ and $2.3 \pm 0.4$, respectively. Great similarity was observed in $\alpha$ and $\beta$ GR mRNA downregulation between the 1 hour "hit and run" exposure and the in vivo situation. The normalization of the GR mRNA downregulation seen in vivo is explained by the pharmacokinetics of inhaled budesonide in the human lung.

In bronchial epithelial cells of healthy volunteers the GR mRNA expression is regulated in a biphasic way, resulting in an upregulated expression within the first 2 hours, followed, after 2 hours, by a downregulation. In chapter 4 a side step in our study design was made in an animal model, to better understand the pattern of $\alpha$ and $\beta$ GR mRNA 
downregulation after glucocorticoid use. We observed no change in GR mRNA levels in the rat lungs. Since a clear upregulation of the control glutamine synthetase mRNA took place in the lungs and, in the gastrocnemius a marked downregulation of both $\alpha$ and $\beta$ GR mRNAs was observed, the lack of response in the lungs was probably due to the diversity in cell population. $\alpha / \beta$ GR mRNA ratios were higher $(2.6 \pm 0.6)$ in the lungs than in the gastrocnemius (1.1 \pm 0.2$)$, which supports the hypothesis of a differential gene regulation by glucocorticoids in different cell types.

In patients with asthma the beneficial effects of oral and inhaled glucocorticoids are well established, but their effectiveness in COPD is limited. To determine whether the lack of response of patients with COPD to glucocorticoids is due to a low GR mRNA expression or an $\alpha / \beta$ GR mRNA ratio below 1, expression levels were compared between patients with COPD using no glucocorticoids and an age-matched control group. In chapter 5 a lower $\alpha$ GR mRNA expression was observed in the bronchial epithelial cells of patients with COPD compared to an age-matched control group. No difference was observed in $\alpha$ and $\beta$ GR mRNA ratios between both groups in bronchial epithelial cells and alveolar macrophages. The $\alpha / \beta$ ratios were $1.6 \pm 0.4$ in the bronchial epithelial cells and $1.9 \pm 0.5$ in the alveolar macrophages, suggesting that the limited response to glucocorticoids in patients with COPD can not be explained by $\alpha / \beta$ GR mRNA ratios below 1.

In bronchial epithelial cells and alveolar macrophages of patients with COPD receiving no glucocorticoids, lower $\alpha$ GR mRNA levels were demonstrated. The aim of chapter 6 was to investigate the transcriptional response of the GR gene in patients with COPD after glucocorticoid use: In contrast to the non-COPD control patients, no downregulated $\alpha$ and $\beta$ GR mRNA was observed, indicating a lack of transcriptional response to glucocorticoids in patients with COPD. This could not be explained by deviative GR mRNA levels and/or $\alpha / \beta$ mRNA ratios, the latter being $1.7 \pm 0.4$ in patients with COPD and $1.7 \pm 0.5$ in the controls.

Recent studies have suggested that regular use of $\beta_{2}$-agonists has adverse effects on asthma control, due to the cross-talk between cAMP response element binding proteins (CREB) and GR. The aim of chapter 7 was to investigate the interaction between the GR and CREB on cytoplasmic protein level and to determine the effect of this interaction on gene transcription. We conclude that $\beta 2$-agonist exposure interferes with the GR gene regulatory function in human bronchial epithelial cells when given simultaneously. However, this is overcome by exposing cells to glucocorticoids first, followed, after 4 
3 , by $\beta 2$-agonists. The disrupted gene transcription was due to interaction between B and GR within the cytoplasm, as demonstrated by EMSA. 
SAMENVATTING 


\section{SAMENVATTING}




\section{Samenvatting}

Ondanks het feit dat de bronchiale epitheelcel een centrale rol speelt in astmatische reacties en inhalatie corticosteroïden veelvuldig gebruikt worden bij astma, is er geen informatie bekend over het effect van glucocorticoïden op de glucocorticoïd receptor (GR) genexpressie in dit cel type. Verder zijn er eveneens geen studies uitgevoerd naar de $\alpha / \beta$ GR mRNA ratio"s, ondanks het feit dat de activiteit van de $\alpha$ GR wordt onderdrukt door de $\beta$ GR, als de laatste in overmaat aanwezig is in cellen. In dit proefsehrift zijn $\alpha$ en $\beta$ GR mRNA niveaus en ratio's bestudeerd in humane bronchiale epitheelcellen na blootstelling aan een glucocorticoïd, budesonide.

In hoofdstuk 1, de introductie, is een samenvatting gegeven over de literatuur betreffende het moleculair mechanisme van de werking van glucocorticoïden. Glucocorticoïden, de GR en hun anti-inflammatoire werking worden in detail besproken. Het doel van de studie wordt uiteengezet en betreft het bestuderen van de $\alpha$ en $\beta$ GR mRNA expressie in bronchiale epitheelcellen in vitro en in vivo.

Bestudering van de genexpressie in humane bronchiale epitheliale cellen met Northern blot analyse is vaak onmogelijk in verband met de geringe verzameling van materiaal. In hoofdstuk 2 is beschreven hoe de hoeveelheid geïsoleerd totaal RNA met 5 keer is vermenigvuldigd. Dit is verkregen door modificatie van een bestaande RNA isolatie methode. Deze modificatie kan mogelijk het onderzoek naar ziektes met betrekking tot het bronchiale epitheel, zoals astma, ziektes gerelateerd aan roken en cystische fibrose enigszins bespoedigen.

In hoofdstuk 3 is het effect van budesonide op de $\alpha$ en $\beta$ GR mRNA expressie in humane bronchiale epitheelcellen bestudeerd in vitro en in vivo. Beide receptorvormen werden dosis- en tijdsafhankelijk verlaagd in hun mRNA expressie. De $\alpha / \beta$ GR mRNA ratio's waren vrijwel hetzelfde in vitro en in vivo. Er bestond een zeer grote gelijkenis tussen het GR mRNA patroon na de 1 uurs "hit and run" blootstelling en de in vivo resultaten. Normalisatie van de GR mRNA verlaging geobserveerd in vivo wordt verklaard door de farmacokinetiek van geïnhaleerd budesonide in de humane long.

De GR mRNA expressie in humane bronchiale epitheelcellen wordt op een bifasische manier door budesonide gereguleerd. Eerst is een geringe stijging waar te nemen, die 2 later gevolgd wordt door een daling. Om dit korte termijn patroon beter te bestuderen, is in hoofdstuk 4 een rattenmodel onderzocht, waarbij geen verandering in GR mRNA 
expressie in de longen na blootstelling aan budesonide waargenomen werd. Aangezien er wel een duidelijk effect op de glutaminesynthetase gen regulatie waarneembaar was in de longen en er een verlaging van de GR mRNA optrad in de gastrocnemius spier, wordt verondersteld dat de afwezigheid van respons in de longen het gevolg is van de diversiteit van de celpopulatie. Interessant is dat $\alpha / \beta$ GR ratio's hoger waren in de longen (2.6 \pm 0.6$)$ vergeleken met die in de gastrocnemius spier (1.1 $\neq 0.2)$. Dit ondersteunt de bypothese dat verschillende celtypen verschillend gereguleerd worden op gen transcriptioneel niveau door glucocorticoïden.

Bij patiënten met astma is de positieve werking van glucocorticoïden algemeen bekend. Echter, bij patiënten met COPD is het muttig effect twijfelachtig. Om te bepalen of het gebrek aan respons op glucocorticoïden bij patiënten met COPD veroorzaakt wordt door lage GR mRNA niveaus of een $\alpha / \beta$ GR mRNA ratio beneden de 1 , zijn patiënten met COPD vergeleken met een leeftijdsovereenkomstige controle groep. De patiënten in beide groepen gebruikten geen glucocorticoïden. In hoofdstuk 5 is een lagere expressie waargenomen van de $\alpha$ GR mRNA niveaus in de bronchiale epitheel cellen van patiënten met COPD. Er bleek geen verschil in $\alpha$ en $\beta$ GR mRNA ratio's tussen beide groepen in bronchiale epitheelcellen en alveolaire macrofagen. De $\alpha / \beta$ GR mRNA ratio's in de bronchiale epitheelcellen en alveolaire macrofagen waren rond de 1.7. Dit suggereert dat de beperkte respons van patiënten met COPD niet veroorzaakt wordt door een $\alpha / \beta$ ratio beneden de 1 of afwijkende GR mRNA niveaus.

In bronchiale epitheelcellen van patiënten met COPD die geen glucocorticoïden gebruiken zijn geen abnormale $\alpha$ en $\beta$ GR mRNA niveaus en ratio's gevonden. Het doel van hoofdstuk 6 is het bestuderen van de $\alpha$ en $\beta$ GR mRNA niveaus en ratio"s in patiènten met COPD na glucocorticoïd gebruik. In tegenstelling tot niet-COPD controle patiènten, is er bij patiënten met COPD geen respons op gen niveau te zien na gebruik van glucocorticoiden. Dit kon echter niet verklaard worden door afwijkende $\alpha$ en $\beta$ GR mRNA niveaus en ratio"s. Deze laatste waren $1.7 \pm 0.4$ in patiënten met COPD en $1.7 \pm 0.5$ in de controle groep.

Recente studies suggereren dat regelmatig gebruik van $\beta_{2}$-agonisten een tegengesteld effect heeft op het onder controle houden van astma. Als oorzaak wordt een interactie tussen cAMP 'responsive element binding proteins' (CREB) en de GR gegeven. Het doel van hoofdstuk 7 is deze interactie op cytoplasmatisch niveau te bestuderen en te bepalen of deze interactie gevolgen heeft voor de gentranscriptie. Geconcludeerd werd dat $\beta_{2}$ agonist blootstelling van bronchiale epitheelcellen interfereert met de GR gereguleerde 
gen transcriptie als beide medicijnen gelijktijdig worden toegediend. Dit kan voorkomen worden door eerst glucocorticoïden toe te dienen en na enige tijd $\beta_{2}$-agonisten. De verstoorde gentranscriptie is veroorzaakt door een interactie tussen CREB en GR, aangetoond met de EMSA analyse. 


\section{REFERENCES}




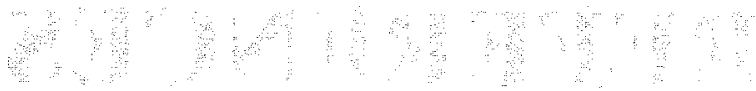




\section{REFERENCES}


\% 


\section{References}

1. Barnes, P. J., and M. Karin. 1997. Nuclear factor-kB: A pivotal transcription factor in chromic inflammatory diseases. N. Engl. J. Med. 336:1066-1071.

2. Bos, J. D., and V. K. Havu. 1989. Updates in dermatology. Acta. Derm. Venereol. 69:S1-S52.

3. Pavord, I., and A. Knox. 1993. Pharmacokinetic optimisation of inhaled steroid therapy in asthma. Clin. Pharmacokinet. 25:126-135.

4. Lee, T. H., R. Brattsand, and D. Leung. 1996. Corticosteroid action and resistance in asthma. Am. J. Respir. Crit. Care. Med. 154:S1-S79.

5. Barnes, P. J., and S. Pedersen. 1993. Efficacy and safety of inhaled corticosteroids in asthma. Am. Rev. Respir. Dis. 148:s1-s26.

6. Mattoli, S., M. Marini, and A. Fasoli. 1992. Expression of the potent inflammatory cytokines, GM-CSF, IL6, and IL8, in bronchial epithelial cells of asthmatic patients. Chest. 101:27S-29S.

7. Vittori, E, F. Sciacca, F. Colotta, A. Mantovani, and S. Mattoli. 1992. Protective effect of nedocromil sodium on the interleukin-1-induced production of interleukin-8 in human bronchial epithelial cells. J. Allergy. Clin. Immunol. 90:76-84.

8. Cromwell, O., Q. Hamid, C. J. Corrigan, J. Barkans, Q. Meng, P. D. Collins, and A. B. Kay. 1992. Expression and generation of interleukin-8, IL-6 and granulocyte-macrophage colony-stimulating factor by bronchial epithelial cells and enhancement by $\mathrm{L}-1$ beta and tumour necrosis factor-alpha Immunology. $77 \div 330-337$.

9. Montefort, S., C. A. Herbert, C. Robinson, and S. T. Holgate. 1992. The bronchial epithelium as a target for inflammatory attack in asthma. Clin. Exp. Allergy: 22:511-520.

10. Sousa, A. R., R. N. Poston, S. J. Lane, J. A. Nakhosteen, and T. H. Lee. 1993. Detection of GM-CSF in asthmatic bronchial epithelium and decrease by inhaled corticosteroids. Am. Rev. Respir. Dis. 147:1557-1561. 
11. Marini, M., E. Vittori, J. Hollemborg, and S. Mattoli. 1992. Expression of the potent inflammatory cytokines, granulocyte-macrophage-colony-stimulating factor and interleukin- 6 and interleukin-8, in bronchial epithelial cells of patients with asthma. J. Allergy. Clin. Immunol. 89:1001-1009.

12. Kwon, O. J., B. T. Au, P. D. Collins, I. M. Adcock, J. C. Mak, R. R. Robbins K. F. Chung, and P. J. Barnes. 1994. Tumor necrosis factor-induced interleukin. 8 expression in cultured human airway epithelial cells. Am. J. Physiol 267:L398-L405.

13. Kwon, O. J., B. T. Au, P. D. Collins, J. N. Baraniuk, I. M. Adcock, K. F. Chung and P. J. Barnes. 1994. Inhibition of interleukin-8 expression by dexamethasons in human cultured airway epithelial cells. Immunology. 81:389-394.

14. Wang, J. H., C. J. Trigg, J. L. Devalia, S. Jordan, and R. J. Davies. 1994. Effec of inhaled beclomethasone dipropionate on expression of proinflammator cytokines and activated eosinophils in the bronchial epithelium of patients will mild asthma. J. Allergy. Clin. Immunol 94:1025-1034.

15. Bedard, M., C. D. McClure, N. L. Schiller, C. Francoeur, A. Cantin, and M Denis. 1993. Release of interleukin-8, interleukin-6, and colony-stimulatin factors by upper airway epithelial cells: implications for cystic fibrosis. Am. $J$ Respir. Cell. Mol. Biol. 9:455-462.

16. Sousa, A. R., S. J. Lane, J. A. Nakhosteen, T. H. Lee, and R. N. Poston. 1996 Expression of interleukin-1 beta ( $L-1 \beta)$ and interleukin-1 receptor antagonis (IL-1ra) on asthmatic bronchial epithelium. Am. J. Respir. Crit. Care. Med 154:1061-1066.

17. Riise, G. C., S. Ahlstedt, S. Larsson, I. Enander, I. Jones, P. Larsson, and B Andersson. 1995. Bronchial inflammation in chronic bronchitis assessed by measurement of cell products in bronchial lavage fluid. Thorax. 50:360-365.

18. Keatings, V. M., P. D. Collins, D. M. Scott, and P. J. Barnes. 1996. Differences in interleukin-8 and tumor necrosis factor-alpha in induced sputum from patients with chronic obstructive pulmonary disease or asthma. Am. J. Respir. Crit. Care. Med. 153:530-534.

19. Thompson, A. B., D. Daughton, R. A. Robbins, M. A. Ghafouri, M. Oehlerking: and S. I. Rennard. 1989. Intraluminal airway inflammation in chronic bronchitis: Characterization and correlation with clinical parameters. Am. Rev. Respir. Dis. 140:1527-1537. 
20 Gibson, P. G., A. Girgis-Gabardo, M. M. Morris, S. Mattoli, I. M. Kay, J. Dolovich, J. Denburg, and F. E. Hargreave. 1989. Cellular characteristics of sputum from patients with asthma and chronic bronchitis. Thorax. 44:693-699.

21. Stanescu, D., A. Sanna, C. Veriter, S. Kostianev, P. G. Calcagni, L. M. Fabbri, and P. Maestrelli. 1996. Airways obstruction, chronic expectoration, and rapid decline of FEV1 in smokers are associated with increased levels of sputum neutrophils. Thorax. 51:267-271.

22. Di Stefano, A., G. Turato, P. Maestrelli, C. E. Mapp, M. P. Ruggien, A. Roggeri, P. Boschetto, L. M. Fabbri, and M. Saetta. 1996. Airflow limitation in chronic bronchitis is associated with T-lymphocyte and macrophage infiltration of the bronchial mucosa. Am. J. Respir. Crit. Care. Med. 153:629-632.

23. Saetta, M., A. Di-Stefano, P. Maestrelli, A. Ferraresso, R. Drigo, A. Potena, A. Ciaccia, and L. M. Fabbri. 1993. Activated T-lymphocytes and macrophages in bronchial mucosa of subjects with chronic bronchitis. Am. Rev. Respir. Dis. 147:301-306.

24. Barnes, P. J. 1995. Inhaled glucocorticoids for asthma. N. Engl. J. Med. 332:868-875.

25. Barnes, P. J., A. P. Greening, and G. K. Crompton. 1995. Glucocorticoid resistance in asthma Am. J. Respir. Crit. Care. Med. 152:S125-S142.

26. Corrigan, C. J., P. H. Brown, N. C. Barnes, S. J. Szefler, J. J. Tsai, A. J. Frew, and A. B. Kay. 1991. Glucocorticoid resistance in chronic asthma. Glucocorticoid pharmacokinetics, glucocorticoid receptor characteristics, and inhibition of peripheral blood $\mathrm{T}$ cell proliferation by glucocorticoids in vitro. Am. Rev. Respir. Dis. 144:1016-1025.

27. Corrigan, C. J., P. H. Brown, N. C. Barnes, J. J. Tsai, A. J. Frew, and A. B. Kay. 1991. Glucocorticoid resistance in chronic asthma. Peripheral blood $T$ lymphocyte activation and comparison of the $T$ lymphocyte inhibitory effects of glucocorticoids and cyclosporin A. Am. Rev. Respir. Dis. 144:1026-1032.

28. Strasser-Wozak, E. M., R. Hattmannstorfer, M. Hala, B. L. Hartmann, M. Fiegl, S. Geley, and R. Kofler. 1995. Splice site mutation in the glucocorticoid receptor gene causes resistance to glucocorticoid-induced apoptosis in a human acute leukemic cell line. Cancer. Res. 55:348-353.

29. Arai, K., and G. P. Chrousos. 1994. Glucocorticoid resistance. Balliere's Clin. Endocrinol. Metab. 8:317-331. 
30. Lida, S., M. Gomi, K. Moriwaki, Y. Itoh, K. Hirobe, Y. Matsuzawa, S. Katagin; T. Yonezawa, and S. Tarui. 1985. Primary cortisol resistance accompanied by a reduction in glucocorticoid receptors in two members of the same family. $J$. Clin Endocrinol Metab., 60:967-971.

31. Hala, M., B. L. Hartmann, G. Bock, S. Geley, and R. Kofler. 1996. Glucocorticoid-receptor-gene defects and resistance to glucocorticoid-induced apoptosis in human leukemic cell lines. Int. J. Cancer. 68:663-668.

32. Renkema, T. E., J. P. Schouten, G. H. Koeter, and D. S. Postma. 1996. Effects of long-term treatment with corticosteroids in COPD. Chest. 109:1156-1162.

33. Auffarth, B., D. S. Postma, J. G. de Monchy, T. W. van der Mark, M. Boorsma, and G. H. Koeter. 1991. Effects of inbaled budesonide on spirometric values, reversibility, airway responsiveness, and cough threshold in smokers with chronic obstructive lung disease. Thorax. 46:372-377.

34. Callahan, C. M., R. S. Dittus, and B. P. Katz. 1991. Oral corticosteroid therapy for patients with stable chronic obstructive pulmonary disease: a meta-analysis. Ann. Intern. Med. 114:216-223.

35. American Thoracic Society. 1995. Standards for the diagnosis and care of patients with chronic obstructive pulmonary disease. Am. J. Respir. Crit. Care. Med: 152:S77-S120.

36. Pauwels, R. A., C. G. Lofdabl, N. B. Pride, D. S. Postma, L. A. Laitinen, and S. V. Ohlsson. 1992. European Respiratory Society study on chronic obstructive pulmonary disease (EUROSCOP): hypothesis and design. Eur. Respir. J. 5:1254-1261.

37. Guyton, A. C. (1986): Textbook of medical physiology. 7th ed. W.B. Saunders Company, Philadelphia. 1057 pages.

38. Carryer, H. M., G. A. Koelsche, L. E. Prickman; C. K. Maytum, C. F. Lake, and H. L. Williams. 1950. Effects of cortisone on bronchial asthma and hay fever occuring in subjects sensitive to ragweed pollen. Proc. Staff: Meet. Mayo. Clin. 25:482-486.

39. Brown, H. M. 1980. The introduction and early developement of inhaled steroid treatment. In Topical steroid treatment in asthma and rhinitis. N. Mygind, and T. J. H. Clark, editors. Bailliere Tindall/London. 66-76. 
40. Szefler, S. J., 1989. General pharmacology of glucocorticoids In Antiinflammatory steroid action. Basic and clinical aspects. R. P. Schleimer, H. N. Claman, and A. Oronsky, editors. Academic press, Ine/San Diego. 353-376.

41. Clark, T. J. H. 1972. Effect of beclomethasone dipropionate delivered by aerosol in patients with asthma. Lancet. June 24:1361-1364.

42. Anderson, R. G. W. 1993. Caveolae: Where incoming and outgoing messengers meet. Proc. Natl. Acad Sci. U. S. A. 90:10909-10913.

43. Anderson, R. G. W. B. A. Kamen, K. G. Rothberg, and S. W. Lacey. 1992. Potocytosis: Sequestration and transport of small molecules by caveolae. Science. 255:410-411.

44. Pratt, W. B., L. C. Scherrer, K. A. Hutchison, and F. C. Dalman. 1992. A model of glucocorticoid receptor unfolding and stabilization by a heat shock protein complex. J. Steroid. Biochem. Mol. Biol. 41:223-229.

45. Beato, M. 1989. Gene regulation by steroid hormones. Cell. 56:335-344.

46. Dahlberg, E., A. Thalen, R. Brattsand, J. A. Gustafsson, U. Johansson, K. Roempke, and T. Saartok. 1984. Correlation between chemical structure, receptor binding, and biological activity of some novel, highly active, 16 alpha, 17 alpha-acetal-substituted glucocorticoids. Mol. Pharmacol. 25:70-78.

47. Pui, C. H., G. V. Dahl, G. Rivera, S. B. Murphy, and M. E. Costlow. 1984, The relationship of blast cell glucocorticoid receptor levels to response to singleagent steroid trial and remission response in children with acute lymphoblastic leukemia. Leuk. Res. 8:579-585.

48. Vanderbilt, J. N., R. Miesfeld, B. A. Maler, and K R. Yamamoto. 1987. Intracellular receptor concentration limits glucocorticoid-dependent enhancer activity. Mol Endocrinol. 1:68-74.

49. Oakley, R. H., and J. A. Cidlowski. 1993. Homologous down regulation of the glucocorticoid receptor: the molecular machinery. Crit. Rev. Eukaryot. Gene. Expr. 3:63-88.

50. Okret, S., Y. Dong, M. Bronnegard, and J. A. Gustafsson. 1991. Regulation of glucocorticoid receptor expression. Biochimie. 73:51-59.

51. Burnstein, K. L., D. L. Bellingham, C. M. Jewell, F. E. Powell-Oliver, and J. A. Cidlowskil. 1991. Autoregulation of glucocorticoid receptor gene expression. Steroids. 56:52-58. 
52. Wikstrom, A. C., O. Bakke, S. Okret, M. Broninegard, and J. A. Gustafsson. 1987. Intracellular localization of the glucocorticoid receptor: evidence for cytoplasmic and nuclear localization. Endocrinology. 120:1232-1242.

53. Cidlowski, J. A., D. L. Bellingham, F. E. Powell-Oliver, D. B. Lubahn, and M. Sar. 1990. Novel antipeptide antibodies to the human glucocorticoid receptor: recognition of multiple receptor forms in vitro and distinct localization of cytoplasmic and nuclear receptors. Mol. Endocrinol. 4:1427-1437.

54. Dingwall, C., and R. Laskey. 1992. The nuclear membrane. Science. 258:942947.

55. Picard, D., and K. R. Yamamoto. 1987. Two signals mediate hormonedependent nuclear localization of the glucocorticoid receptor. Embo. J. 6:33333340 .

56. Guiochon-Mantel, A., and E. Milgrom. 1993. Cytoplasmic nuclear trafficking of steroid hormone receptors. Trends. Endocrinol. Metab. 4:322-328.

57. Oakley, R. H., M. Sar, and J. A. Cidlowski. 1996. The human glucocorticoid receptor beta isoform: Expression, biochemical properties, and putative function. J. Biol. Chem. 271:9550-9559.

58. Hollenberg, S. M., C. Weinberger, E. S. Ong, G. Cerelli, A. Oro, R. Lebo, E. B. Thompson, M. G. Rosenfeld, and R. M. Evans. 1985. Primary structure and expression of a functional human glucocorticoid receptor cDNA. Nature. 318:635-641.

59. Encio, I. J., and S. D. Detera-Wadleigh. 1991. The genomic structure of the human glucocorticoid receptor. J. Biol. Chem. 266:7182-7188.

60. Bamberger, C. M., A. M. Bamberger, M. de Castro, and G. P. Chrousos. 1995. Glucocorticoid receptor beta, a potential endogenous inhibitor of glucocorticoid action in humans. J. Clin. Invest. 95:2435-2441.

61. Yeh, J. Y., B. R. Ou, and N. E. Forsberg. 1994. Effects of dexamethasone on muscle protein homeostasis and on calpain and calpastatin activities and gene expression in rabbits. J. Endocrinol. 141:209-217.

62. Power, R. F., O. M. Conneely, and B. W. O'Malley. 1992. New insights into activation of the steroid hormone receptor superfamily. Trends. Pharmacol. Sci. 13:318-323.

63. Lane, S. J., and T. H. Lee. 1993. Limitations of corticosteroid effects in asthma: biochemical approach. Monaldi. Arch. Chest. Dis. 48:635-639. 
64. Evans, R. M. 1988. The steroid and thyroid hormone receptor super-family. Science: $240: 889-895$.

65. Scherrer, L. C., F. C. Dalman, E Massa, S. Meshinchi, and W. B. Pratt. 1990. Structural and functional reconstitution of the glucocorticoid receptor-hsp90 complex. J. Biol. Chem. 265:21397-21400.

66. Smith, D. F., and D. O. Toft. 1993. Steroid receptors and their associated proteins. Mol. Endocrinol. 7:4-11.

67. Sanchez, E. R., M. Hirst, L. C. Scherrer, H. Y. Tang, M. J. Welsh, J. M. Harmon, S. S. Simons Jr., G. M. Ringold, and W. B. Pratt. 1990. Hormone-free mouse glucocorticoid receptors overexpressed in Chinese hamster ovary cells are localized to the nucleus and are associated with both hsp70 and hsp90. $J$. Biol. Chem. 265:20123-20130.

68. Sanchez, E. R., L. E. Faber, W. J. Henzel, and W. B. Pratt. 1990. The 56-59kilodalton protein identified in untransformed steroid receptor complexes is a unique protein that exists in cytosol in a complex with both the 70- and 90kilodalton heat shock proteins. Biochemistry. 29:5145-5152.

69. Sanchez, E. R. 1990. Hsp56: a novel heat shock protein associated with untransformed steroid receptor complexes. J. Biol. Chem. 265:22067-22070.

70. Pratt, W. B., E. R. Sanchez, E. H. Bresnick, S. Meshinchi, L. C. Scherrer, F. C. Dalman, and M. J. Welsh. 1989. Interaction of the glucocorticoid receptor with the $\mathrm{Mr} 90,000$ heat shock protein: an evolving model of ligand-mediated receptor transformation and translocation. Cancer. Res. 49:2222s-2229s.

71. Lebeau, M. C. 1992. P59, a HSP90. J. Biol. Chem. 267:4281-4284.

72. Ohara-Nemoto, Y., P. E. Stromstedt, K. Dahlman-Wright, T. Nemoto, J. A. Gustafsson, and J. Caristedt-Duke. 1990. The steroid-binding properties of recombinant glucocorticoid receptor: a putative role for heat shock protein hsp90. J. Steroid. Biochem. Mol. Biol. 37:481-490.

73. Kang, K. I., J. Devin, F. Cadepond, N. Jibard, A. Guiochon-Mantel, E. E. Baulieu, and M. G. Catelli. 1994. In vivo functional protein-protein interaction: nuclear targeted hsp90 shifts cytoplasmic steroid receptor mutants into the nucleus. Proc. Natl. Acad. Sci. U. S. A. 91:340-344.

74. Akner, G., A. C. Wikstrom, and J. A. Gustafsson. 1995. Subcellular distribution of the glucocorticoid receptor and evidence for its association with microtubules. J. Steroid. Biochem. Mol. Biol. 52:1-16. 
75. Akner, G., K. G. Sundqvist, M. Denis, A. C. Wikstrom, and J. A. Gustafsson. 1990. Immunocytochemical localization of glucocorticoid receptor in human gingival fibroblasts and evidence for a colocalization of glucocorticoid receptor with cytoplasmic microtubules. Eur. J. Cell. Biol. 53:390-401.

76. Munck, A., D. B. Mendel, L. I. Smith, and E. Orti. 1990. Glucocorticoid receptors and actions. Am. Rev. Respir. Dis. 141:2-10.

77. Barnes, P. J., and I. Adcock. 1993. Anti-inflammatory actions of steroids: molecular mechanisms. Trends. Pharmacol. Sci. 14:436-441.

78. Beato, M., G. Chalepakis, M. Schauer, and E. P. Slater. 1989. DNA regulatory elements for steroid hormones. J. Steroid Biochem. 32:737-747.

79. McEwan, I. J., A. P. Wright, K. Dahlman-Wright, J. Carlstedt-Duke, and J. A. Gustafsson. 1993. Direct interaction of the tau 1 transactivation domain of the human glucocorticoid receptor with the basal transcriptional machinery. Mol. Cell. Biol. 13:399-407.

80. McEwan, I. J., K. Dahlman-Wright, T. Amlof, J. Ford, A. P. Wright, and J. A. Gustafsson. 1995. Mechanisms of transcription activation by nuclear receptors: studies on the human glucocorticoid receptor tau 1 transactivation domain. Mutat. Res. 333:15-22.

81. Kumar, V., S. Green, G. Stack, M. Berry, J.-R. Jin, and P. Chambon. 1987. Functional domains of the human estrogen receptor. Cell. 51:941-951.

82. Hollenberg, S. M, and R. M. Evans. 1988. Multiple and cooperative transactivation domains of the human glucocorticoid receptor. Cell. 55:899-906.

83. Green, S., and P. Chambon. 1987. Oestradiol induction of a glucocorticoidresponsive gene by a chimaeric receptor. Nature. 325:75.

84. Petkovich, M., N. J. Brand, A. Krust, and P. Chambon. 1987. A human retinoic acid receptor which belongs to the familly of nuclear receptors. Nature. 330:444.

85. Chalepakis, G., J. P. M. Postma, and M. Beato. 1988. A model for hormone receptor binding to the mouse mammary tumour virus regulatory element based on hydroxyl radical footprinting. Nucl. Acids. Res. 16:10237-10247.

86. Archer, T. K., G. L. Hager, and J. G. Omichinski. 1990. Sequence-specific DNA bindingby glucocorticoid "zinc-finger peptides". Proc. Natl. Acad. Sci. U. S. A. 87:7560-7564. 
87. Danielsen, M., L. Hinck, and G. M. Ringold. 1989. Two amino acids within the knuckle of the first zinc finger specify DNA response element activation by the glucocorticoid receptor. Cell 57:1131-1138.

88. Green, S., V. Kumar, I. Thenlaz, W. Wahli, and P. Chambron. 1988. The Nterminal DNA binding zinc finger of the estrogen and glucocorticoid receptors determines target gene specificity. Embo. J. 7:3037-3044.

89. Rosewicz, S., A. R. McDonald, B. A. Maddux, I. D. Goldfine, R. L. Miesfeld, and C. D. Logsdon. 1988. Mechanism of glucocorticoid receptor downregulation by glucocorticoids. J. Biol. Chem. 263:2581-2584.

90. Cippitelli, M., A. Sica, V. Viggiano, J. Ye, P. Ghosh, M. J. Birrer, and H. A. Young. 1995. Negative transcriptional regulation of the interferon-gamma promoter by glucocorticoids and dominant negative mutants of c-Jun. J. Biol. Chem. 270:12548-12556.

91. Zong, J., J. Ashraf, and E. B. Thompson. 1990. The promoter and first, untranslated exon of the human glucacorticoid receptor gene are $\mathrm{GC}$ rich but lack consensus glucocorticoid receptor element sites. Mol. Cell. Biol. 10:55805585.

92. Scheinman, R. I, P. C. Cogswell, A. K. Lofquist, and A. S. Baldwin. 1995. Role of transcriptional activation of $\mathrm{IkBa}$ in mediation of immunosuppression by glucocorticoids. Science. 270:283-286.

93. Ray, A., S. LaForge, and P. B. Sehgal. 1990. On the mechanism for efficient repression of the Interleukin-6 promotor by glucocorticoids: Enhances, TATA Box and RNA start site (Inr Motif) occlusion. Mol. Cell. Biol. 10:5736-5746.

94. Bumstein, K. L., C. M. Jewell, and J. A. Cidlowski. 1990. Human glucocorticoid receptor cDNA contains sequences sufficient for receptor downregulation. J Biol. Chem. 265:7284-7291.

95. Barnes, P. J, and I. M. Adcock. 1995. Steroid resistance in asthma. $Q . J . M e d$. $88: 455-468$.

96. Barnes, P. J. 1996. Transcription factors and inflammatory disease. Hospital Practice. June 15:93-106.

97. Cato, A. C., and E. Wade. 1996. Molecular mechanisms of anti-inflammatory action of glucocorticoids. Bioessays. 18:371-378. 
98. Jonat, C., H. J. Rahmsdorf, K. K. Park, A. C. Cato, S. Gebel, H. Ponta, and P. Herrlich. 1990. Antitumor promotion and antinflammation: down-modulation of AP-1 (Fos/Jun) activity by glucocorticoid hormone. Cell. 62:1189-1204.

99. Yang-Yen, H. F., J. C. Chambard, Y. L. Sun, T. Smeal, T. J. Schmidt, J. Drouin, and M. Karin. 1990. Transcriptional interference between c-Jun and the glucocorticoid receptor: mutual inhibition of DNA binding due to direct proteinprotein interaction. Cell. 62:1205-1215.

100. Schule, R, P. Rangarajan, S. Kliewer, L. J. Ransone, J. Bolado, N. Yang, I. M. Verma, and R. M. Evans. 1990. Functional antagonism between oncoprotein cJun and the glucocorticoid receptor. Cell. 62:1217-1226.

101. Ray, A., M. D. Siegel, K. E. Prefontaine, and P. Ray. 1995. Anti-inflammation: Direct physical association and functional antagonism between transcription factor NF-kB and the glucocorticoid receptor. Chest. 107:139S.

102. Brostjan, C., J. Anrather, V. Csizmadia, D. Stroka, M. Soares, F. H. Bach, and H. Winkler 1996. Glucocorticoid-mediated repression of NFkB activity in endothelial cells does not involve induction of $\mathrm{IkBalpha}$ synthesis. J. Biol. Chem. 271:19612-19616.

103. Caldenhoven, E., J. Liden, S. Wissink, A. Van-de-Stolpe, J. Raaijmakers, L. Koenderman, S. Okret, J. A. Gustafsson, and P. T. Van-der-Saag. 1995. Negative cross-talk between RelA and the glucocorticoid receptor: a possible mechanism for the antiinflammatory action of glucocorticoids. Mol. Endocrinol. 9:401-412.

104. Peters, M. J., I. M. Adcock, C. R. Brown, and P. J. Barnes. 1995. BetaAdrenoceptor agonists interfere with glucocorticoid receptor DNA binding in rat lung. Eur. J. Pharmacol. 289:275-281.

105. Imai, E., J. N. Miner, J. A. Mitchell, K. R. Yamamoto, and D. K. Granner. 1993. Glucocorticoid receptor-cAMP response element binding protein interaction and the response of the phosphoenolpyruvate carboxykinase gene to glucocorticoids. J. Biol. Chem. 268:5353-5356.

106. Stauber, C., J. Altschmied, 1. E. Akerblom, J. L. Marron, and P. L. Mellon. 1992. Mutual cross-interference between glucocorticoid receptor and CREB inhibits transactivation in placental cells. New. Biol. 4:527-540. 
107. Akerblom, I. E., E. P. Slater, M. Beato, J. D. Baxter, and P. L. Mellon. 1988. Negative regulation by glucocorticoids through interference with a CAMP responsive enhancer. Science. 241:350-353.

108. Stocklin, E., M. Wissler, F. Gouilleux, and B. Groner. 1996. Functional interactions between Stat5 and the glucocorticoid receptor. Nature. 383:726728.

109. Adcock, I. M., C. R. Brown, and P. J. Barnes. 1996. Tumour necrosis factor alpha causes retention of activated glucocorticoid receptor within the cytoplasm of A549 cells. Biochem. Biophys. Res. Commun. 225:545-550.

110. Adcock, I. M., and P. J. Barnes. 1995. Actions of the glucocorticeid receptor on transcription factors within the cytoplasm. Am. J. Respir. Crit. Care. Med. 151:A195.

111. Vig, E., T. J. Barrett, and W. V. Vedeckis. 1994. Coordinate regulation of glucocorticoid receptor and c-jun mRNA levels: evidence for cross-talk between two signaling pathways at the transcriptional level. Mol. Endocrinol. 8:13361346.

112. Brattsand, R., and M. Linden. 1996. Cytokine modulation by glucocorticoids: mechanisms and actions in cellular studies. Aliment. Pharmacol. Ther. 10:8190.

113. Ray, A., D.-H. Zhang, M. D. Siegel, and P. Ray. 1995. Regulation of interleukin-6 gene expression by steroids. Ann. N. Y. Acad. Sci. 762:79-87.

114. Paliogianni, F., A. Raptis, S. S. Ahuja, S. M. Najjar, and D. T. Boumpas. 1993. Negative transcriptional regulation of human interleukin 2 (IL2) gene by glucocorticoids through interference with nuclear transcription factors AP-1 and NF-AT. J. Clin. Invest. 91:1481-1489.

115. Auphan, N., J. A. DiDonato, C. Rosette, A. Helmberg, and M. Karin. 1995. Immunosupression by glucocorticoids: Inhibition of NF-kB activity through induction of IkB. Science. 270:286-290.

116. Tobler, A., R. Meier, M. Seitz, B. Dewald, M. Baggiolini, and M. F. Fey. 1992. Glucocorticoids downregulate gene expression of GM-CSF, NAP-1/L-8, and IL-6, but not of M-CSF in human fibroblasts. Blood. 79:45-51. 
117. Boumpas, D. T., E. D. Anastassiou, S. A. Older, G. C. Tsokos, D. L. Nelson, and J. E. Balow. 1991. Dexamethasone inhibits human $\mathbb{L}-2$ but not $\mathbb{L}-2 \mathrm{R}$ gene expression in vitro at the level of nuclear transcription. J. Cin. Invest. 87:1739. 1747.

118. Stocklin, $\mathbf{G}_{w,}$ S. Hahn, and C. Moroni. 1994. Functional hierarchy of AUUUA motifs in mediating rapid interleukin 3 mRNA decay. J. Biol. Chem. 269:2859128597.

119. Peppel, K., J. M. Vinci, and C. Baglioni. 1991. The AU-rich sequences in the 3 untranslated region mediate the increased tumover of interferon mRNA induced by glucocorticoïds. J. Exp. Med. 173:349-355.

120. Okamoto, S., N. Mukaida, K. Yasumoto, H. Horiguchi, and K. Matsushima. 1993. Molecular mechanism of interieukin-8 gene expression. Adv. Exp. Med. Biol. 351:87-97.

121. British Thoracic Society. 1990. Guidelines for management of asthma in adults: 1-chronic persistent asthma: $B M J$. 301:651-653.

122. Haahtela, T., M. Jarvinen, T. Kava, K. Kiviranta, S. Koskinen, K. Lehtonen, et al. 1991. Comparison of a B2-agonist, terbutaline, with an inhaled corticosteroid, budesonide, in newly detected asthma. N. Engl. $J . M e d .325: 388$ 392.

123. Juniper, E. F., P. A. Kline, M. A. Vanzieleghem, E. H. Ramsdale, P. M. O'Byrne, and F. E. Hargreave. 1990. Effect of long-term treatment with an inhaled corticosteroid (Budesonide) on airway hyperresponsiveness and clinical asthma in nonsteroid-dependent asthmatics. Am. Rev. Respir. Dis. 142:832-836.

124. Pratt, W. B. 1990. Glucocorticoid receptor structure and the initial events in signal transduction. Prog. Clin. Biol Res. 322:119-132.

125. Erzurum, S. C., C. Danel, A. Gillissen, C. S. Chu, B. C. Trapnell, and R. G. Crystal. 1993. In vivo antioxidant gene expression in human airway epithelium of normal individuals exposed to $100 \%$ O2. J. Appl. Physiol 75:1256-1262.

126. Davis, L. G., M. D. Dibner, and J. F. Battey. 1986. Guanidine isothiocyanate preparation of total RNA. In Basic methods in molecular biology. L. G. Davis, M. D. Dibner, and J. F. Battey, editors. Elsevier/New York. 130-135. 
127. Weinberger, C., S. M. Hollenberg, E. S. Ong, J. M. Hamon, S. T. Brower, J, Cidlowski, E. B. Thompson, M. G. Rosenfeld, and R. M. Evans. 1985. Identification of human glucocorticoid receptor complementary DNA clones by epitope selection. Science. 228:740-742.

128. La-Baer, J., and K. R. Yamamoto. 1994. Analysis of the DNA-binding affinity, sequence specificity and context dependence of the glucocorticoid receptor zinc finger region. J. Mol. Biol. 239:664-688.

129. Adcock, I. M., C. R. Brown, C. M. Gelder, H. Shirasaki, M. J. Peters, and P. J. Barnes. 1995. Effects of glucocorticoids on transcription factor activation in human peripheral blood mononuclear cells. Am. J. Physiol. 268:C331-C338.

130. Silva, C. M., F. E. Powell-Oliver, C. M. Jewell, M. Sar, V. E. Allgood, and J. A. Cidlowski. 1994. Regulation of the buman glucocorticoid receptor by long-term and chronic treatment with glucocorticoid. Steroids. 59:436-442.

131. Dong, Y., L. Poellinger, J. A. Gustafsson, and S. Okret. 1988. Regulation of glucocorticoid receptor expression: evidence for transcriptional and posttranslational mechanisms. Mol. Endocrinol 2:1256-1264.

132. Adcock, I. M., M. Bronnegard, and P. J. Bames. 1991. Glucocorticoid receptor mRNA localization and expression in human lung. Am. Rev. Respir. Dis. 143:A628.

133. Reddel, R. R., Y. Ke B. I. Gerwin, M. G. McMenamin, J. F. Lechner, R. T. Su, D. E. Brash, J. B. Park, J. S. Rhim, and C. C. Harris. 1988. Transformation of human bronchial epithelial cells by infection with SV40 or adenovirus- 12 SV40 hybrid virus, or transfection via strontium phosphate coprecipitation with a plasmid containing SV40 early region genes. Cancer. Res. 48:1904-1909.

134. Lechner, J. F., and M. A. LaVeck. 1985. A serum-free method for culturing normal human bronchial epithelial cells at clonal density. Journal of Tissue Culture Methods. 9 (2):43-48.

135. Chanoine, F., C. Grenot, P. Heidmann, and J. L. Junien. 1991. Pharmacokinetics of butixocort 21 -propionate, budesonide, and beclomethasone dipropionate in the rat after intratracheal, intravenous, and oral treatments. Drug. Metab. Dispos. Biol. Fate. Chem. 19:546-553. 
136. Van-den-Bosch, J. M., C. J. Westermann, J. Aumann, S. Edsbacker, M. Tonnesson, and O. Selroos. 1993. Relationship between lung tissue and blood plasma concentrations of inhaled budesonide. Biopharm. Drug. Dispos. 14:455459.

137. Brattsand, R., L. Kallstrom, E. Nilsson, A. Ryffeldt, and M. Tonnesson. 1982. The lung disposition of budesonide in guinea pig and rat. Eur. Respir. $J$. 122:263-265.

138. Miller-Larsson, A, and R Brattsand. 1990. Topical anti-inflammatory activity of the glucocorticoid budesonide on airway mucosa. Evidence for a "hit and rü" type of activity. Agents. Actions. 29:127-129.

139. Bleecker, E. R. 1991. Workshop summery and guidelines: Investigative use of bronchoscopy, lavage and bronchial biopsies in asthma and other airways diseases. Clin. Exp. Allergy. 21:533-539.

140. Guo, F. H, H. R. de Raeve, T. W. Rice, D. J. Stuehr, F. B. Thunnissen, and S. C. Erzurum. 1995. Continuous nitric oxide synthesis by inducible nitric oxide synthase in normal human airway epithelium in vivo. Proc. Natl. Acad. Sci. U. S. A. $92: 7809-7813$.

141. Danel, C., S. C. Erzurum, N. G. McElvaney, and R. G. Crystal. 1996. Quantitative assessment of the epithelial and inflammatory cell populations in large airways of normals and individuals with cystic fibrosis. Am. J. Respir. Crit. Care. Med 153:362-368.

142. Andersson, O, M. Bronnegard, T. Sonnenfeld, B. Schmekel, J. Lund, E. Ripe, and J. A. Gustafsson. 1991. Gucocorticoid receptor mRNA expression in pulmonary alveolar macrophages in sarcoidosis. Chest. 99:1336-1341.

143. Karin, M., A. Haslinger, H. Holtgreve, R. I. Richards, P. Krauter, H. M. Westphal, and M. Beato. 1984. Characterisation of DNA sequences through which cadmium and glucocorticoid hormones induce tuman metallothionein11 A gene. Nature. 308:513-519.

144. Sweezey, N., C. Mawdsley, F. Ghibu, L. Song, S. Buch, A. Moore, T. Antakly, and M. Post 1995. Differential regulation of glucocorticoid receptor expression by ligand in fetal rat lung cells. Pediatr. Res. 38:506-512.

145. Knutsson, U., P. Stierna, C. Marcus, J. Carlstedt-Duke, K. Carlstrom, and M. Bronnegard. 1995. Effects of intranasal glucocorticoids on endogenous glucocorticoid peripheral and central function. J. Endocrinol. 144:301-310. 
146. Schlecte, J. A., B. H. Ginsberg, and B. M. Sherman. 1982. Regulation of the glucocorticoid receptor in human lymphocytes. J. Steroid Biochem 16:69-74.

147. Korn, S. H., E. F. M. Wouters, G. J. Wesseling, J.-W. Arends, and F. B. J. M. Thunnissen. 1997. In vitro and in vivo modulation of alpha and beta glucocorticoid receptor mRNA in human bronchial epithelium. Am $J$. Respir. Crit. Care. Med. 155:1117-1122.

148. Okret, S., L. Pòellinger, Y. Dong, and J. A. Gustafsson. 1986. Down-regulation of glucocorticoid receptor mRNA by glucocorticoid hormones and recognition by the receptor of a specific binding sequence within a receptor cDNA clone. Proc. Natl. Acad. Sci. U. S. A. 83:5899-5903.

149. Adcock, I. M., T. Gilbey, C. M. Gelder, K. F. Chung, and P. J. Barnes. 1996. Glucocorticoid receptor localization in mormal and asthmatic lung. Am. J. Respir. Crit. Care. Med. 154:771-782.

150. Chomczynski, P., and N. Sacchi. 1987. Single-step method of RNA isolation by acid guanidinium thiocyanate-phenol-chloroform extraction Anal. Biochem. 162:156-159.

151. Feng, B., D. C. Hilt, and S. R. Max. 1990. Transcriptional regulation of glutamine synthetase gene expression by dexamethasone in L6 muscle cells. $J$. Biol. Chem. 265:18702-18706.

152. Abcouwer, S. F., B. P. Bode, and W. W. Souba. 1995. Glucocorticoids regulate rat glutamine synthetase expression in a tissue-specific manner. $J$. Surg. Res. 59:59-65.

153. Cole, N. B., C. L. Smith, N. Sciaky, M. Terasaki, M. Edidin, and J. LippincottSchwartz. 1996. Diffusional mobility of golgi proteins in membranes of living cells Science. 273:797-801.

154. Eisen, L. P., M. S. Elsasser, and J. M. Harmon. 1988. Positive regulation of the glucocorticaid receptor in human T-cells sensitive to the cytolytic effects of glucocorticoids. J. Biol Chem 263:12044-12048:

155. Hanania, N. A., K. R. Chapman, and S. Kesten. 1995. Adverse effects of inhaled corticosteroids. Am. J. Med. 98:196-208.

156. Kamada, A. K., S. J. Szefler, R. J. Martin, H. A. Boushey, V. M. Chinchilli, J. M. Drazen, J. E. Fish, E. Israel, S. C. Lazarus, and R. F. Lemanske. 1996. Issues in the use of inhaled glucocorticoids. Am. J. Respir. Crit. Care Med. 153:17391748. 
157. Bronnegard, M., S. Werner, and J. A. Gustafsson. 1991. Regulation of glucocorticoid receptor expression in cultured fibroblasts from a patient with familial glueocorticoid resistance. J. Steroid. Biochem. Mol. Biol. 39:693-701.

158. Zeiner, M., and U. Gehring. 1993. Glucocorticoid receptor expression during differentiation of human promyeloic leukemia cells. Cancer. Res. 53:3513-3517.

159. Kalinyak, J. E., R. I. Dorin, A. R. Hoffman, and A. J. Perlman. 1987. Tissuespecific regulation of glucocorticoid receptor mRNA by dexamethasone. J. Biol. Chem. 262:10441-10444.

160. Bronnegard, M., and S. Okret. 1991. Regulation of the glucocorticoid receptor in fetal rat lung during development. J. Steroid. Biochem. Mol. Biol. 39:13-17.

161. Truss, M., and M. Beato. 1993. Steroid hormone receptors: interaction with deoxyribonucleic acid and transcription factors. Endocr. Rev. 14:459-479.

162. Adcock, I. M., S. J. Lane, C. R. Brown, T. H. Lee, and P. J. Bames. 1995. Abnormal glucocorticoid receptor-activator protein 1 interaction in steroidresistant asthma. J. Exp. Med. 182:1951-1958.

163. Quanjer, P. H., G. J. Tammeling, J. E. Cotes, O. F. Pedersen, R. Peslin, and JC. Yernault. 1993. Lung volumes and forced ventilatory flows. Eur. Respir. J. 6:S5-S40,

164. Bosken, C. H., J. Hards, K. Gatter, and J. C. Hogg. 1992. Characterization of the inflammatory reaction in the peripheral airways of cigarette smokers using immunocytochemistry. Am. Rev. Respir. Dis. 145:911-917.

165. Totti, N., K. T. McCusker, E. J. Campbell, G. L. Griffin, and R. M. Senoir. 1984. Nicotine is chemotactic for neutrophils and enhances neutrophil responsiveness to chemotactic peptides. Science. 223:169-171.

166. Pedersen, B., R. Dahl, R. Karlstrom, C. G. B. Peterson, and P. Venge. 1996. Eosinophil and neutrophil activity in asthma in a one-year trial with inhaled budesonide. Am. J. Respir. Crit. Care. Med. 153:1519-1529.

167. Paakko, P., P. Kokkonen, S. Anttila, and P.-L. Kalliomaki. 1989. Cadmium and Chromium as markers of smoking in human lung tissue. Environ. Res. 49:197207.

168. Adcock, I. M., M. J. Peters, C. R. Brown, D. A. Stevens, and P. J. Barnes. 1995. High concentrations of beta-adrenergic agonists inhibit DNA binding of glucocorticoids in human lung in vitro. Biochem. Soc. Trans. 23:217S. 
169. Stevens, D. A., P. J. Barnes, and I. M. Adcock. 1995. Beta-agonists inhibit DNA-binding of glucocorticoid receptors in human pulmonary and bronchial epithelial cells. Am. J. Respir. Crit. Care. Med. 151:A195.

170. Kam, J. C., S. J. Szefler, W. Surs, E. R. Sher, and D. Y. Leung. 1993. Combination $\mathbb{I L}-2$ and $\mathrm{IL}-4$ reduces glucocorticoid receptor-binding affinity and T cell response to glucocorticoids. J. Immunol. 151:3460-3466.

171. Verheggen, M. M., P. ThW. van Hal, P. W. C. Adriaansen-Soeting, B. J. A. Goense, H. C. Hoogsteden, A. O. Brinkmann, and M. A. Versnel. 1996. Modulation of glucocorticoid receptor expression in human bronchial epithelial cell lines by IL1-beta, TNF-alfa and LPS. Eur. Respir. J. 9:2036-2043.

172. Nimmagadda, S. R., S. J. Szefler, J. D. Spahn, W. Surs, and D. Y. M. Leung. 1997. Allergen exposure decreases glucocorticoid receptor binding affinity and steroid responsiveness in atopic asthmatics. Am. J. Respir. Crit. Care. Med. 155:87-93.

173. Salowski, C. A., and S. N. Vogel. 1992. IFN-gamma mediates increased glucocorticoid receptor expression in murine macrophages. J. Immunol. 148:2770-2777.

174. Linden, M., J. B. Rasmussen, E. Piitulainen, A. Tunek, M. Larson, H. Tegner, P. Venge, L. A. Laitinen, and R. Brattsand. 1993. Airway inflammation in smokers with nonobstructive and obstructive chronic bronchitis. Am. Rev. Respir. Dis. 148:1226-1232.

175. Keatings, V. M., A. Jatakanon, Y. M. Worsdell, and P. J. Barnes. 1997. Effects of inhaled and oral glucocorticoids on inflammatory indices in asthma and COPD. Am. J. Respir. Crit. Care. Med. 155:542-548.

176. Adcock, I. M., D. A. Stevens, and P. J. Bames. 1996. Interactions of glucocorticoids and beta2-agonists. Eur. Respir. J. 9:160-168.

177. Cockcroft, D. W., V. A. Swystun, and R. Bhagat. 1995. Interaction of inhaled beta 2 agonist and inhaled corticosteroid on airway responsiveness to allergen and methacholine. Am. J. Respir. Crit. Care. Med. 152:1485-1489.

178. Dompeling, E., C. P. Schayck van, P. M. Grunsven van, C. L. Herwaarden van, R. Akkermans, J. Molema, H. Folgering, and C. Weel van. 1993. Slowing the deterioration of asthma and chronic obstructive pulmonary disease observed during bronchodilator therapy by adding inhaled corticosteroids. A 4-year prospective study. Ann. Intern. Med. 118:770-778. 
179. Bames, P. J. 1995. Beta-adrenergic receptors and their regulation. Am. J. Respir. Crit. Care. Med. 152:838-860.

180. Gonzalez, G. A, and M. R. Montminy. 1989. Cyclic AMP stimulates somatostatin gene transcription by phosphorylation of CREB at serine 133. Cell 59:675-680.

181. Yamamoto, K. K., G. A. Gonzalez, W. H. Biggs 3d., and M. R. Montminy. 1988. Phosphorylation-induced binding and transcriptional efficacy of nuclear factor CREB. Nature. 334:494-498.

182. Dong, Y, M. Aronsson, J. A. Gustafsson, and S. Okret. 1989. The mechanism of cAMP-induced glucocorticoid receptor expression. Correlation to cellular glucocorticoid response. J. Biol Chem. 264:13679-13683.

183. Lang, I, M. Scholz, and R. Peters. 1986. Molecular mobility and nucleocytoplasmic flux in hepatoma cells. J. Cell. Biol. 102:1183-1190.

184. Nakamura, H., K. Yoshimura, H. A. Jaffe, and R. G. Crystal. 1991. Interleukin8 gene expression in human bronchial epithelial cells. J. Biol. Chem. 266:19611-19617.

185. Zitnilk, R. J., N. L. Whiting, and J. A. Elias. 1994. Glucocorticoid inhibition of interleukin-1-induced interleukin-6 production by human lung fibroblasts: evidence for transcriptional and post-transcriptional regulatory mechanisms. Am. J. Respir. Cell. Mol. Biol. 10:643-650.

186. Linden, M., and R. Brattsand. 1994. Effects of a corticosteroid, budesonide, on alveolar macrophage and blood monocyte secretion of cytokines: differential sensitivity of GM-CSF, IL-1 beta, and IL-6. Pulm. Pharmacol 7:43-47.

187. Saag, P. T. van der, E. Caldenhoven, and A. van de Stolpe. 1996. Molecular mechanisms of steroid action: a novel type of cross-talk between glucocorticoids and NF-kB transcription factors. Eur. Respir. J. 9:146S-153S.

188. Wu, H. Y., I. Tan, and M. Fang. 1995. Long-range interaction between two promoters: activation of the leu-500 promoter by a distant upstream promoter. Cell. $82: 445-451$.

189. Leid, M., P. Kastner, B. Durand, A. Krust, P. Leroy, R. Lyons, C. Mendelson, S. Nagpal, H. Nakshatri, C. Reibel, M. Saunders, and P. Chambon. 1993. Retinoic acid signal transduction pathways. Ann. N. Y. Acad. Sci: 684:19-34. 
190. Meyer, T. E., G. Waeber, J. Lin, W. Beckmann, and J. F. Habener 1993. The promoter of the gene encoding $3^{\prime}, 5^{\prime}$-cyclic adenosine monophosphate (cAMP) response element binding protein contains cAMP response elements: evidence for positive autoregulation of gene transcription. Endocrinology. 132:770-780.

191. Angel, P., K. Hattori, T. Smeal, and M. Karin. 1988. The jun proto-oncogene is positively autoregulated by its product, Jun/AP-1, Cell. 55:875-885.

192. Lalli, E., and P. Sassone-Corsi. 1994. Signal transduction and gene regulation: the nuclear response to CAMP. J. Biol. Chem. 269:17359-17362.

193. Sassone-Corsi, P., J. C. Sisson, and I. M. Verma 1988. Transcriptional autoregulation of the proto-oncogene fos. Nature. 334:314-319.

194. Schonthal, A., P. Herrlich, H. J. Rahmsdorf, and H. Ponta 1988. Requirement for fos gene expression in the transcriptional activation of collagenase by other oncogenes and phorbol esters. Cell. 54:325-334.

195. Tzen, C. Y., R. L. Cox, and R. E. Scott. 1994. Coordinate induction of I kappa B alpha and NF kappa B genes. Exp. Cell. Res. 211:12-16.

196. Ten, R. M., C. V. Paya, N. Israel, O. Le-Bail, M. G. Mattei, J. L. Virelizier, P. Kourilsky, and A. Israel. 1992. The characterization of the promoter of the gene encoding the p50 subunit of NF-kappa B indicates that it participates in its own regulation. Embo. J. 11:195-203.

197. Hagiwara, M., A. Alberts, P. Brindle, J. Meinkoth, J. Feramisco, T. Deng, M. Karin, S. Shenolikar, and M. Montminy. 1992. Transcriptional attenuation following cAMP induction requires PP-1-mediated dephosphorylation of CREB. Cell. 70:105-113.

198. Chakravarti, D., V. J. LaMorte, M. C. Nelson, T. Nakajima, I. G. Schulman, H. Juguilon, M. Montminy, and R. M. Evans. 1996. Rolle of CBP/P300 in nuclear receptor signalling. Nature. 383:99-103.

199. Kamei, Y., L. Xu, T. Heinzel, J. Torchia, R. Kurokawa, B. Gloss, S. C. Lin, R. A. Heyman, D. W. Rose, C. K. Glass, and M. G. Rosenfeld. 1996. A CBP integrator complex mediates transcriptional activation and AP-1 inhibition by nuclear receptors. Cell. 85:403-414.

200. Chrivia, J. C., R. P. Kwok, N. Lamb, M. Hagiwara, M. R. Montminy, and R. H. Goodman. 1993. Phosphorylated CREB binds specifically to the nuclear protein CBP. Nature. 365:855-859. 
201. Hoeck; W., S. Rusconi, and B. Groner. 1989. Down-regulation and phosphorylation of glucocorticoid receptors in cultured cells. Investigations with a monospecific antiserum against a bacterially expressed receptor fragment. J. Biol. Chem. 264:14396-14402.

202. Knutsson, P. U., M. Bronnegard, C. Marcus, and P. Stierna. 1996. Regulation of glucocorticoid receptor mRNA in nasal mucosa by local administration of fluticasone and budesonide. J. Allergy. Clin. Immunol. 97:655-661.

203. Bellingham, D. L., M. Sar, and J. A. Cidlowski. 1992. Ligand-dependent downregulation of stably transfected human glucocorticoid receptors is associated with the loss of functional glucocorticoid responsiveness. Mol. Endocrinol. 6:2090-2102. 


\section{DANKWOORD}


?

औe 


\section{DANKWOORD}




\section{Dankwoord}

Dat het dankwoord vaak veel hoofdbrekens teweeg brengt is bij ieder bekend. Ik ben hierop dan ook geen uitzondering. Er zijn namelijk veel mensen betrokken geweest bij de tot standkoming van dit boekje, zowel wetenschappelijk als ontspannend. Allen will ik zeer hartelijk bedanken, maar een aantal wil ik bij naam noemen.

Allereerst mijn co-promotor Erik Thunnissen. Onze start is niet ideaal geweest en er zijn vast en zeker genoeg momenten geweest dat je je vertrouwen in mij en het onderzoek verloren had (net als ikzelf). Maar je ziet, het is toch gelukt! Ik heb veel van je geleerd, maar ik denk dat het belangrijkste kritisch denken en nauwkeurig werken is geweest. Misschien nog niet zoals jij het graag ziet, maar ik heb nog veel leerjaren voor de boeg. Bedankt voor je goede discussies, de kritische adviezen cq opmerkingen en tissues.

Ik had het geluk (of de pech?) 2 promotoren te hebben. Professor Wouters, u bent er vanaf het begin bij geweest en hebt altijd een goede lijn in het onderzoek gehouden en waardevolle ideeën geopperd. Ook bij het schrijven van de artikelen heeft $\mathrm{u}$ adviezen gegeven die zeer relevant waren. Vooral bij het verzamelen van de patienten heeft $u$ zich veel moeite gedaan. Bedanikt voor al uw ideeën en wijsheden. De tweede promotor, professor Arends, is wat later bij het onderzoek betrokken. Een onderzoek dat buiten uw vakgebied valt, maar $u$ wist als zogenaamde "leek" altijd uw vinger op de problemen te leggen en structuur aan te brengen waardoor artikelen en discussies overzichtelijker werden. Als wij moeite hadden door de bomen het bos te zien gaf u duidelijke aanwijzingen. Ook u bedankt voor al uw inzicht!

Terwijl ik eigenlijk tot de vakgroep Pulmonologie behoorde, was mijn standplaats de vakgroep Pathologie. Ik heb hier altijd met veel plezier gewerkt, en ik hoop dat ik in mijn toekomstige banen net zo'n goede sfeer aantref als in deze groep. Allereerst wil ik Veerle bedanken. Mijn steun en toeverlaat als er weer eens iets was misgegaan. Ze heeft vaak naar mijn gezucht en gekreun moeten luisteren, hiervoor 10000000 maal dank! Verder dank ik de rest van de AIO-kamer ("het kippenhok" volgens velen), Birgit, Rob, Han en Claudia voor alle fun, drop en prullebak zitten wat we gedaan hebben. Hopelijk zijn mijn collega"s in Lund net zo gestoord! Annick en Margriet, bedankt voor alle coupes die jullie

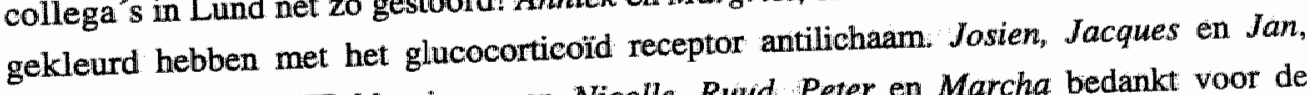
bedankt voor alle HE kleuringen en Nicolle, Ruid, Peter en Marcha bedankt voor de celtellingen en giemsa kleuringen. Verder wil ik Magda, Peter en Edith bedanken voor 
alle adviezen betreffende technieken e.d. De rest van alle labs en het secretariaat, BEDAAAAANK!

Dan de mensen van de Longafdeling. Hierbij wil ik Geertjan bedanken voor het lezen van artikelen en abstracts en voor het doorspitten van de patienten dossiers. De mensen van de Longfunctie, die ik elke dag kwam lastigvallen met de bekende vraag "is er vandaag nog iets voor mij bij?". Bedankt voor alle oplettendheid en hulp die jullie hebben geboden bij het verzamelen van patienten, biopten en brushes! Vervolgens de AIO's. De 3 E's (Erika, Eva, Esther), Mariëlle, oud AlO Mieke en niet AlO Francien, bedankt voor alle gezellige etentjes die we hebben gehad. De broodnodige variatie op het werk! Manom Gonda en Francien, ook jullie bedank voor alle hulp!

Dan wil ik nog enkele mensen van buiten de afdelingen bedanken voor hun hulp. Roselie, ik kon altijd op jouw rekenen als ik weer ATP nodig had! Peter, bedankt voor alle hulp bij de ratten! Lou, Roel, Roger, Paul en Ad, bedankt voor alle hulp bij de phosphorimager en de gezellige momenten op de congressen!

Een aantal hoofdstukken van dit proefschrift zouden niet tot stand zijn gekomen zonder vrijwilligers en patienten. Allemaal zeer bedankt voor jullie medewerking!

Natuurlijk waren er ook mensen die niet direct betrokken waren met het werk (en er tot vervelens toe mee geconfronteerd werden). Zoals Club Culinair. Manon, we gaan al heel wat jaren terug en je bent al die tijd een lieve vriendin geweest. Je kon goed relativeren op momenten dat ik het liefst van het dak gesprongen was. Harstikke bedaank! Suzanne, Jacques; Gastom, Per en Mariëlle, bedankt voor alle gezellige (culinaire) avonden. Ik was de laatste tijd erg saai, maar ik hoop dat jullie het mij vergeven. Ik zal jullie exg missen in Lund! Anneke, bedankt voor alle praatuurtjes en heerlijke etentjes. We hebben elkaar vaker misgelopen, maar ik beloof je dat als je naar Lund komt dat niet zal voorkomen! Het BGK-clubje, Martine, Bertine, Yvonne, Sonja, Jolanda, Heleen en aanhang. Jullie zag ik niet meer zo vaak omdat iedereen her en der in Nederland verspreid zat. Maar als we iets afspraken was het steeds weer gezellig en van goed wetenschappelijk niveau (lasergames).

Dan blijven er natuurlijk nog 2 belangrijke personen over. Pap; bedankt voor alle dingen die je me hebt bijgebracht in de laatste 28 jaar: Je onvoorwaardelijke stenn is erg belangrijk voor me geweest. Je eeuwig aanwezige rust en nuchterheid brachten me vaak weer snel "back to earth". Teejoo, zoals je nu genoemd wordt. Ook jij bedankt voor al je steun. Ook al ben je mijn kleine broertje, je had soms meer wijsheid dan ik. Mam, dit is een van de dingen waar je voor leefde, een goede toekomst voor je kinderen. Tot nu toe hebben we het toch niet slecht gedaan! Jammer dat je elders bent. 


\section{PUBLICATIONS}




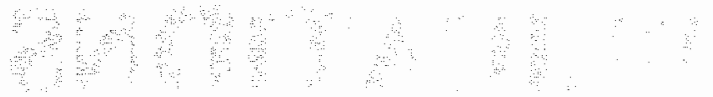




\section{PUBLICATIONS}




\section{Publications}

Articles:

S.H. Korn, P.T.M. Moerkerk, and A.F.P.M. de Goeij. 1993. K-ras point mutations in routinely processed tissues: Non-radioactive screening by single strand conformational polymorphism analysis. Journal of Clinical Pathology. 46:621-623.

S.H. Korn, P.T.M. Moerkerk en A.F.P.M. de Goeij. 1993. Niet-radioactieve detectie van puntmutaties in het $\mathrm{K}$-ras gen met behulp van Single Stranded Conformation Polymorphism (SSCP) analyse. Tijdschrift voor de Nederlandse Vereniging van Klinisch Chemici. 18:73-77.

S.H. Korn, E.F.M. Wouters, G-J. Wesseling, J-W. Arends and F.B.J.M. Thunnissen. 1997. In vitro and in vivo modulation of giucocorticoid receptor mRNA by budesonide in human bronchial epithelial cells. American Joumal of Respiratory and Critical Care Medicine: $155: 1117-1122$.

S.H. Korn, E. Koerts-de Lang, G.E.J. Engel, J-W Arends, E.F.M. Wouters and F.B.J.M. Thunnissen. 1997. $\alpha$ And $\beta$ glucocorticoid receptor mRNA expression in skeletal muscle. Submitted.

S.H. Korn, F.B.J.M. Thunnissen, G-J. Wesseling, J-W. Arends and E.F.M. Wouters. 1997. Giucocorticoid receptor mRNA levels in bronchial epithelial cells of patients with COPD: Influence of glucocorticoids. Submitted.

S.H. Korn, E.F.M. Wouters, G-J. Wesseling, J-W. Arends and F.B.J.M. Thunnissen. 1997. Interaction between glucocorticoids and $\beta_{2}$-agonists: $\alpha$ and $\beta$ glucocorticoid receptor mRNA expression in human bronchial epithelial cells. Submitted. 
Abstracts:

S.H. Korn, P.T.J. Marx, A. van Belle, Sj.Sc. Wagenaar, E.F.M. Wouters and F.B.J.M. Thunnissen. 1994. The glucocorticoid receptor gene expression in human bronchial epithelial cells. American Joumal of Respiratory and Critical Care Medicine 149: A986.

P.T. Marx, M.A.E. Verbeeck, S.H. Korn, E. Schuuring, Sj,Sc. Wagenaar and F.B.J.M. Thunnissen. 1994. Amplification and expression of the chromosome 11Q13 genes EMS1 and CCND1 in lung cancer. American Joumal of Respiratory and Critical Care Medicine 149: A173.

S.H. Korn, E.F.M. Wouters, Sj.Sc Wagenaar and F.B.M.M. Thunnissen. 1994. Downregulation of the glucocorticoid receptor gene expression in a human bronchial epithelial cells line by different steroids. The European Respiratory Joumal 7. S75.

S.H. Kom, P.TI. Marx, A. van Belle, E.F.M. Wouters and F.B.J.M. Thunnissen. 1995. RNA isolation from human bronchial epithelial cells: A rapid technique. American Journal of Respiratory and Critical Care Medicine 151: A174.

S.H. Korn, EFM. Wouters and F.B.J.M. Thunnissen. 1995. Short term increase of glucocorticoid receptor (GR) mRNA in bronchial epithelial cells by TNF $\alpha$ and IL1 $\beta$. American Joumal of Respiratory and Critical Care Medicine 151: A175.

S.H. Kom, F.B.J.M. Thunnissen, G-J. Wesseling, J.W. Arends and E.F.M. Wouters. 1996. In vitro and in vivo modulation of glucocorticoid receptor mRNA by budesonide in human bronchial epithelial cells. American Joumal of Respiratory and Critical Care Medicine 153: A645.

S.H. Korn, F.B.J.M. Thunnissen, G.J. Wesseling, J-W. Arends and E.F.M. Wouters. 1997. Is the $\beta$ glucoconticoid receptor (GR) mRNA level high enough for inhibition of the GR function in COPD? American Journal of Respiratory and Critical Care Medicine 155: A587. 
S.H. Korn, G.E.J. Engel, E. Koerts-de Lang, J-W. Arends, E.F.M. Wouters, and F.B.J.M. Thunnissen. 1997. $\alpha$ and $\beta$ glucocorticoid receptor mRNA expression in rat lung and gastrocnemius after intra-tracheal instillation of budesonide. American Joumal of Respiratory and Critical Care Medicine 155: A358.

S.H. Korn, E.F.M. Wouters, J-W Arends and F.B.J.M. Thunnissen. 1997. Interaction between glucocorticoids and $\beta 2$-agonists: $\alpha$ and $\beta$ glucocorticoid receptor mRNA expression in human bronchial epithelial cells. The European Respiratory Journal 10: S291.

S.H. Korn, F.B.J.M. Thunnissen, G-J Wesseling, J-W Arends and E.F.M. Wouters. 1998. Glucocorticoid receptor mRNA levels in bronchial epithelial cells of patients with COPD: Influence of glucocorticoids. American Journal of Respiratory and Critical Care Medicine: Submitted. 


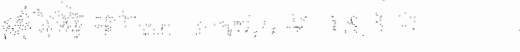

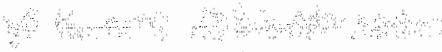

An: $)^{4}$

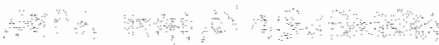

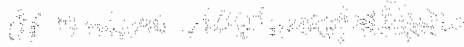




\section{CURRICULUM VITAE}




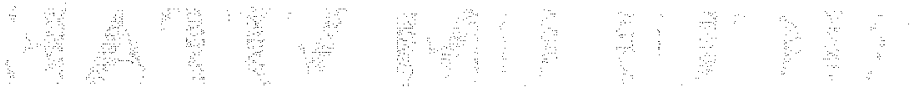




\section{CURRICULUTM VITAE}




\section{Curriculum Vitae}

De schrijfster van dit proefschrift werd geboren in Maastricht op 7 maart 1969. $\mathrm{Na}$ in 1986 haar HAVO diploma behaald te hebben begon ze aan het VWO, dat in 1988 afgerond werd. In hetzelfde jaar begon ze aan de studie Gezondheidswetenschappen, met als afstudeerrichting Biologische Gezondheidkunde. Na een stage aan de afdeling Pathologie van het Academisch Ziekenhuis te Maastricht behaalde ze in augustus 1992 haar doctoraal diploma. Per 1 oktober 1992 werd ze voor 2 jaar aangesteld als onderzoeksassistent bij de afdeling Pathologie, in nauwe samenwerking met de afdeling Pulmonologie. In 1994 is ze vervolgens assistent in opleiding (AIO) geworden bij de afdeling Pulmonologie. Het onderzoeksproject beschreven in dit boekje is in 1997 afgerond. Per 1 december 1997 is Solange aangesteld als Postdoc bij Astra Draco in Lund, Zweden. 